\title{
SHORT CHAIN FATTY ACIDS MODULATE FLAGELLA EXPRESSION IN ENTEROHEMORRHAGIC ESCHERICHIA COLI
}

\author{
by \\ Jee In Kim \\ Honors Bachelor of Science, Western University, 2013 \\ A thesis presented to Ryerson University \\ in partial fulfillment of the requirements for the degree of Master of Science \\ in the Program of Molecular Science
}

Toronto, Ontario, Canada, 2017

@ Jee In Kim 2017 


\begin{abstract}
AUTHOR'S DECLARATION
I hereby declare that I am the sole author of this thesis. This is a true copy of the thesis, including any required final revisions, as accepted by my examiners.

I authorize Ryerson University to lend this thesis to other institutions or individuals for the purpose of scholarly research I further authorize Ryerson University to reproduce this thesis by photocopying or by other means, in total or in part, at the request of other institutions or individuals for the purpose of scholarly research. I understand that my thesis may be made electronically available to the public.
\end{abstract}




\title{
SHORT CHAIN FATTY ACIDS MODULATE FLAGELLA EXPRESSION IN ENTEROHEMORRHAGIC ESCHERICHIA COLI
}

\author{
Jee In Kim \\ Honors Bachelor of Science, Western University, 2013 \\ Program of Molecular Science \\ Ryerson University
}

\begin{abstract}
During passage through the human gastrointestinal tract, enterohemorrhagic Escherichia coli (EHEC) encounters numerous stresses. EHEC utilizes various strategies to combat and survive these host assaults and possibly employs them as cues about the local microenvironment to enhance infection. This investigation looks at how exposure to changing concentrations of short chain fatty acid mixtures (SCFA) associated with passage through the human small (SI) and large intestines (LI) affects EHEC flagella expression and motility. In addition, the study also examines several two component systems for their involvement with SCFA-induced flagella regulation.

The results indicate that SCFA mixture typical of SI may cue increased EHEC flagellar expression and function while SCFA mixture typical of LI, the site of EHEC colonization, may promote diminished flagella expression and function. Overall, this study contributes to our knowledge on how EHEC sense and respond to host environmental signals in a way that may promote to infection.
\end{abstract}




\section{Acknowledgements}

I am thankful to Dr. Debora Foster, Dr. Joseph McPhee, Dr. Martina Hauser and my colleagues in the Molecular Science program for their continuous guidance and support throughout my Master's study. I acknowledge Dr. Seav Ly Tran and Tracy Lackraj for their contributions to this project. Because of these contributions and support, my Master's experience was very successful and enjoyable.

I would also like to thank Dr. Debora Foster, Molecular Science program and Ryerson YSGS for the funding and various professional opportunities. I have gained so much valuable academic experience that will greatly benefit my career in science. As well, I have learned so much and gained my own perspective about professionalism, for which I am very grateful, as such knowledge cannot be learned within the confinement of a classroom.

Finally, I would like to thank my friends and family members that have unconditionally been by my side and believed in me, in the times of happiness and adversity throughout my academic career. These are the people that inspire and motivate me to do better everyday and without them, I wouldn't be as successful and happy as I am today. 


\section{Table of Contents}

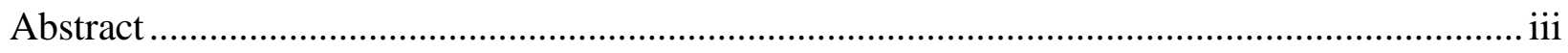

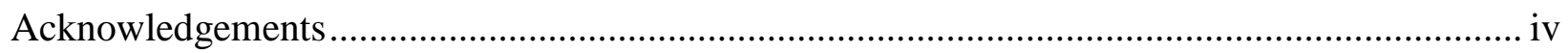

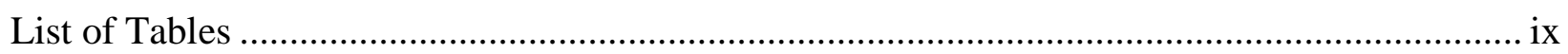

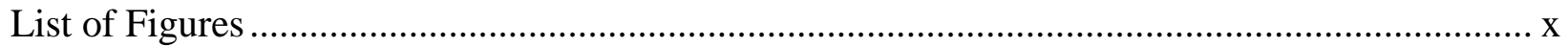

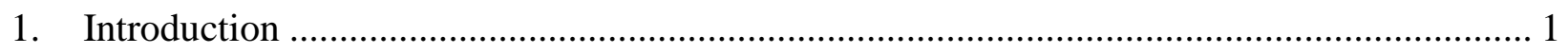

1.1 Microenvironments in human gastrointestinal tract..................................................... 1

1.2 Commensal and pathogenic Escherichia coli ................................................................. 1

1.3 Enterohemorrhagic Escherichia coli (EHEC) O157:H7 ................................................... 2

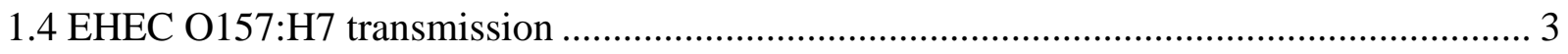

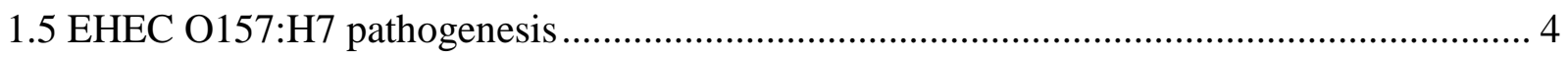

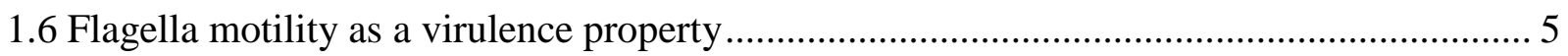

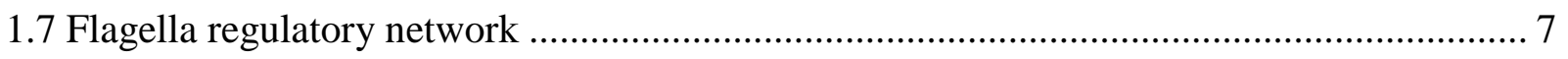

1.8 Short chain fatty acids (SCFAs) in human GI tract ......................................................... 9

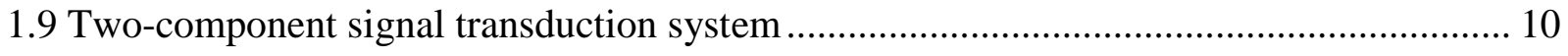

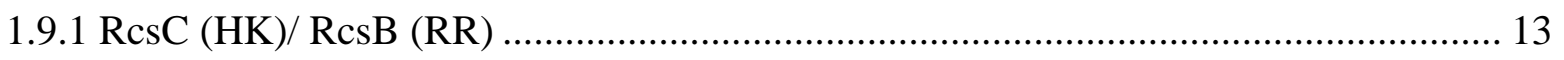

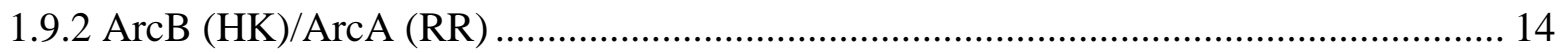

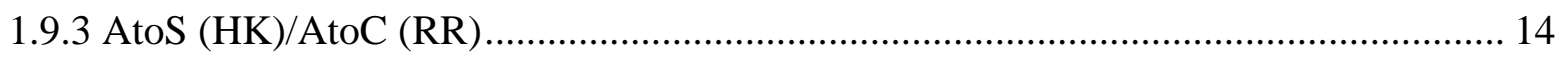

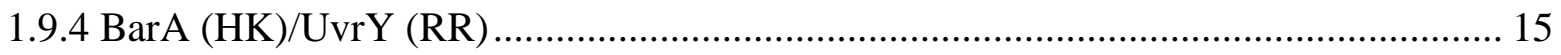

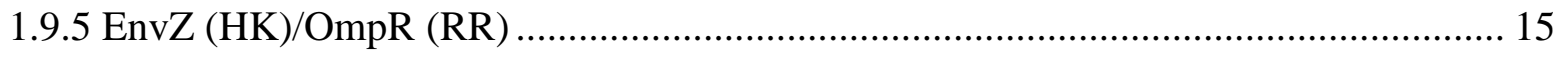

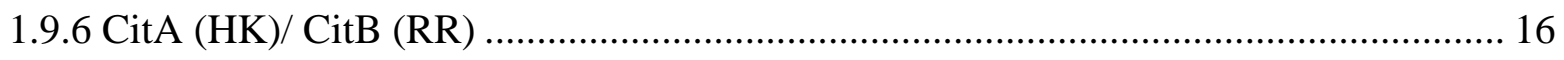

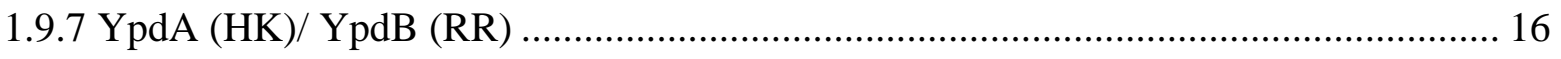

1.10 Rationale 


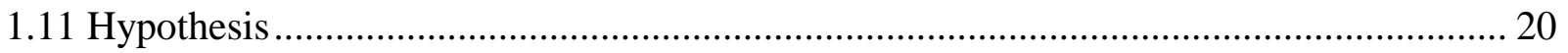

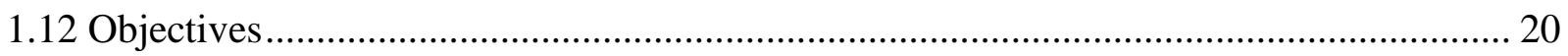

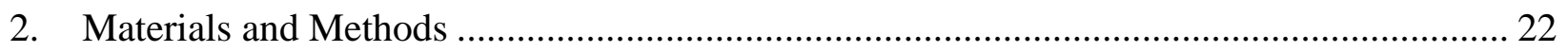

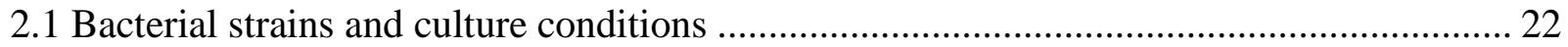

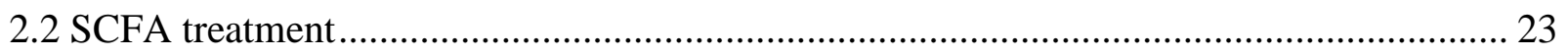

2.3 DNA microarray analysis of gene expression ............................................................... 24

2.4 Quantitative real-time PCR (qRT-PCR) …………..................................................... 25

2.5 Immunoblot analysis of flagella protein expression ....................................................... 26

2.6 Flagella protein isolation and preparation ................................................................... 26

2.7 Flow cytometry analysis of EHEC flagella expression...................................................... 27

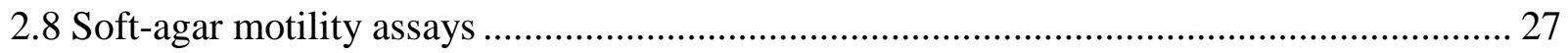

2.9 Growth rate assay of $E$. coli K-12 wild-type and the TCS mutants .................................. 28

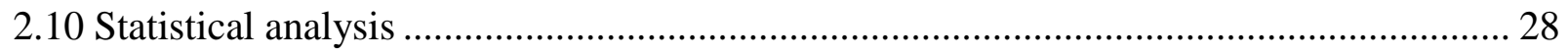

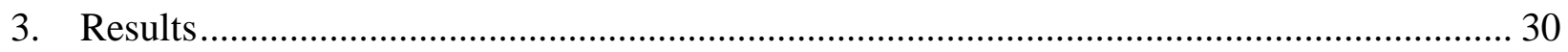

3.1 Gene expression analyses of SCFA-treated EHEC ............................................................ 30

3.2 Flagella protein expression analyses of SCFA-treated EHEC ………................................ 33

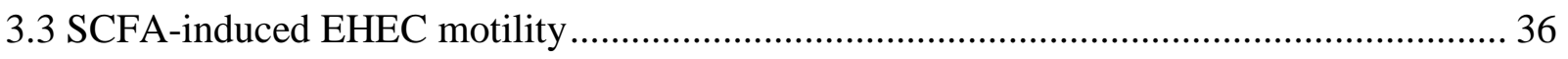

3.4 Impact of individual and mixtures of SCFAs on E. coli K-12 and selected TCS mutants . 39

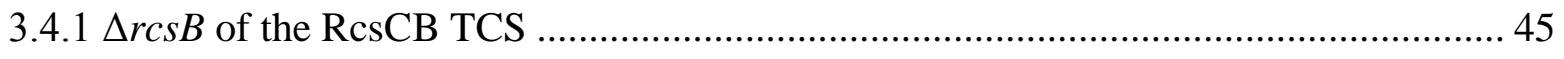

3.4.1.1 Motility and flagella protein expression with SCFA mix treatments ................... 45

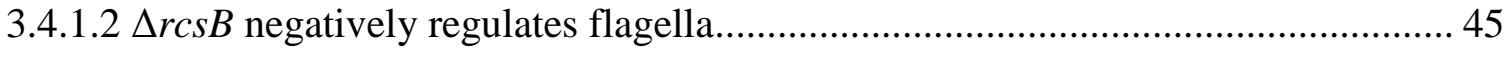

3.4.1.3 Motility and flagella protein expression with individual SCFA treatments ......... 45

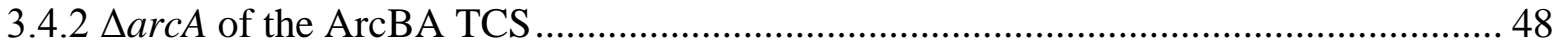


3.4.2.1 Motility and flagella protein expression with SCFA mix treatments 48

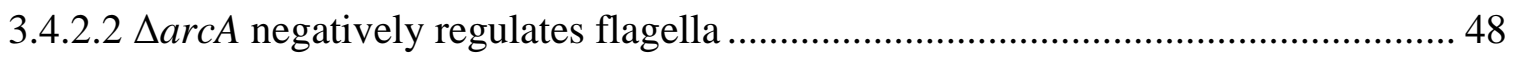

3.4.2.3 Motility and flagella protein expression with individual SCFA treatments ......... 48

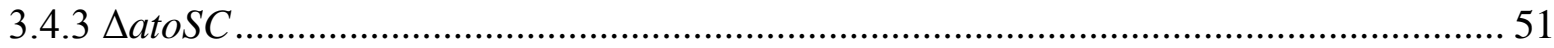

3.4.3.1 Motility and flagella protein expression with SCFA mix treatments ................. 51

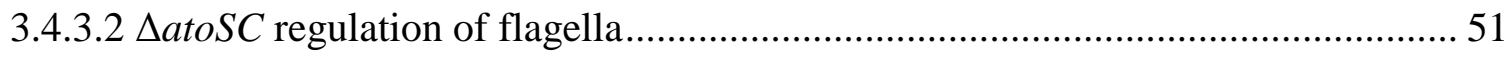

3.4.3.3 Motility and flagella protein expression with individual SCFA treatments ........ 51

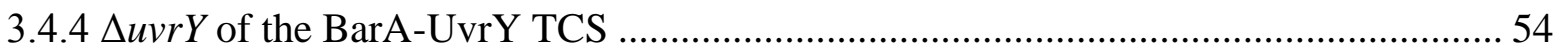

3.4.4.1 Motility and flagella protein expression with SCFA mix treatments .................. 54

3.4.4.2 $\Delta u v r Y$ negatively regulates flagella ....................................................... 54

3.4.4.3 Motility and flagella protein expression with individual SCFA treatments ......... 54

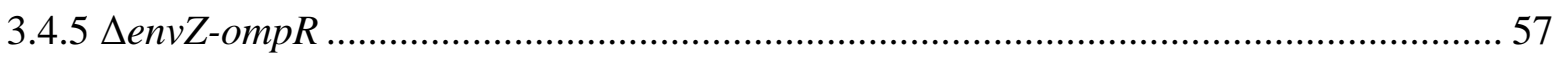

3.4.5.1 Motility and flagella protein expression with SCFA mix treatments .................. 57

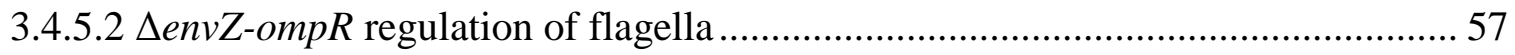

3.4.5.3 Motility and flagella protein expression with individual SCFA treatments ........ 57

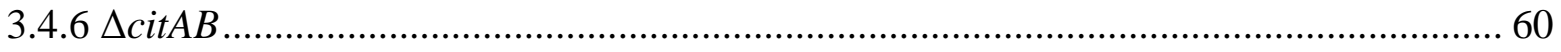

3.4.6.1 Motility and flagella protein expression with SCFA mix treatments .................. 60

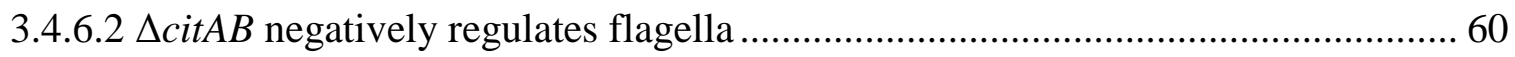

3.4.6.3 Motility and flagella protein expression with individual SCFA treatments ......... 60

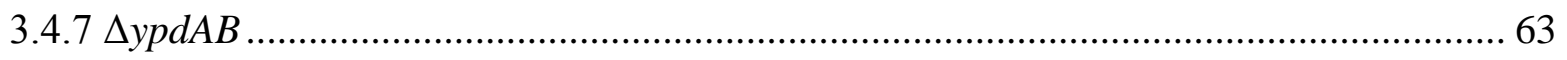

3.4.7.1 Motility and flagella protein expression with SCFA mix treatments ................... 63

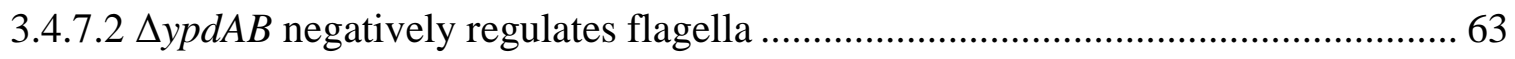

3.4.7.3 Motility and flagella protein expression with individual SCFA treatments ......... 63 


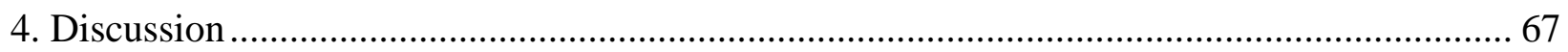

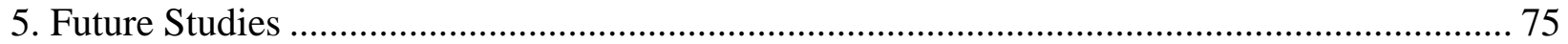

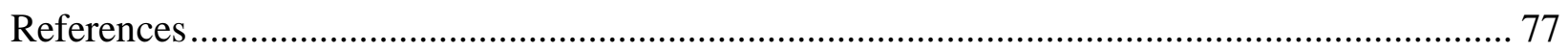




\section{List of Tables}

Table 1. Summary of selected TCSs' involvement in non-flagellar regulon........................... 17

Table 2. DNA microarray results showing differential regulation of flagellar genes under small $(30 \mathrm{mM})$ and large intestinal $(172 \mathrm{mM})$ SCFAs concentrations................................................ 19

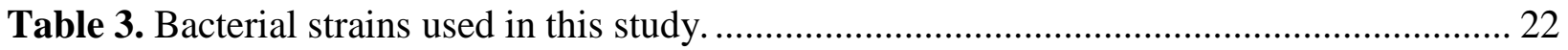

Table 4. Primer sequences used for qRT-PCR .................................................................. 25

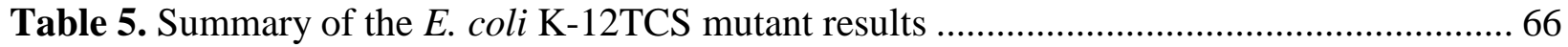




\section{List of Figures}

Figure 1. A bacterial flagellum is anchored to the inner membrane of a bacterium and are composed of three distinct units including the basal body, functioning as an anchor and a motor, the hook, functioning as a joint, and the filament, functioning as a propeller.......................... 6

Figure 2. Escherichia coli flagella hierarchical transcription network ................................... 8

Figure 3. Schematic image of classical and unorthodox two-component systems ................... 11

Figure 4. Quantitative real-time PCR analysis of EHEC O157:H7 treated with the small and large intestinal SCFA mixtures on flagellar gene expression .......................................... 32 Figure 5. Immunoblot analysis of H7 flagella protein expression of EHEC O157:H7 treated with

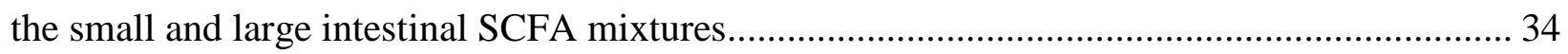
Figure 6. Flow cytometry analysis of EHEC O157:H7 flagella expression with 30mM SCFA

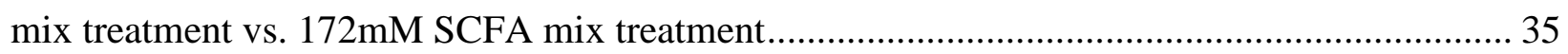

Figure 7. Effect of SCFA treatments on EHEC motility. ............................................... 37

Figure 8. CFU count of each motility halo homogenates of EHEC O157:H7 treated with

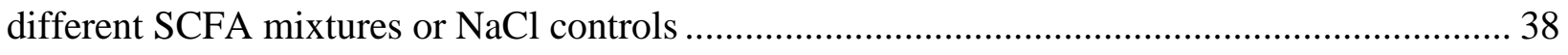

Figure 9. Effect of varying concentrations of SCFAs on the mean motility halo diameter and

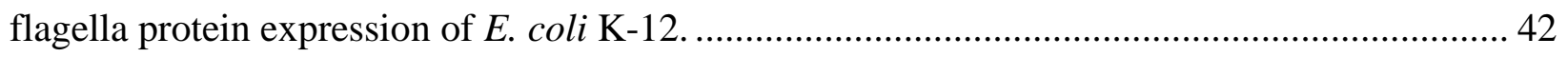

Figure 10. Growth rate of $E$. coli $\mathrm{K}-12$ post-SCFA treatment ............................................. 43

Figure 11. The overview demonstration of the effect of 30 and 172mM SCFA mix treatments on the motility of E. coli K-12 wild-type and TCS mutants. 44

Figure 12. Effect of varying concentrations of SCFAs on the mean motility halo diameter and flagellin protein expression of $E$. coli $\mathrm{K}-12$ and $\Delta r c s B$ 46 
Figure 13. Growth rate of $\Delta r \operatorname{cs} B$ post-SCFA treatment.

Figure 14. Effect of varying concentrations of SCFAs on the mean motility halo diameter and flagellin protein expression of $E$. coli $\mathrm{K}-12$ and $\triangle \operatorname{arc} A$ 49

Figure 15. Growth rate of $\triangle \operatorname{arc} A$ post-SCFA treatment 50

Figure 16. Effect of varying concentrations of SCFAs on the mean motility halo diameter and flagellin protein expression of $E$. coli $\mathrm{K}-12$ and $\triangle a t o S C$. 52

Figure 17. Growth rate of $\triangle a t o S C$ post-SCFA treatment 53

Figure 18. Effect of varying concentrations of SCFAs on the mean motility halo diameter and flagellin protein expression of $E$. coli $\mathrm{K}-12$ and $\Delta u v r Y$ 55

Figure 19. Growth rate of $\Delta u v r Y$ post-SCFA treatment ................................................ 56

Figure 20. Effect of varying concentrations of SCFAs on the mean motility halo diameter and flagellin protein expression of E. coli $\mathrm{K}-12$ and $\Delta e n v Z$-ompR ......................................... 58

Figure 21. Growth rate of $\Delta e n v Z-o m p R$ post-SCFA treatment ........................................ 59

Figure 22. Effect of varying concentrations of SCFAs on the mean motility halo diameter and

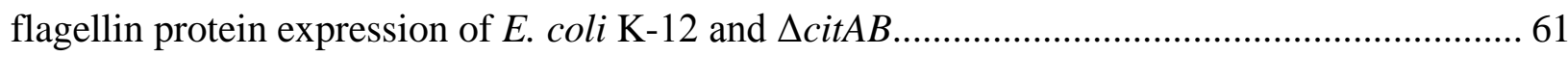

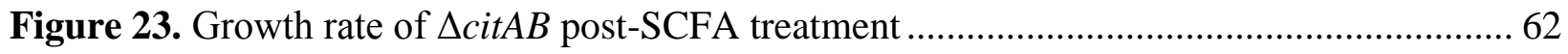

Figure 24. Effect of varying concentrations of SCFAs on the mean motility halo diameter and

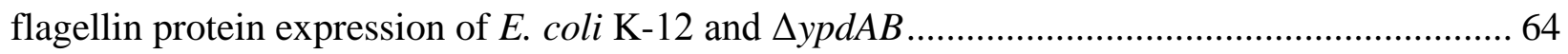

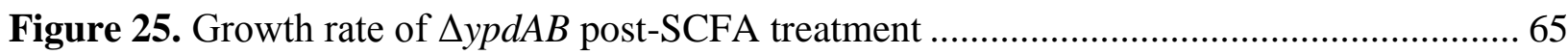




\section{Introduction}

$\underline{1.1 \text { Microenvironments in human gastrointestinal tract }}$

The human gastrointestinal tract (GIT) includes all the structures between the mouth and the anus, and is composed of variety of complex microenvironments to which commensal and pathogenic bacteria are exposed to during transit and colonization. These microenvironments include a number of antimicrobial stresses and bacteria need to find ways to adapt to or overcome these hostile stresses in order to optimize survival and colonization/infection. The stressors in the GIT include but are not limited to gastric acid in the stomach, bile salts in the small intestine and short-chain fatty acids in the small and large intestines. Both the native and non-native bacterial species of GIT have adapted and evolved to utilize these stressors to enhance their fitness advantage. This thesis focuses on how a specific microenvironment stress within human GIT impacts Escherichia coli's flagella expression and function and provides the first insight into the complex sensing mechanism of that microenvironment.

\subsection{Commensal and pathogenic Escherichia coli}

Escherichia coli (E.coli) is a ubiquitous gram-negative, facultative anaerobic, rod-shaped bacterium that is commonly found in GIT of warm-blooded animals, including humans. Many strains reside in their host as a symbiont, however some strains have acquired pathogenicity through horizontal gene transfer. Comparison of the commensals and pathogenic E. coli variants' genome size has revealed a difference of approximately a million base pairs, and the additional genetic material can encode virulence and fitness genes. Within the E. coli species, there are antigenically distinct varieties. These are recognized as different serotypes of $E$. coli and most 
commonly defined by specific combination of $\mathrm{O}$ (lipopolysaccharide) and $\mathrm{H}$ (flagella) surface antigens (Lior 1994).

As the human GIT can harbor both pathogenic and commensal E. coli, it is important to realize that the gastrointestinal stressors that the pathogens encounter and survive during its travel to the colonization site may also pose a challenge for commensal gut flora. Therefore, some research questions in this investigation utilize non-pathogenic E. coli $\mathrm{K}-12$, in addition to the main focus on the pathogenic enterohemorrhagic E. coli, to gain better understanding of the bacterial sensing mechanism in response to changing microenvironments.

\subsection{Enterohemorrhagic Escherichia coli (EHEC) O157:H7}

One of the commonly studied serotype of pathogenic E. coli includes enterohemorrhagic E. coli (EHEC) O157:H7 which is characterized by the presence of locus of enterocyte effacement (LEE) pathogenicity island and the ability to produce cytotoxin known as Shiga toxins (Stxs) (Nataro and Kaper 1998). EHEC is a virulent food and waterborne zoonotic pathogen that causes severe foodborne illness with symptoms such as abdominal cramps, bloody diarrhea and hemorrhaging colitis (Nataro and Kaper 1998). The manifestation of EHEC infection may even lead to a fatal systemic complication called hemolytic uremic syndrome (HUS) attributed to the Stxs (Besser et al. 1999). HUS includes conditions such as thrombocytopenia, hemolytic anemia and kidney failure that are commonly linked to morbidity caused by EHEC infection (Besser et al. 1999). EHEC's ability to trigger fatal sequelae in conjunction with the lack of an effective treatment pose a serious public health concern worldwide and emphasize the importance in EHEC pathogenesis research. 
The first recognition of EHEC serotype O157:H7 occurred in 1982 in association with outbreak of bloody diarrhea caused by the consumption of undercooked hamburger patties in Oregon and Michigan, USA (Wells et al. 1983). Since the 1980s, numerous outbreaks associated with EHEC have been reported and continue to occur today. The largest outbreak that affected Canadians occurred in June 2000, where a contaminated municipal water source in Walkerton, Ontario caused over 2,000 illnesses (PHAC 2000). Due to its ongoing prevalence, infections caused by EHEC are also considered a great economic burden. There are significant implications in the fields of veterinary, environmental, food and clinical microbiology. It has been reported that the annual cost of EHEC-related illnesses is approximately 405 million dollars (in 2003 dollars) which encompasses the lost productivity, medical care and premature deaths (Frenzen $e t$ al. 2005). This significant economic burden further motivates the EHEC pathogenesis research.

\subsection{EHEC O157:H7 transmission}

The primary reservoir of enterohemorrhagic E. coli (EHEC) is the GIT of domesticated ruminants such as cattle, with less common occurrences in wide variety of animals including sheep, swine and dogs (Weiss et al. 2011). Not all serotypes in cattle are transmitted to humans, however cattle are still considered to be the main source of human EHEC infections (Dorn and Angrick 1991; Toth et al. 2009; Ferens and Hovde 2011). Major outbreaks are commonly linked to consumption of cattle by-products, either through undercooked meat or unpasteurized dairy products (Chauret 2011). The low infectious dosage of EHEC further poses challenge in prevention and detection of the pathogen (Tilden et al. 1996). One investigation has reported that the highest level of contaminants in their investigated beef patty only contained 675 organisms and suggested that potentially even lesser amount is required to infect the host (Tuttle et al. 
1999). In addition, cattle feces harboring EHEC may contaminate the environment, and the agriculture vegetation grown in such environment can potentially infect humans (Solomon et al. 2002). The major transmission pathway is through ingestion of EHEC contaminated medium such as food and water, however direct transmission between people are also possible as well as from animal and human contact (Snedeker et al. 2009).

\subsection{EHEC O157:H7 pathogenesis}

EHEC 0157:H7 is a non-invasive enteric pathogen that colonizes human intestinal mucosa in the large intestine (Lewis et al. 2015). The primary virulence genes harboured by EHEC include the Stx genes and a variety of adhesins and effector proteins encoded in the chromosomal pathogenicity island called the Locus of Enterocyte Effacement (LEE) (McDaniel et al. 1995).

Lambdoid prophages on the bacterial chromosome encode Stxs that are released during bacterial lysis of the phage lytic cycle (Wagner et al. 2001). Once Stxs are released from the bacteria, they bind to a membrane glycolipid receptor (globotriaosylceramide, Gb3) that is highly expressed on the microvascular endothelium in the kidney, an event that can lead to the development of HUS (Hughes et al. 2002; Chilcott and Hughes 2000).

The LEE genomic island encodes the proteins that form the type 3 secretion system (T3SS) utilized in the formation of attachment and effacement (A/E) lesions (McDaniel et al. 1995). A/E lesions are characterized by localized destruction of brush border microvilli and intimate attachment of the pathogen to the host colonocytes, leading to a successful colonization and infection (Garmendia et al. 2005). Initial attachment is mediated primarily by the interaction of a bacteria membrane bound adhesin, intimin, to a bacterial receptor called Tir which is 
translocated into the host by the T3SS (Garmendia et al. 2005). The T3SS also allows injection of effector proteins into the host cells, a number of which hijack several host cell signalling pathways (Liu et al. 2002). These events lead to, among many things, the effacement of microvilli (Liu et al. 2002). The interaction of Tir and intimin triggers the host cell to polymerize the actin beneath the site of bacterial attachment to form a pedestal-like structure (Kenny et al. 1997). The disrupted host colonic epithelium and microvilli leads to the symptoms characteristic of EHEC infection.

\section{$\underline{1.6 \text { Flagella motility as a virulence property }}$}

In order for EHEC to reach the site of colonization required for successful formation of A/E lesions, EHEC must move towards the suitable colonization location. This is achieved through the swimming motion of the pathogen, known as motility. Motility also permits chemotaxis, the ability to move towards attractants. Overall, motility is an important virulence property in EHEC, as it allows movement and localization of the most optimal site for infection.

Swimming motility is commonly achieved through a specialised surface-associated rotating organelle, the flagellum, that is powered by a proton-driven rotary motor (Macnab 2003). A flagellum is a helical shaped structure composed of three distinct units including the basal body that functions as an anchor and a motor, the hook that functions as a joint, and the filament composed of protein subunit, flagellin, which functions as a propeller (Figure 1; Beatson et al. 2016). The basal body is embedded within the inner membrane of the bacteria whereas the hook and filament extend outwards from the cell (Figure 1). Flagella has also been implicated in other virulence functions such as surface attachment and host cell invasion (Girón et al. 2002). 
Therefore, understanding the impact of gut microenvironments on flagella regulation may provide important clues to aid in prevention of EHEC infection.

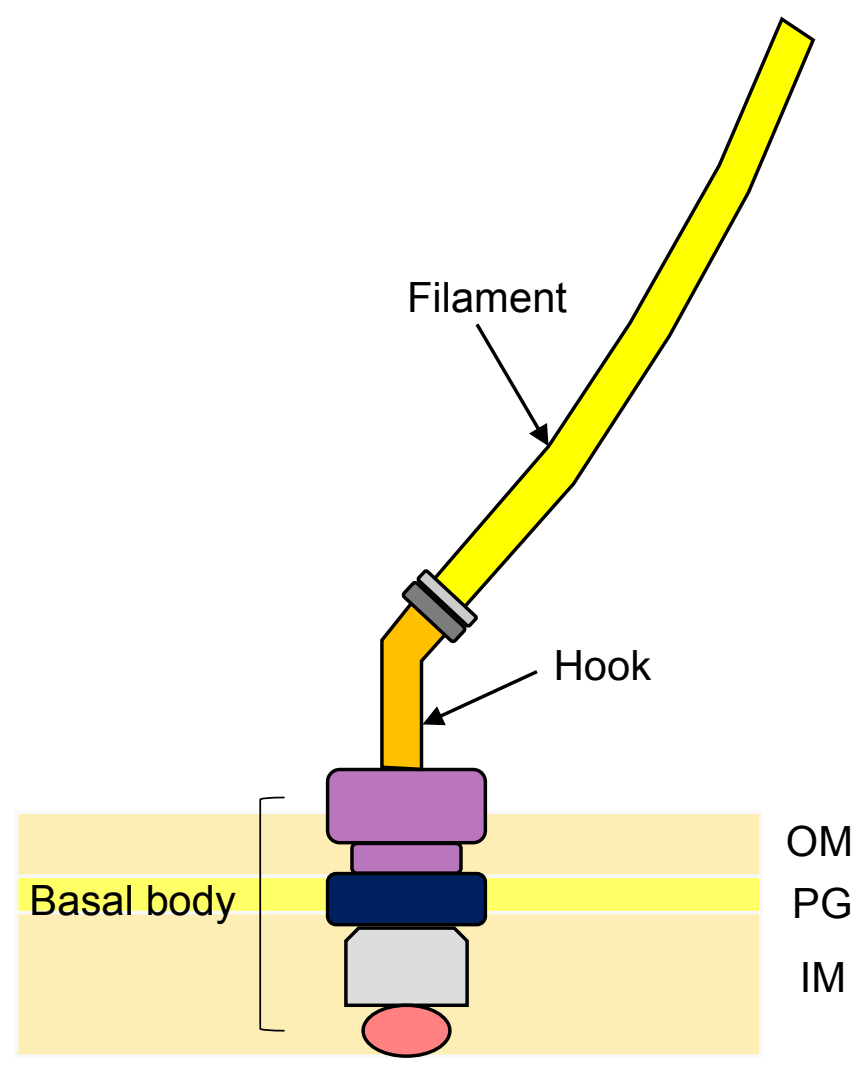

Figure 1. A bacterial flagellum is anchored to the inner membrane (IM) of a bacterium and are composed of three distinct units including the basal body, functioning as an anchor and a motor, the hook, functioning as a joint, and the filament, functioning as a propeller. OM, outer membrane; PG, peptidoglycan. (Figure adapted from Beatson et al. 2006). 


\subsection{Flagella regulatory network}

In $E$. coli, flagella and motility is tightly regulated by several global regulatory circuits that largely modulate the expression of the flagella master regulator, flhDC. The flagella biosynthesis system includes a minimum of 13 operons encoding more than 50 genes organized in a hierarchical transcription network divided into three classes that enables sequential production and assembly of flagellar units (Shi et al. 1993).

Flagella master operon, $f h D C$, is at the top of the hierarchy and is considered the sole Class 1 transcription unit (Figure 2; Fitzgerald et al. 2014). This operon encodes the master flagellar regulator, FlhDC, essential for the transcription of all downstream genes involved in the synthesis and assembly of the flagellar system (Fitzgerald et al. 2014). FlhDC is able to bind to Class 2 promoters and activate transcription of regulatory factors for Class 3 operons, as well as the transcription of basal body structural proteins and associated export apparatus (Fitzgerald $e t$ al. 2014). The most notable Class 2 operons include fliAZY and flgAMN that respectively encode flagellar sigma factor FliA $\left(\sigma^{28}\right)$ and anti-sigma factor FlgM (Figure 2; Barembruch and Hengge 2007). The transition from the early flagellar gene expression to late-stage gene expression is permitted by the interplay between FliA and FlgM. FliA initiates the transcription of Class 3 operons encoding flagella filament subunit, flagellin, motor components and chemotaxis-related regulatory factors (Figure 2; Fitzgerald et al. 2014). Once the flagella structure assembly is completed, motAB-cheAW Class 3 operon transcribes proteins necessary for the motor and chemotaxis functions essential for efficient locomotion (Figure 2; Fitzgerald et al. 2014).

Studies have shown that various environmental parameters including oxygen, nutrients and $\mathrm{pH}$ act as signals that induce virulence gene regulation in pathogenic $E$. coli ; such as microaerobic condition (oxygen concentrations of $1-2 \%$ atmospheric pressure) induction of 
EHEC type III secretion and adherence to epithelial cells (House et al. 2009; Schüller and Phillips 2010; Chingcuanco et al. 2012; Njoroge et al. 2012; Lewis et al. 2015). Specifically, different signals in the gut microenvironment have been shown to induce GI pathogens' motility which is an important virulence factor (Heroven et al. 2012). The GI signal of interest for this investigation is the concentration gradient of short chain fatty acids observed in the human small and large intestines.

\section{flhDC}

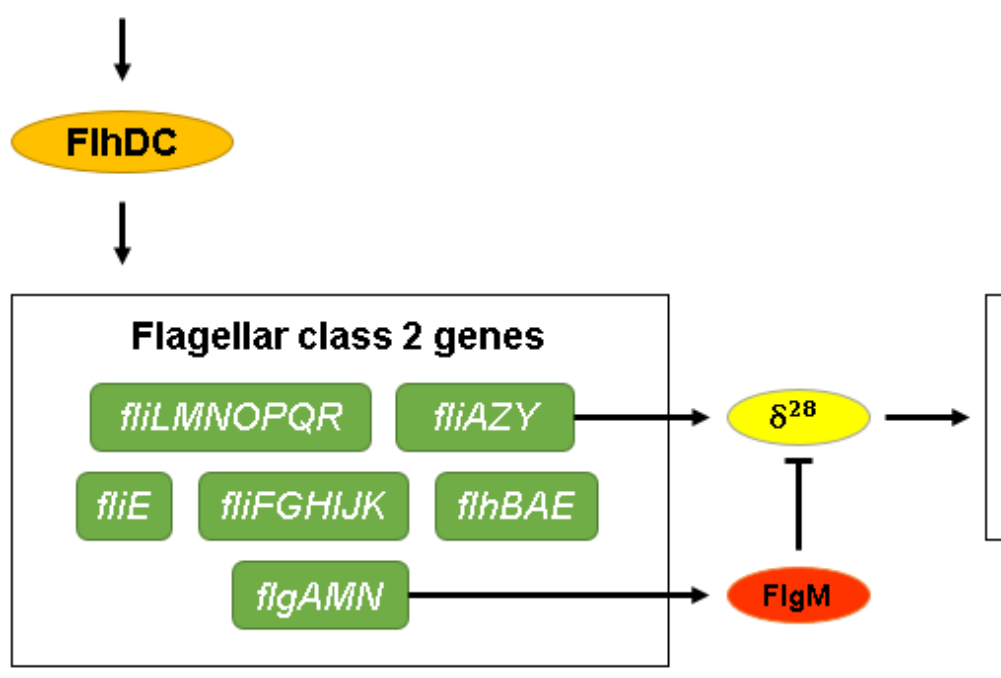

Flagellar class 3 genes flic

Figure 2. Escherichia coli flagella hierarchical transcription network. $f l h D C$ is the $1^{\text {st }}$ class gene encoding the master regulator, FlhDC, necessary for the expression of all the downstream genes involved with synthesis and assembly of flagella system. FlhDC directly activates Class 2 promoters and encodes, the most notable, FliA $\left(\sigma^{28}\right)$, which in turn activates Class 3 genes encoding flagellin subunits (FliC), motors (MotA \& B) and chemotaxis units (CheA \& W). 


\subsection{Short chain fatty acids (SCFAs) in human GI tract}

Short chain fatty acids (SCFAs) are saturated aliphatic organic acids with 2-6 carbons. They are one of the major fermentation end products of nondigestible dietary fiber by human GI microbiota. Gut SCFAs are composed primarily of a mix of acetate (C2), propionate $(\mathrm{C} 3)$, and butyrate $(\mathrm{C} 4)$ with the individual fatty acid ratios within the mixture varying between persons according to their diet, genotype and microbiota composition (Henningsson et al. 2003; Wong et al. 2006; Tan et al. 2014).

For the host, SCFAs play an important role in maintaining colonic health by decreasing the risk of colon cancer and inflammatory bowel disease (Wong et al. 2006). Butyrate is utilized by colonocytes as the main energy source and plays an important role in the maintenance of colonic homeostasis (Wong et al. 2006). Acetate and propionate are transported to other tissues, such as the liver, to be used for the synthesis of cholesterol and as a precursor for gluconeogenesis, respectively (Wolever et al. 1991).

Commensal microbial composition and numbers vary significantly along the human GI tract with the colon harboring the largest microbial ecosystem. In the stomach, the bacterial count is low due to the acidic pH (Salminen et al. 1998). In the small intestine, the bacterial count is greater than the stomach but significantly lower than the colon due to the rapid transit of contents and secretion of bile and pancreatic juice (Salminen et al. 1998). Microbiota ferment indigestible saccharides into SCFAs and hence the SCFAs production and composition change accordingly to the local bacterial population. Therefore, SCFAs are observed as a gradient with a lower concentration ranging from 20 to $40 \mathrm{mM}$ in the small intestine and a higher concentration in the proximal colon ranging between 160 to 200mM (Cummings et al. 1987; Macfarlane et al. 1992). EHEC attaches to (i.e. colonizes) the human large intestine epithelium (Lewis et al. 2015) 
and it is suggested that EHEC may utilize such SCFAs gradient as a cue to recognize appropriate colonization location.

Overall, this project aims to understand how the concentration gradient of short chain fatty acids, specifically the lower SCFAs concentration in the small intestine and the higher SCFAs concentration in the colon, affects expression and function of EHEC O157:H7 flagella, which are important virulence factors in EHEC pathogenesis.

\subsection{Two-component signal transduction system}

A two-component regulatory system (TCS) is a signal transduction system used by prokaryotes to link external stimuli, through regulatory pathways, to specific adaptive functions. The system is not exclusive to prokaryotes but is also used by archaea and eukaryotes, such as plants and fungi (Wurgler-Murphy and Saito 1997). TCSs are especially important for organisms that are continuously exposed to changing surroundings because they allow efficient adaptation to the environmental fluctuations. Invasion and infection of the host mucosa by pathogenic bacteria involve the exploitation of numerous microenvironments and therefore investigating the TCSs used in response to the microenvironments will lead to better understanding of mechanism of pathogenesis.

A prototypical TCS is composed of histidine protein kinase sensor (HK) and response regulator (RR) (Figure 3). The histidine kinase is a transmembrane receptor that contains nonconserved sequences that provide the specific sensory function and conserved amino acid sequences encoding the ATP binding domain responsible for catalyzing autophosphorylation of

the histidine residue (Hoch et al. 1995). The phosphorylated HK donates its phosphoryl group to the aspartate residue of RR. Hybrid kinases also exist and contain both His- and Asp domains 
within a single HK. Phosphotransfer from the HK to the RR activates the RR and generates output response of the signaling pathway. RR also contains a conserved amino acid domain and non-conserved effector domain to provide specific outputs. This system that involves sensor and regulator proteins is described as the classical type (Perraud et al. 1999).

Another type of TCS involves multi-component phosphorelay system and is described as the unorthodox type (Perraud et al. 1999). It is a more complex version of the classical TCS and involves multiple phosphotransfer steps with several proteins (Figure 3; Perraud et al. 1999). Generally, unorthodox type contains a hybrid HK. Unorthodox systems utilize His-containing phosphotransfer (HPt) proteins that play an essential middle role in the transfer of phosphoryl groups from hybrid HKs to cytoplasmic RRs (Stock et al. 2000).

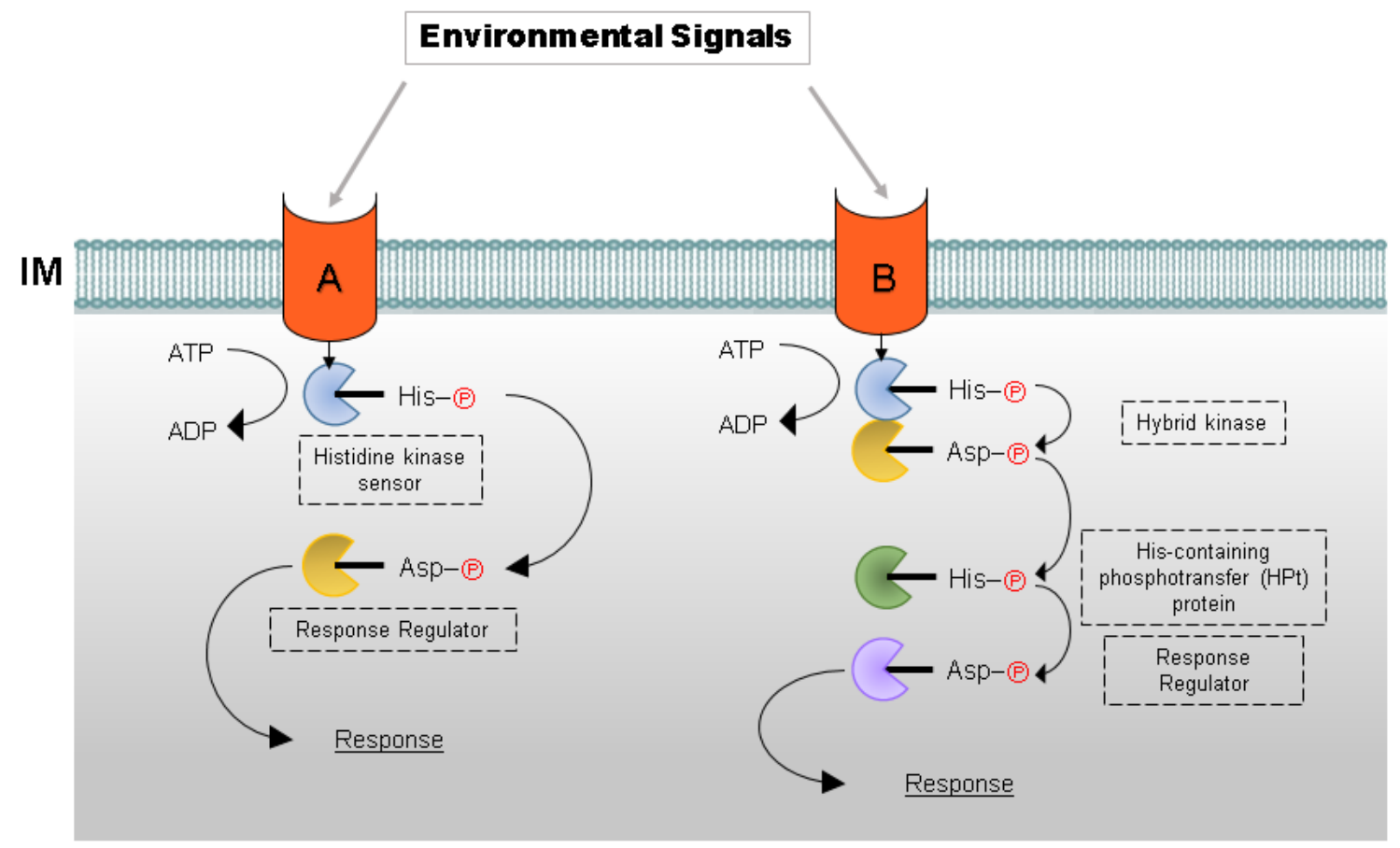

Figure 3. Schematic image of classical and unorthodox two-component systems; IM, inner membrane. (A) A classical system is composed of two proteins including the histidine kinase (HK) sensor and response regulator (RR). (B) An unorthodox system involves multi-components, including His-containing phosphotransfer (HPt) proteins that play an essential middle role in the transfer of phosphoryl groups from hybrid HK to cytoplasmic RRs. (Figure adapted from Bretl et al. 2011). 
In most prokaryotic systems, the phosphorylated RR directly or indirectly dictates the output response as a transcription factor (Stock et al. 2000). Therefore, the level of RR phosphorylation is the ultimate regulatory strategy to modulate the output response. RRs also have autophosphatase activity to precisely limit its phosphorylated state according to the environmental stimuli (Stock et al. 2000).

E. coli contains $30 \mathrm{HK}$, of which 5 are hybrid kinases, as well as 32 RRs (Mizuno 1997). In EHEC O157:H7, there is an additional fucose sensing TCS that is not found in other strains of E. coli (Pacheco et al. 2012). Numerous classical and unorthodox TCSs are involved in E. coli flagella regulation. However, the understanding of how TCSs are involved in SCFAs recognition still remains elusive. Specifically, there is a gap in the literature about TCSs involved in SCFA modulated flagella regulation. Therefore, this study aims to contribute to our understanding of the role of TCSs in SCFA-modulated flagella expression. Because of the homology observed in many TCS sequences between different $E$. coli strains, commercially available $E$. coli K-12 TCS mutants were chosen to evaluate the role of selected TCSs in SCFA-induced flagella regulation. Microarray analysis of each of $E$. coli TCSs deletion mutants demonstrated that several TCS mutants had altered flagella gene expression and motility relative to wild-type (Oshima et al. 2002). These TCS knockouts include mutations in $r c s B$ of the RcsCB TCS, the $y p d A B$ TCS, the envZ-ompR TCS, the atoSC TCS, arcA of the ArcBA TCS, the citAB TCS and $u v r Y$ of the BarA-UvrY TCS (Oshima et al. 2002). These TCSs are significantly involved in the flagellar regulatory pathway, however it is important to recognize that they are also involved in a number of other signaling pathways and multiple gene regulations. Therefore, the following sections discuss how above TCSs are involved in flagellar regulation in addition to their involvement in other regulons. The selected TCSs' involvement in other regulons are summarized on Table 1. In 
this investigation, the above seven TCSs are selected as the potential candidates that may be playing a role in flagella modulation upon SCFAs recognition by E. coli.

\subsection{1 $\mathrm{RcsC}(\mathrm{HK}) / \mathrm{RcsB}(\mathrm{RR})$}

This is an unorthodox phosphorelay system with RcsD (previously known as YojN) Hiscontaining phosphotransferase $(\mathrm{HPt})$ protein, which receives the phosphoryl group from phospho-RcsC hybrid HK then relays it to RcsB RR (Takeda et al. 2001). This system regulates expression of multiple genes including the capsular polysaccharide synthesis cps genes, the cell division $f t s A Z$ genes, an osmoregulated $o s m C$ gene, and the small RNA gene rprA that positively regulates RpoS translation, modulating the response to starvation and the transition to stationary phase (Carballès et al. 1999; Davalos-Garcia et al. 2001; Majdalani et al. 2002; Oshima et al. 2002; Fredericks et al. 2006). In addition, $\Delta r \operatorname{cs} B$ and $\Delta y o j N$ (i.e. $\Delta r c s D$ ) single mutants and triple $\triangle y o j N-r c s B C$ mutant have shown hypersensitivity to sodium chloride therefore it has been speculated to have a role in osmotic protection (Zhou et al. 2003).

More relevantly, acetyl phosphate (acetyl-P) represses E. coli flagellar biogenesis through the Rcs phosphorelay system (Fredericks et al. 2006). RcsB and RcsC inversely regulates the timing of flagellar biogenesis where $\Delta r c s B$ produced flagella prematurely and $\Delta r \operatorname{cs} C$ delayed the display of flagella, suggesting that the Rcs system, through the acetyl-P induction, may be involved in the transition of motile, planktonic individuals into biofilm communities (Fredericks et al. 2006). A separate study showed $\Delta r \operatorname{cs} B$ upregulating expression of numerous flagellar genes which corroborates that the system is negatively regulating flagella (Oshima et al. 2002). 


\subsection{2 $\mathrm{ArcB}(\mathrm{HK}) / \operatorname{ArcA}(\mathrm{RR})$}

This classical TCS modulates number of regulons involved in respiratory and fermentative metabolism in response to oxygen deficiency or redox potential (Iuchi and Lin 1988; Iuchi and Lin 1991). In addition, the system has shown to inhibit E. coli chromosomal replication initiation under anaerobic growth conditions (Lee et al. 2001).

In relation to flagella regulation, $\triangle \operatorname{arc} A$ demonstrated downregulation of numerous flagellar genes in E. coli supporting that the RR protein is positively regulating flagella (Oshima et al. 2002). Further study showed that $\triangle \operatorname{arc} A$, however not $\triangle \operatorname{arc} B$, inhibits the expression of FliA, the $2^{\text {nd }}$ class sigma factor necessary for the transcription of class 3 flagellar genes, and motility (Kato et al. 2007). This finding suggests that ArcA may be potentially cross-regulated for flagellar genes modulation (Kato et al. 2007).

\subsubsection{AtoS (HK)/AtoC (RR)}

This classical TCS regulates atoDAEB operon modulating acetoacetate metabolism (Chen et al., 1991). It was demonstrated that $\triangle a t o S C$ increased the use of glucuronamide as a carbon source as well as showing increased sensitivity to sodium chloride (Zhou et al. 2003).

AtoSC has been implicated in flagella biogenesis and chemotaxis in E. coli, where $\triangle a t o S C$ demonstrated non-motility and downregulation of numerous flagellar genes indicating that this TCS is a positive regulator of flagella (Oshima et al. 2002; Theodorou et al. 2012). AtoSC has shown to enhance the transcription of the flhDC and fliAZY operons through acetoacetate sensitivity (Theodorou et al. 2012). 


\section{$\underline{1.9 .4 \mathrm{BarA}(\mathrm{HK}) / \mathrm{UvrY}(\mathrm{RR})}$}

This classical system contains a hybrid BarA HK and UvrY RR in which the genes are not linked together (Pernestig et al. 2001). This system has been shown to protect against hydrogen peroxide-mediated stress via signalling through RpoS, which controls the synthesis of the major catalase in E. coli (Pernestig et al. 2001). The TCS also recognizes SCFAs including acetate, propionate, valerate and caproate but it was shown that BarA is not necessary for this recognition and can act through UvrY alone (Gonzalez Chavez et al. 2010).

Phosphorylation of this TCS induces the production of small non-coding RNA CsrB, which inhibits a regulatory RNA-binding protein, CsrA, required for efficient switching between glycolytic and gluconeogenic carbon source (Pernestig et al. 2003). CsrA also positively regulates the flagellar master regulator, $f l h D C$, but inhibits curli fimbriae and bacterial extracellular polysaccharides (Romeo 1998; Wei et al. 2001). $\Delta u v r Y$ has shown to increase numerous flagellar gene expression, corroborating the negative regulatory pathway of BarA/UvrY TCS through CsrB (Oshima et al. 2002)

\section{$\underline{1.9 .5 \mathrm{EnvZ}(\mathrm{HK}) / \mathrm{OmpR}(\mathrm{RR})}$}

EnvZ/OmpR TCS is a classical system in which the phosphorylated OmpR serves as a transcription factor, differentially modulating the expression of the major outer membrane porin genes, ompF and ompC (Cai and Inouye 2002). OmpF with a larger pore diameter is favoured at low-medium osmolarity while OmpC with a smaller pore diameter is favoured at high-medium osmolarity (Cai and Inouye 2002).

In addition to porin regulation, it was shown that acetyl-P modulates flagellar expression at the level of $f l h D C$ operon, through OmpR (Shin and Park 1995). As well, $\Delta e n v Z$-ompR 
demonstrated to increase flagella production and motility, supporting that the TCS is a negative regulator of E. coli flagella biosynthesis (Oshima et al. 2002).

\section{$\underline{1.9 .6 \mathrm{CitA}(\mathrm{HK}) / \mathrm{CitB}(\mathrm{RR})}$}

CitAB system has an alternative designation as DpiB (HK)/DpiA (RR) (destabilizer of plasmid inheritance) due to its involvement in plasmid inheritance regulation (Ingmer et al. 1998). DpiA has also been implicated in the repression of the promoter of a gene involved in $E$. coli anaerobic metabolism (Ingmer et al. 1998). Later study of the TCS showed that E. coli CitA functions as a citrate receptor and that CitAB TCS plays a role in the induction of citrate fermentation genes (Kaspar and Bott 2002).

In relation to flagella regulation, a study showed that $\triangle c i t A B$ upregulates numerous flagellar genes and motility, suggesting negative regulation of flagella by the TCS (Oshima et al. 2002). However, the signalling pathway relating the TCS to the flagella regulatory network still remains elusive.

\subsection{7 $\mathrm{YpdA}(\mathrm{HK}) / \mathrm{YpdB}(\mathrm{RR})$}

This system has shown to react to the presence of exogenous pyruvate in E. coli, suggesting its involvement in the carbon control network (Fried et al. 2013). In relation to flagella regulation, a study showed that $\triangle y p d A B$ upregulated numerous flagellar genes and motility, suggesting negative regulation of flagella by the TCS in a signalling pathway that has not yet been elucidated (Oshima et al. 2002). 
Table 1. Summary of selected TCSs' involvement in non-flagellar regulon.

\begin{tabular}{|c|c|}
\hline HK/RR & Function \\
\hline RcsC/RcsB & Capsular synthesis \\
\hline ArcB/ArcA & Respiratory and fermentative metabolism \\
\hline AtoS/AtoC & Acetoacetate metabolism \\
\hline BarA/UvrY & Hydrogen peroxide sensitivity \& acetate sensitivity \\
\hline EnvZ/OmpR & Osmotic regulation \\
\hline CitA/CitB & Regulation of the citrate fermentation \\
\hline YpdA/YpdB & Nutrient scavenging before entry into stationary phase \\
\hline
\end{tabular}




\subsection{Rationale}

Studies have shown that SCFA concentrations present in the human GIT can trigger different virulence gene regulation of enteric pathogens (Lawhon et al. 2002; Herold et al. 2009; Tobe et al. 2011; Sun and O'Riordan 2013). Most interestingly, it has been shown that butyrate alone, which is the least abundant type of SCFAs in the human GIT can trigger increased expression of virulence genes in EHEC including genes involved with flagella (Tobe et al. 2011). However, investigating the effect of concentration gradient of SCFAs mixture relevant to the human GIT on EHEC flagella regulation, motility and in turn, virulence, will be a novel research pursuit in the field of EHEC pathogenesis.

A DNA microarray study by our research group showed that SCFA mixtures, at concentrations representative of the small and large intestines, modulate expression of several gene networks in EHEC O157:H7. Of particular interest, numerous genes involved with flagellar biogenesis showed differential expression at a concentration representative of the large intestine, $172 \mathrm{mM}$ mix, when compared to the concentration representative of the small intestine, $30 \mathrm{mM}$ $\operatorname{mix}$ (Table 2). 
Table 2. DNA microarray results showing differential regulation of flagellar genes under small $(30 \mathrm{mM})$ and large intestinal $(172 \mathrm{mM})$ SCFAs concentrations. Significant fold changes for flagellar genes under $30 \mathrm{mM}$ and $172 \mathrm{mM}$ SCFA mix treatments relative to their respective sodium chloride osmolarity controls $(P<0.05$, unpaired t-test; - not significant). Table contributed by Dr. Seav Ly Tran and modified from Lackraj and Kim et al. (In press).

\begin{tabular}{|c|c|c|c|c|}
\hline Gene & Class & Gene Description & $30 \mathrm{mM}$ & $172 \mathrm{mM}$ \\
\hline$f l h C$ & 1 & Transcriptional activator & 2.50 & - \\
\hline$f l h D$ & 1 & Transcriptional activator & 2.40 & - \\
\hline$f l g A$ & 2 & Flagellar basal body P-ring biosynthesis protein & 2.33 & -6.60 \\
\hline$f \lg B$ & 2 & Flagellar basal body rod protein & $*$ & -23.53 \\
\hline$f \lg C$ & 2 & Flagellar basal body rod protein & 2.00 & -20.37 \\
\hline$f l g D$ & 2 & Flagellar hook assembly protein & 2.08 & -15.68 \\
\hline$f l g E$ & 2 & Flagellar hook protein & 2.37 & -14.55 \\
\hline$f \lg G$ & 2 & Flagellar basal body rod protein & 2.26 & -20.50 \\
\hline$f l g H$ & 2 & Basal body L-ring lipoprotein & 2.28 & -11.98 \\
\hline flgI & 2 & Flagellar basal body P-ring protein & 1.78 & -10.22 \\
\hline flgJ & 2 & Flagellar rod assembly protein & 2.11 & -7.09 \\
\hline$f \lg K$ & 2 & Flagellar hook filament junction protein & 2.50 & -8.43 \\
\hline$f l g M$ & 2 & Anti-FliA: FlhD regulator & 2.23 & - \\
\hline$f l g N$ & 2 & Intiator of flagellar filament assembly & 2.24 & - \\
\hline flhE & 2 & Flagella protein & 2.98 & -12.24 \\
\hline fliA & 2 & Alternative sigma factor 28 & 2.62 & -21.00 \\
\hline fliF & 2 & Flagellar basal body MS-ring \& collar protein & 1.94 & -11.37 \\
\hline fliG & 2 & Flagellar motor switch protein & 2.02 & -11.78 \\
\hline fliI & 2 & Flagellum specific ATP synthase & 2.52 & -9.12 \\
\hline fliJ & 2 & Flagellar rod assembly protein & 2.28 & -17.14 \\
\hline fliK & 2 & Flagellar hook length control protein & 2.37 & -9.66 \\
\hline fliL & 2 & Flagellar basal body -associated protein & 2.12 & -10.50 \\
\hline fliM & 2 & Flagellar motor switching & 2.27 & -13.02 \\
\hline fliN & 2 & Flagellar switch protein & 2.22 & -10.29 \\
\hline fliO & 2 & Flagellar biosynthesis protein & 2.82 & -10.05 \\
\hline fliP & 2 & Flagellar biosynthesis protein & 2.71 & -16.38 \\
\hline fliQ & 2 & Flagellar biosynthesis protein & 2.81 & -4.43 \\
\hline fliR & 2 & Flagellar biosynthesis: export pore protein & 4.27 & -9.88 \\
\hline fliZ & 2 & RpoS antagonist & 1.90 & -10.92 \\
\hline fliC & 3 & Flagellin & 1.75 & - \\
\hline motA & 3 & Proton conductor component of flagella motor & 1.58 & - \\
\hline $\operatorname{mot} B$ & 3 & Protein that enables flagellar motor rotation & 1.76 & - \\
\hline cheA & 3 & Chemotaxis response regulator & 1.26 & - \\
\hline cheW & 3 & Purine-binding chemotaxis protein & 1.44 & - \\
\hline
\end{tabular}




\subsection{Hypothesis}

Short chain fatty acids serve as an environmental cue to modulate EHEC flagellar expression and motility, with upregulation of flagella at SCFA concentrations relevant to the small intestine and downregulation of flagella at SCFA concentrations relevant to the large intestine. The SCFAs are sensed by number of TCSs in which different TCSs may be responding to specific SCFAs or combination of SCFAs.

\section{$\underline{1.12 \text { Objectives }}$}

While this project is one coherent investigation, there have been three researchers involved in the experimental work. The author(s) of each result are indicated beside each objective and also noted in the materials and methods chapter.

I. To determine EHEC flagellar gene expression under varying SCFAs mix concentrations.

A DNA microarray analysis by Dr. Seav Ly Tran et al (Lackraj and Kim et al. In press) provided support for the hypothesis of this project. The microarray analysis demonstrated differential expression of flagellar genes in response to physiologically relevant SCFA mixtures.

The expression of selected flagellar genes exposed to SCFAs mixes reflective of the small and large intestines was determined using quantitative real-time PCR (qRTPCR) by Tracy Lackraj (PhD candidate). The results of this research confirmed the DNA microarray analysis.

II. To determine EHEC flagella protein expression under varying SCFAs mix concentrations. Immunoblot and flow cytometry analyses were used to determine the flagella protein expression. Immunoblot analysis to determine the flagella expression of EHEC 
O157:H7 was completed by Tracy Lackraj. Flow cytometric analysis of EHEC O157:H7 flagella protein was completed by Jee In Kim.

III. To determine EHEC and E. coli K12 motility under varying SCFA mix concentrations. Soft-agar motility assay was used to determine the motility function of the pathogenic and non-pathogenic E. coli. This objective was completed by Jee In Kim.

IV. To elucidate the two-component signaling systems involved in SCFA-induced flagella regulation.

Soft-agar motility assay and immunoblot analyses with varying SCFA concentrations were conducted with seven TCS mutants of E. coli K-12 to aid in the elucidation of the TCSs involved in SCFA-induced flagella regulation. This objective was completed by Jee In Kim. 


\section{Materials and Methods}

\section{$\underline{2.1 \text { Bacterial strains and culture conditions }}$}

Escherichia coli O157:H7 strain EDL933, 86-24 and K-12 strain BW25113, along with the TCS mutants of BW25113, were used in this study (Table 3). E. coli K-12 and its TCS mutants are commercially available from the E. coli Genetic Stock Centre at Yale University (New Haven, Connecticut, US). Bacterial glycerol stocks were maintained at $-80^{\circ} \mathrm{C}(15 \%$ glycerol, v/v) and streaked onto Luria-Bertani (LB) agar plates (1\% tryptone w/v, $0.5 \%$ yeast extract w/v, $1 \%$ sodium chloride w/v, 1.5\% agar w/v; BioShop, Burlington, ON, Canada) in order to obtain single colonies. Bacterial working stocks were streaked onto a new LB agar plates every two weeks. Overnight cultures were prepared by inoculating single colonies into LB broth, with added antibiotics to standard concentrations when needed, which were incubated at $37^{\circ} \mathrm{C}$ with shaking (200 rpm) for 12-16 hours.

Table 3. Bacterial strains used in this study.

\begin{tabular}{|c|c|c|}
\hline Strain & Characteristics & References \\
\hline $86-24$ & Wild-type EHEC O157:H7 & (Giron et al. 2002) \\
\hline EDL933 & Wild-type EHEC O157:H7 & (Li et al. 1999) \\
\hline BW25113 & Wild-type E. coli K-12 & (Datsenko and Wanner 2000) \\
\hline JW2205-2 & $\Delta r c s B:: k a n$ & (Baba et al. 2006) \\
\hline BW29655 & $\Delta($ envZ-ompR $):: F R T$ & (Zhou et al. 2003) \\
\hline JW1899-1 & $\Delta u v r Y:: k a n$ & (Baba et al. 2006) \\
\hline BW27876 & $\Delta(\operatorname{cit} A-\operatorname{cit} B)$ & (Oshima et al. 2002) \\
\hline JW4364-1 & $\triangle \operatorname{arcA}:: k a n$ & (Baba et al. 2006) \\
\hline BW27875 & $\Delta(y p d A-y p d B)$ & (Zhou et al. 2003) \\
\hline BW28878 & $\Delta($ atos-atoC $)$ & (Oshima et al. 2002) \\
\hline JW1908-1 & $\Delta f l i C:: k a n$ & (Baba et al. 2006) \\
\hline
\end{tabular}




\subsection{SCFA treatment}

For the 30mM SCFA mix treatment, LB overnight culture was resuspended in LB containing 100mM MOPS (morpholinepropanesulfonic acid; $\mathrm{pH}$ 6.7) and the 30mM SCFA mixture $(25 \mathrm{mM}$ sodium acetate, $2.5 \mathrm{mM}$ sodium propionate, $2.5 \mathrm{mM}$ sodium butyrate) (Herold et al. 2009) to an $\mathrm{OD}_{600}$ of 0.05 and then incubated at $37^{\circ} \mathrm{C}$ with $5 \% \mathrm{CO}_{2}$ to late log phase $\left(\mathrm{OD}_{600}\right.$ of approximately 1.0 ). The $30 \mathrm{mM}$ and $172 \mathrm{mM}$ sodium chloride osmolarity controls were treated in the same manner as the $30 \mathrm{mM}$ SCFA treatment. For the $172 \mathrm{mM}$ SCFA mix treatment $(95 \mathrm{mM}$ sodium acetate, $60 \mathrm{mM}$ sodium propionate, $17 \mathrm{mM}$ sodium butyrate) (Herold et al. 2009), due to the prolonged lag phase of EHEC incubated with this mixture, LB overnight culture was resuspended in LB containing $100 \mathrm{mM}$ MOPS ( $\mathrm{pH}$ 6.7) to an $\mathrm{OD}_{600}$ of 0.2 , subcultured for 2 hours, followed by the addition of $172 \mathrm{mM}$ SCFA mixture which was incubated at $37^{\circ} \mathrm{C}$ with $5 \%$ $\mathrm{CO}_{2}$ to late $\log$ phase $\left(\mathrm{OD}_{600} \cong 1.0\right)$.

For the individual SCFAs treatments, LB overnight cultures were subcultured in the same manner as the SCFA mixture treatments. The individual SCFAs at their respective concentrations within the small or large intestinal SCFA mixes were used, however with added $\mathrm{NaCl}$, in order to make the final concentrations consistent with the mixtures. For example, the small intestinal acetate concentration was composed of $25 \mathrm{mM}$ sodium acetate and $5 \mathrm{mM} \mathrm{NaCl}$, to make the final concentration $30 \mathrm{mM}$. For the large intestinal acetate $(95 \mathrm{mM}$ sodium acetate + $77 \mathrm{mM} \mathrm{NaCl})$ and propionate $(60 \mathrm{mM}$ sodium propionate $+112 \mathrm{mM} \mathrm{NaCl})$ treatments, prolonged lag phase was observed therefore the 172mM SCFA mix treatment protocol was applied.

For the microarray study, same overnight culture and subculture protocols were used as mentioned above, however LB was substituted with Dulbecco's Modified Eagle Medium (DMEM) containing 4.5g/L glucose, L-glutamine and sodium pyruvate. DMEM was used for the 
microarray study as it has been shown to enhance expression of virulence genes (Iyoda et al. 2006; Tobe et al. 2011). However, for the subsequent experiments including qRT-PCR, immunoblot, flow cytometry, and soft-agar motility assay, LB was the media of choice as it generated higher flagella protein expression that was more consistent with the differential flagella expression observed from the microarray results.

\subsection{DNA microarray analysis of gene expression}

DNA microarray analysis was completed with O157:H7 strain EDL933. The different treatment groups included EHEC treated with $30 \mathrm{mM} \mathrm{NaCl}, 30 \mathrm{mM}$ SCFA, $172 \mathrm{mM} \mathrm{NaCl}$ and 172mM SCFA, with each treatments having four independent biological replicates. RNA purification was performed as described by Kus et al (Kus et al. 2011). Agilent Technologies Bioanalyser 2100 was used to verify the quality and integrity of total RNA in each sample. An Agilent E. coli Gene Expression 8x15K Microarray with 10,691 probes (Agilent Product number G4813A) was used for gene expression analysis. The cDNA generation and hybridization for the microarrays was performed at the Princess Margaret Genomics Centre, Toronto, Canada according to standard protocols. Quality of the data was verified using R (v2.14.1) with the Bioconductor framework and the Array Quality Metrics package. Agilent spatial detrending method was used for data normalization which was conducted on Genespring v12.1. All data analysis and visualization were performed on normalized $\log 2$ transformed data.

For the $172 \mathrm{mM}$ treatment, only 2 of the 4 replicates were used for analysis as the others were identified as outliers. Data were filtered to remove probes that showed no signal, in order to eliminate confounding effect. The upper $80^{\text {th }}$ percentile of the distribution of intensities in $100 \%$ of all the sample groups was the threshold to pass filtration. The $30 \mathrm{mM}$ condition contained 
8513 probes and the $172 \mathrm{mM}$ condition contained 8643 probes in the final set. Unpaired t-test $(\mathrm{P}<0.05)$ was used to identify the significant genes in each treatment. Complete dataset is available at NCBI Gene Expression Omnibus Series, accession number GSE79509. This protocol was optimized and conducted by Dr. Seav Ly Tran.

\subsection{Quantitative real-time PCR (qRT-PCR)}

Following the bacterial treatment with SCFA mixtures or $\mathrm{NaCl}$ controls, total RNA was isolated using a GeneJet RNA Purification Kit (ThermoFisher Scientific, Waltham, MA, USA). RNA conversion to cDNA was conducted using iScript cDNA synthesis kit (BioRad, Mississauga, ON, Canada) according to manufacturer's instructions. Gene expression was analyzed using primers against $g a p A$ (control), fliC, flhC, flhD, motAB, cheW and cheA (Table 4) using Roche LightCycler ${ }^{\circledR}$ FastStart DNA Master SYBR Green I, and Roche LightCycler 2.0 Instrument (Roche Life Science, New York, NY, USA). This protocol was optimized and conducted by Tracy Lackraj (PhD candidate).

Table 4. Primer sequences used for qRT-PCR. Table contributed by Tracy Lackraj and modified from Lackraj and Kim et al. (In press)

\begin{tabular}{ccl}
\hline Primer & Sequence $\left(\mathbf{5}^{\prime} \rightarrow \mathbf{3}^{\prime}\right)$ & Reference \\
\hline gapA_F & AGGTCTGATGACCACCGTTC & This study \\
gapA_R & GGAACGCCATACCAGTCAGT & This study \\
fliC_F & CAAGTTGCCTGCATCGTCTA & This study \\
fliC_R & TCAGCTTCAAAACGTGATGC & This study \\
flhC_F & GTGGGATAATATCGGCAGGA & This study \\
flhC_R & GCGGTTTGTTGAAAGTGGAT & This study \\
flhD_F & GATGCCGGTATGAATTTGCT & This study \\
flhD_R & CAGCGTCTGATTGTTCAGGA & This study \\
motAB_F & TTCTAAACATCGGGCGATTC & This study \\
motAB_R & CAGGGGGAAGTGAATAAGCA & This study \\
cheA_F & CTGATGTTCGGCAGACAGAA & This study \\
cheA_R & AACTCGGCAAGCAGGTAGAA & This study \\
cheW_F & CGTCAATGAAAGCACGTCTG & This study \\
cheW_R & AGGTAACACGGATTGCGAAC & This study \\
\hline
\end{tabular}




\section{$\underline{2.5 \text { Immunoblot analysis of flagella protein expression }}$}

In order to determine the flagella (FliC) protein expression, immunoblot analysis was conducted. Following the SCFA treatments, bacterial pellets were collected from subcultures using centrifugation at 3,500rpm for 10 mins at $4^{\circ} \mathrm{C}$, washed twice in $1 \mathrm{X}$ PBS $(137 \mathrm{mM} \mathrm{NaCl}$, 2.7mM KCl, $\left.10 \mathrm{mM} \mathrm{Na}_{2} \mathrm{HPO}_{4}, 1.8 \mathrm{mM} \mathrm{KH}_{2} \mathrm{PO}_{4}\right)$, and re-suspended in $1 \mathrm{X}$ SDS sample buffer $(10 \%$ Glycerol, $60 \mathrm{mM}$ Tris/HCl $\mathrm{pH} \quad 6.8,2 \% \quad \mathrm{SDS}, \quad 0.01 \%$ bromophenol blue, $1.25 \% \quad \beta$ mercaptoethanol). The re-suspended bacterial pellets were heated at $95^{\circ} \mathrm{C}$ for 10 minutes followed by cell lysis by syringing using $27 \mathrm{G}$ x1/2 inch needle (BD, Missiauga, ON, Canada). Samples were run on a $10 \%$ SDS-polyacrylamide gel and transferred onto a $0.45 \mu \mathrm{m}$ ImmobilonP PVDF membrane (EMD Millipore, Etobicoke, ON, Canada). Membranes were blocked in 7\% skim milk (w/v in $1 \%$ TBST) for a minimum of 1 hour at room temperature with shaking and incubated overnight in either polyclonal anti-H7 for O157:H7 strain 86-24 (1:500 dilution; Denka-Seiken, Tokyo, Japan), polyclonal anti-H48 for E. coli K-12 (1:20 dilution; Statens Serum Institut, Copenhagen, Denmark) or monoclonal anti-DnaK (1:10,000 dilution; Enzo Life Sciences, Farmingdale, NY, USA). This was followed by incubation with a horseradish peroxidase-conjugated secondary antibody and visualization using ECL detection. Immunoblot assay with EHEC flagella H7 was conducted by Tracy Lackraj.

\subsection{Flagella protein isolation and preparation}

In order to confirm the specificity of the serum polyclonal anti-H48 (1:20 dilution; Statens Serum Institut, Copenhagen, Denmark), E. coli K-12 wild-type and $\Delta$ fliC mutant (negative control) flagella protein were isolated and prepared with the protocol adapted from Guyon et al (Guyon et al. 2015). Briefly, bacteria were grown overnight in LB media followed 
by subculturing in $\mathrm{LB}$ to $\mathrm{OD}_{600}$ of approximately 1.0. $\mathrm{LB}$ was the media of choice because it has been shown to promote flagella expression (Tobe et al. 2011). Bacteria flagella were sheared by syringing with $25 \mathrm{G} \times 5 / 8$ inch needle (BD, Mississauga, ON, Canada) on ice and isolated through repeated centrifugation at $17,700 \mathrm{xg}$ for $10 \mathrm{~min}$ at $4^{\circ} \mathrm{C}$. The sheared flagella protein was precipitated with trichloroacetic acid and pelleted by centrifugation at 17,700 $\mathrm{x}$ g for $40 \mathrm{~min}$ at $4^{\circ} \mathrm{C}$. Isolated flagella protein was mixed with $1 \mathrm{X}$ SDS sample buffer and Tris-HCL (pH 9) and visualized using the protocol from section 2.5 .

\subsection{Flow cytometry analysis of EHEC flagella expression}

EHEC flagellar protein expression was also assessed by flow cytometry. SCFA-stressed EHEC was pelleted at 5000rpm for 10 mins and washed with Gibco Hank's balanced salt solution (HBSS) (Life Technologies). Following the wash, the bacterial pellet was incubated with anti-H7 (1:50 dilution; Denka-Seiken, Tokyo, Japan) for 30 mins at $4{ }^{\circ} \mathrm{C}$ then wash with HBSS. Bacteria were then incubated with Alexa Fluor 488-conjugated secondary antibody (Life Technologies) for 20 mins at $4^{\circ} \mathrm{C}$, washed with HBSS, and fixed with $2 \%$ paraformaldehyde for 15 mins at room temperature followed by quenching with glycine and a final wash with HBSS. BD LSRFortessa ${ }^{\mathrm{TM}}$ X-20 cell analyzer (St. Michael's Hospital, Toronto, Canada) was used to measure the fluorescence intensity of the stained flagella on minimum of 10,000 bacteria for each condition. Data was analyzed using FCS Express 5 (De Novo Software).

\section{$\underline{2.8 \text { Soft-agar motility assays }}$}

The impact of SCFA treatments on EHEC, E. coli K-12 and selected K-12 TCS mutants' motility was assessed by soft agar motility assay using $0.25 \%$ Bacto $^{\mathrm{TM}}$ Tryptone agar plates 
supplemented with appropriate SCFA mixtures. Following the SCFA and NaCl treatments, $2 \mu l$ of the subcultured bacteria was spotted into the soft-agar and the diameter of the motility halo was measured after $12 \mathrm{~h}$ static incubation at $37^{\circ} \mathrm{C}$. In order to control for the differences in growth affecting halo sizes, motility halos were homogenized. The homogenates were serially diluted and plated to determine the CFU counts.

\subsection{Growth rate assay of $E$. coli $\mathrm{K}-12$ wild-type and the TCS mutants}

It was questioned that the differences between the motility diameters, of the E. coli K-12 wild-type and its TCS deletion mutants treated with SCFAs mixtures, may be due to the growth rate differences caused by the mutations. Therefore, the growth rate of the wild-type and mutant strains were measured for 12 hours, post-SCFA mix treatments and the corresponding $\mathrm{NaCl}$ osmolarity control treatments. $2 \mu \mathrm{l}$ of the subcultured wild-type and mutants were inoculated into appropriate wells of the 96-well plate containing $300 \mu \mathrm{L}$ of Bacto ${ }^{\mathrm{TM}}$ Tryptone supplemented with appropriate SCFA mixtures or $\mathrm{NaCl}$ controls. $\mathrm{OD}_{630}$ was measured every 30 minutes for the total of 12 hours. BioTek ${ }^{\circledR}$ Synergy ${ }^{\mathrm{TM}}$ HT Multi-Detection Microplate Reader and BioTek ${ }^{\circledR}$ Gen5 $5^{\mathrm{TM}}$ Microplate Data Collection \& Analysis Software were used for the optical density measurement of the 96-well plate.

\section{$\underline{2.10 \text { Statistical analysis }}$}

All the experiments were conducted with a minimum of three biological replicates ( $N=$ biological replicate, $n=$ technical replicate). All data are presented with the standard errors of the means (SEMs). Two-way ANOVA with Sidak's multiple-comparison test was used to determine the differences among multiple groups in immunoblot analysis and motility assay 
conducted with EHEC O157:H7 strain 86-24. One-way ANOVA with Tukey's multiplecomparison test was used to determine the differences among multiple groups in motility assay conducted with $E$. coli $\mathrm{K}-12$. $P$ value of $<0.05$ was considered significant. 


\section{Results}

\subsection{Gene expression analyses of SCFA-treated EHEC}

The full transcriptome dataset of EHEC O157:H7 treated with either 30mM or 172mM SCFA mixtures and their respective $\mathrm{NaCl}$ osmolarity controls are available on GEO database; accession no. GSE79509. Numerous genes, including EHEC virulence genes, were differentially expressed when treated with the small and large intestinal SCFA mix treatments that were normalized to their corresponding $\mathrm{NaCl}$ controls. The housekeeping gene, gapA, which encodes glyceraldehyde-3-phosphate dehydrogenase, did not show any significant differences in the expression when treated with the two SCFA mixes.

Of particular interest, almost all EHEC flagellar genes showed upregulation of 1.5-4.3 fold with 30mM SCFA mix treatment and downregulation of 3-23 fold with 172mM SCFA mix treatment (Table 2). To further confirm the expression trends observed with flagellar genes, quantitative real-time (qRT) PCR was conducted. qRT-PCR analysis of several selected genes including $f l h D C$, the Class 1 master regulator gene, $f l i C$, the Class 3 flagellin gene, and motAB \& che $A W$, the motor and chemotaxis genes, was consistent with the microarray data. The $f l h D C$, $m o t A B$ and $c h e A$ genes were significantly upregulated with the $30 \mathrm{mM}$ SCFA mix treatment relative to the $172 \mathrm{mM}$ SCFA mix treatment (Figure 4). Surprisingly, fliC and che $W$ genes showed no significant differences in expression between the SCFA mix treatments (Figure 4).

The transcriptome analysis also identified numerous non-flagellar genes that demonstrated differential expression with SCFA mix treatments. Interestingly, $r c s$ genes encoding the RcsCB TCS were upregulated (1.6-2.14 fold) while the $r c s$ gene encoding the RcsD His-containing phosphotransfer (HPt) protein was downregulated (1.2 fold) with the $30 \mathrm{mM}$ SCFA mix treatment relative to the control. RcsCB TCS has been selected in this study as a 
potential candidate SCFA sensor and the transcriptome results suggest an association between this TCS and SCFA-induced flagella expression changes. All the genes in $s d h$ operon also showed upregulation (3.2-4 fold) with the 30mM SCFA mix treatment. This operon is involved in succinate metabolism and has been shown to be regulated by ArcA, which is another selected TCS RR to be investigated as a SCFA sensor that is in association with flagella expression. 
A

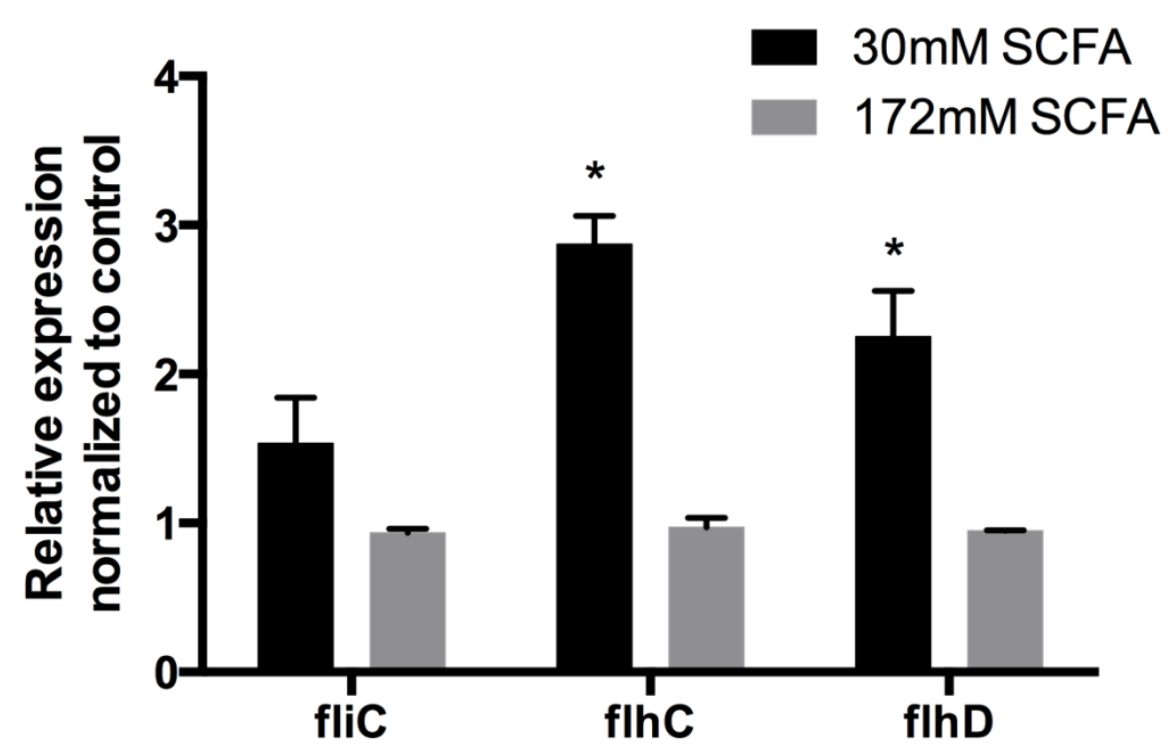

B

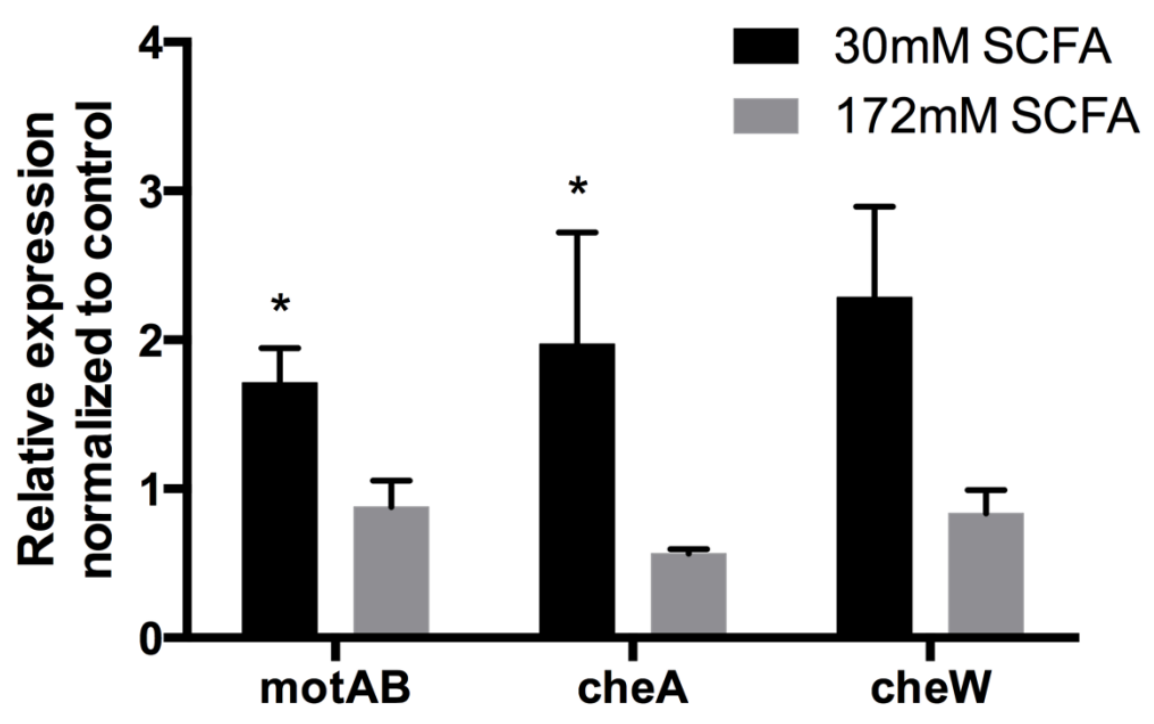

Figure 4. Quantitative real-time PCR analysis of EHEC O157:H7 treated with the small and large intestinal SCFA mixtures on (A) fliC, flhC, and $f l h D$ gene expression and (B) motAB, cheA, and $c h e W$ gene expression. The expression was normalized to the corresponding $\mathrm{NaCl}$ osmolarity control. Data bars represent means \pm SEMs, $N=4$. *significantly different from $172 \mathrm{mM}$ SCFA mix treatment; $P<0.05$, unpaired t-test. Figure contributed by Tracy Lackraj and modified from Lackraj and Kim et al. (In press). 


\subsection{Flagella protein expression analyses of SCFA-treated EHEC}

To determine if the differential flagellar gene expression by small and large intestinal SCFA mixes is translated to protein expression, immunoblot and flow cytometry analyses were conducted. Flagella protein expression of EHEC treated with the 30mM SCFA mix showed significant upregulation relative to its appropriate $\mathrm{NaCl}$ control and to the $172 \mathrm{mM}$ SCFA mix treatment (3.7 fold difference) (Figure 5). The 30mM and 172mM sodium chloride control treatments showed no significant change in the protein expression when compared with each other, confirming that concentration is not the sole factor affecting flagella expression. The results suggest that the SCFAs' composition and concentration are the driving force behind the differential flagella expression.

Flow cytometric analysis also confirmed the immunoblot analysis, showing significantly higher percentage of EHEC (35\%) expressing $\mathrm{H} 7$ flagella protein in the sample treated with the 30mM SCFA mix (Figure 6). In contrast, significantly lower percentage of EHEC (9.5\%) expressed flagella in a population treated with the172mM SCFA mix (Figure 6). Overall, immunoblot and flow cytometry analyses both confirmed the gene expression data, where the small intestinal SCFA mix treatment increased EHEC flagella expression relative to the large intestinal SCFA mix treatment. 
A

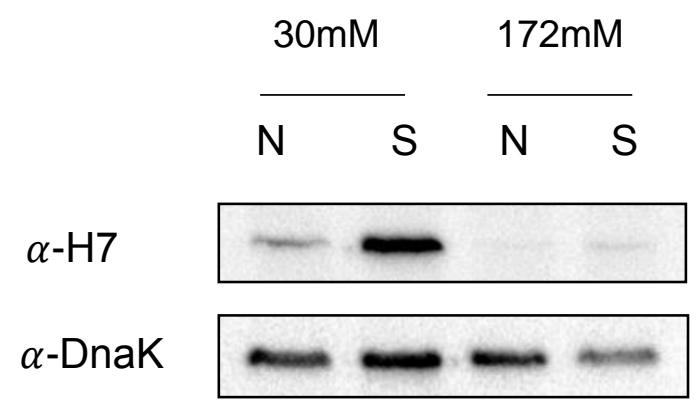

B

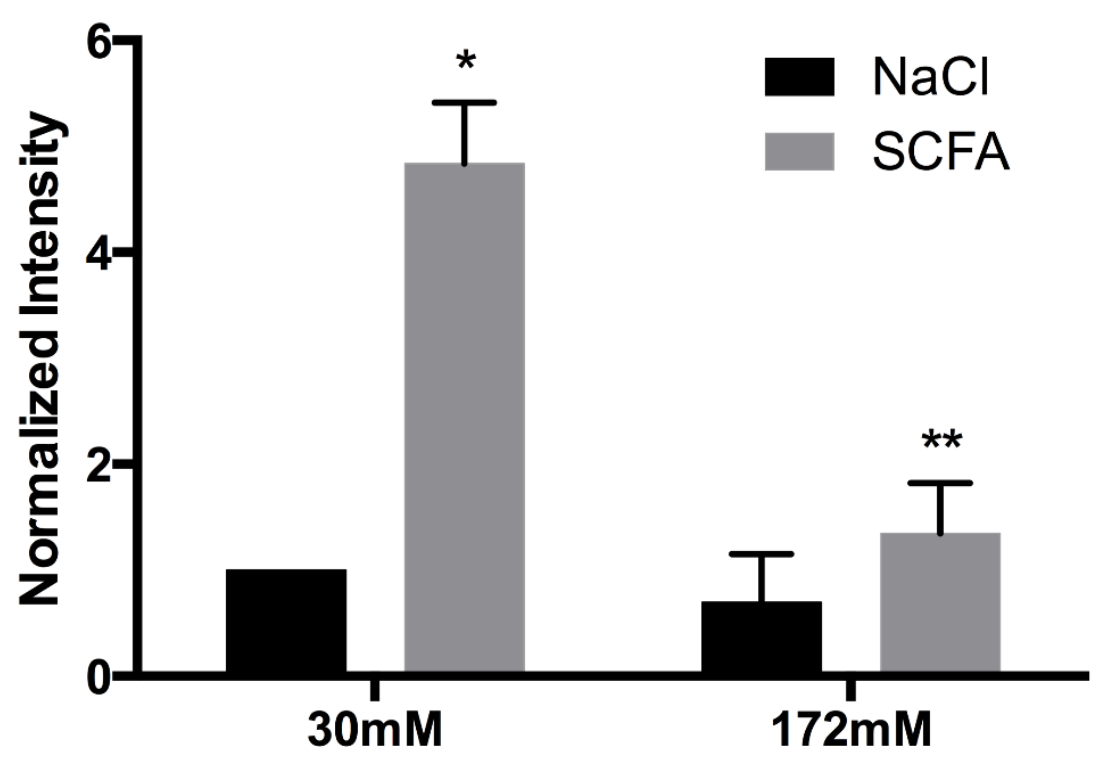

Figure 5. Immunoblot analysis of $\mathrm{H} 7$ flagella protein expression of EHEC O157:H7 treated with the small and large intestinal SCFA mixtures. EHEC treated with either 30mM or 172mM SCFA mixes were subjected to protein cell lysis using SDS sample buffer. Samples were run on a $10 \%$ SDS-polyacrylamide gel, transferred onto a PVDF membrane, then probed using either anti-H7 or anti-DnaK (loading control). (A) ECL-detected blot images; $\mathrm{N}=\mathrm{NaCl}, \mathrm{S}=\mathrm{SCFA}$. (B)

Quantified protein expression from A. Data bars represent means \pm SEMs, $N=3$. *significantly different from corresponding $\mathrm{NaCl}$ control, ${ }^{* *}$ significantly different from 30mM SCFA treatment. Figure contributed by Tracy Lackraj and modified from Lackraj and Kim et al. (In press). 


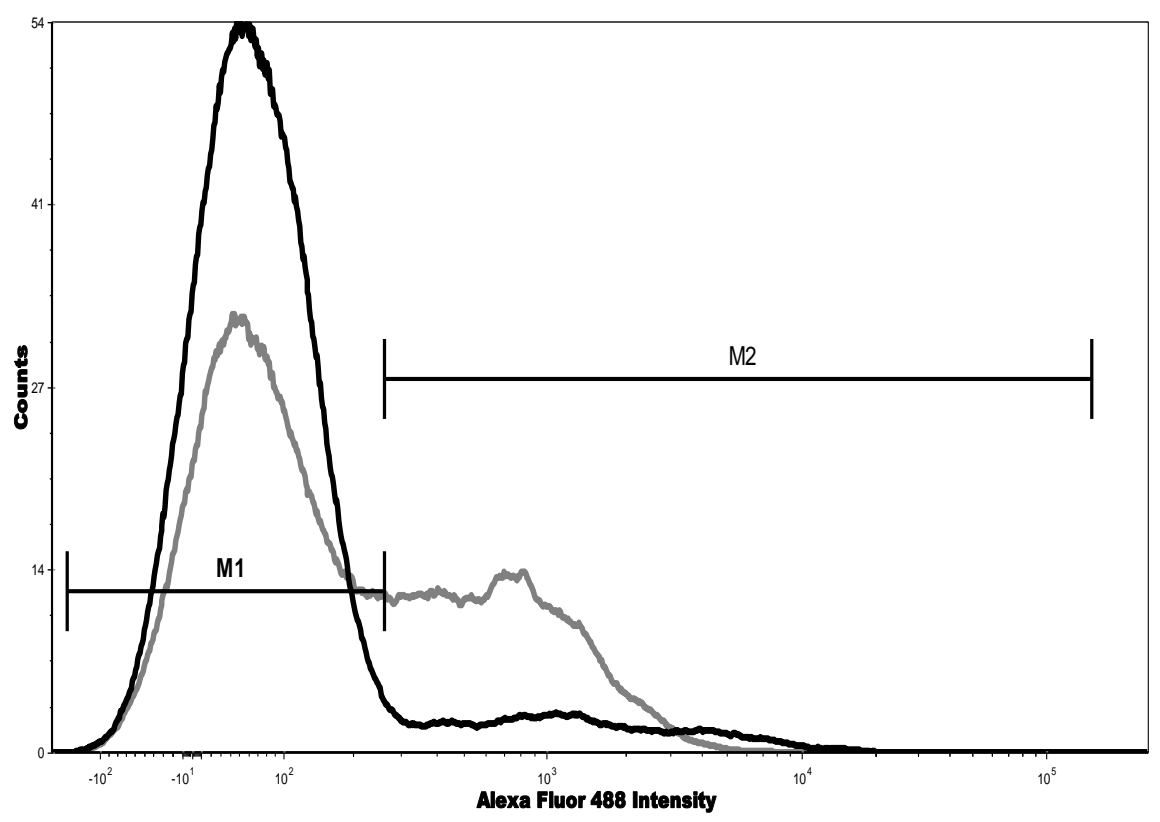

\begin{tabular}{|c|c|c|}
\hline \multirow{2}{*}{ Treatments } & \multicolumn{2}{|c|}{ \% of gated cells for each marker } \\
\cline { 2 - 3 } & M1 & M2 \\
\hline $30 \mathrm{mM} \mathrm{SCFA}$ & 64.62 & 35.38 \\
\hline $30 \mathrm{mM} \mathrm{NaCl}$ & 85.10 & 14.90 \\
\hline $172 \mathrm{mM} \mathrm{SCFA}$ & 90.49 & 9.51 \\
\hline $172 \mathrm{mM} \mathrm{NaCl}$ & 98.43 & 1.57 \\
\hline
\end{tabular}

Figure 6. Flow cytometry analysis of EHEC O157:H7 flagella expression with 30mM SCFA mix (gray histogram) treatment vs. 172mM SCFA mix (black histogram) treatment. The X-axis indicates the fluorescence intensity of the fluorescently stained flagella, and the $\mathrm{Y}$-axis indicates bacteria cell count. Markers M1 (no fluorescence) and M2 (fluorescence) and percent of gated cells for each marker are provided in the table below the graph. Results are representative of three independent experiments. Figure modified from Lackraj and Kim et al. (In press). 


\subsection{SCFA-induced EHEC motility}

Increased flagellar genes and protein expression were observed in EHEC treated with 30mM SCFA mix, representative of human small intestine, relative to $172 \mathrm{mM}$ SCFA mix treatment, representative of human large intestine. To examine if the upregulation is reflected in flagellar function, soft agar motility assay was conducted. Bacterial motility is measured as the function of the halo diameter that is produced upon inoculating subcultured bacteria into semiviscous media. The highest motility halo diameter was observed in EHEC treated with 30mM SCFA mix (Figure 7). The lowest motility was observed with 172mM SCFA mix treatment (Figure 7). The $30 \mathrm{mM}$ and $172 \mathrm{mM} \mathrm{NaCl}$ control treatments showed no significant change in the motility when compared with each other however showed decreased motility relative to the 30mM SCFA treatment (Figure 7). The motility changes observed are consistent with the gene and protein expression analyses and also confirm that the osmolarity differences is not the sole factor contributing to flagella expression and function.

In order to ensure that the differences in motility diameter are not due to the growth variances, all the motility halos formed at the end of the motility assay were homogenized, serially diluted and plated to compare the CFU counts. Two independent experiments showed no significant differences in the CFU counts of halo homogenates of EHEC treated with 30mM and 172mM SCFA mixes (Figure 8). In addition, no significant differences were detected between the CFU counts of halo homogenates when comparing the SCFA treatment groups to their respective $\mathrm{NaCl}$ controls (Figure 8). Overall, these results suggest that the differential motility diameters observed between the SCFA treatments are not due to the differences in growth. 
A

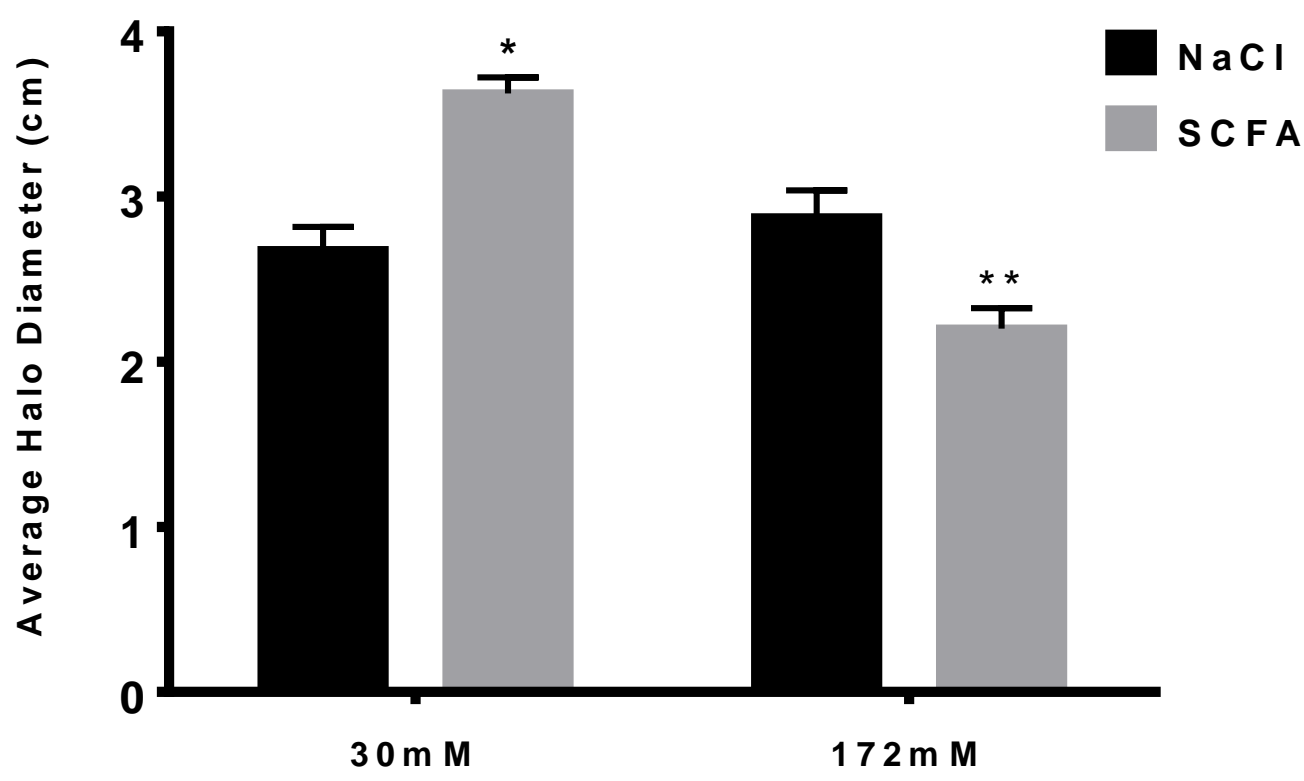

EHEC 0157:H7 strain 86-24

B

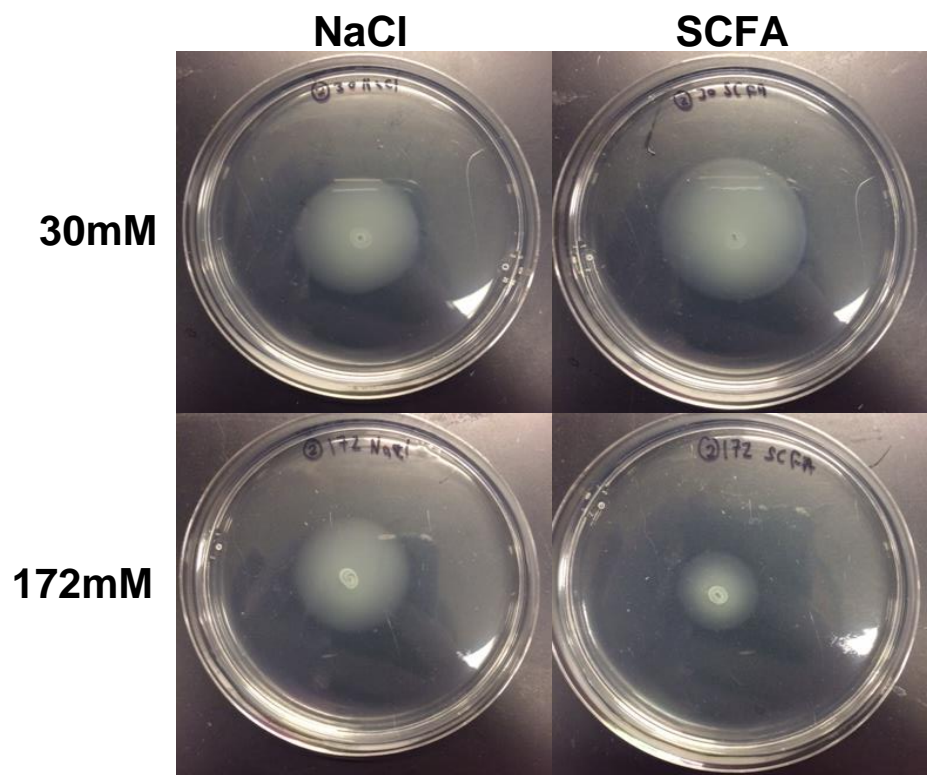

Figure 7. Effect of SCFA treatments on EHEC motility. (A) Motility halo diameter means \pm SEMs of EHEC O157:H7 exposed to either 30mM or 172mM SCFA mixes relative to the respective sodium chloride controls. Results are representative of two independent experiments $(N=6, n=3)$; * significantly different from the corresponding sodium chloride control; ** significantly different from the 30mM SCFA mix and from the corresponding sodium chloride control. (B) Sample halo images of motility results. Figure modified from Lackraj and Kim et al. (In press). 


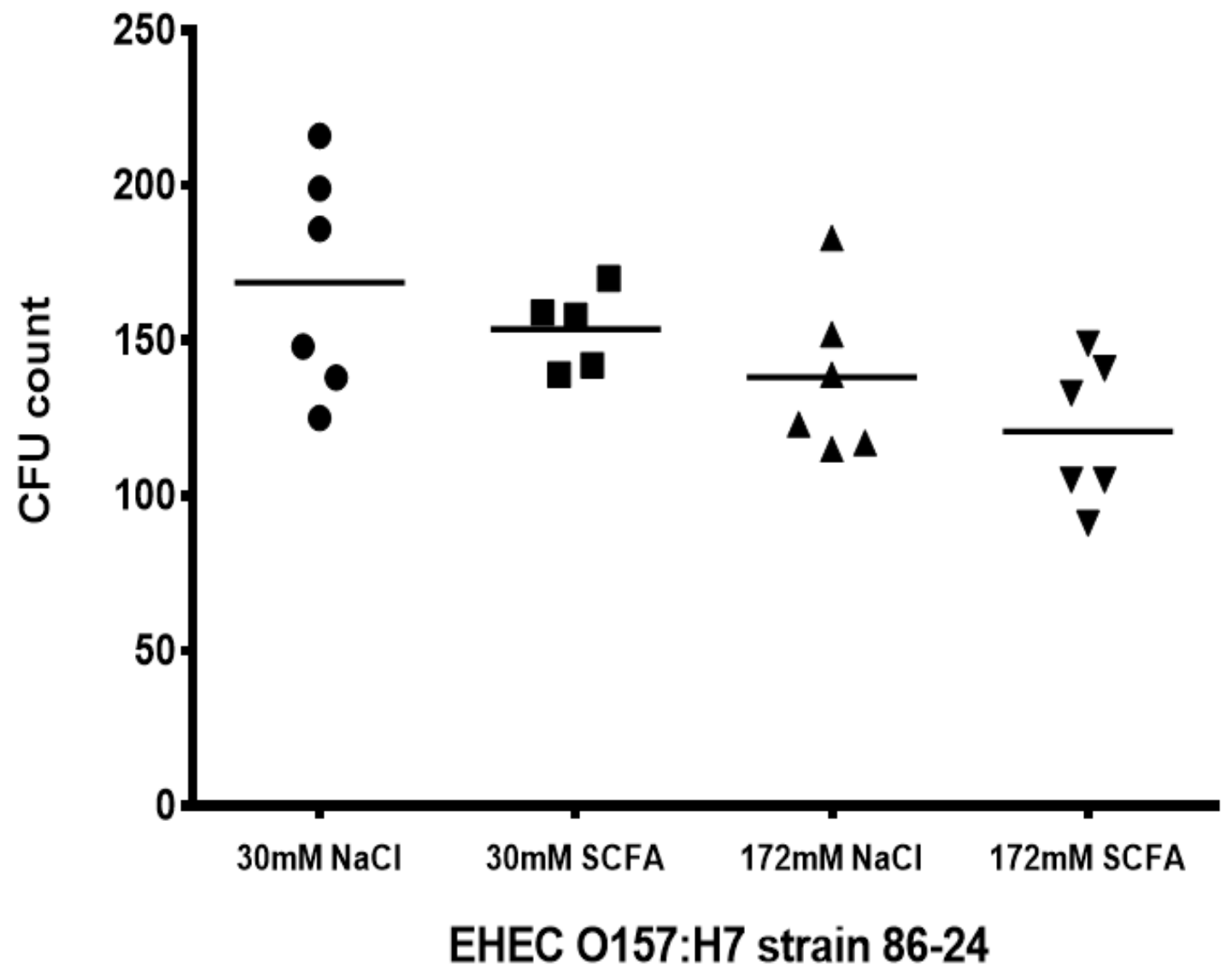

Figure 8. CFU count of each motility halo homogenates of EHEC O157:H7 treated with different SCFA mixtures or $\mathrm{NaCl}$ controls $(n=6)$. No significant differences detected between the CFU counts of halo homogenates of EHEC treated with $30 \mathrm{mM}$ and $172 \mathrm{mM}$ SCFA mixes. No significant differences detected between the CFU counts of halo homogenates when comparing the SCFA treatment groups and their respective $\mathrm{NaCl}$ controls $(P<0.05$, one-way ANOVA with Tukey's multiple-comparison test). 


\subsection{Impact of individual and mixtures of SCFAs on E. coli K-12 and selected TCS mutants}

In order to investigate which TCSs play a role in SCFA recognition and corresponding flagella modulation, the TCSs that have previously been reported to be involved in E. coli flagella regulation were chosen as the candidates. It was hypothesized that if a TCS mediates SCFA-induced flagella expression, the TCS deletion mutant will no longer demonstrate the differential flagella expression and motility behaviour observed for wild-type, when exposed to the two different SCFA mixes. All the TCS isogenic mutants in a E. coli K-12 background were commercially available from the E. coli Genetic Stock Centre at Yale University. When wildtype K-12 was exposed to SCFAs mixes representative of human small and large intestines and their respective $\mathrm{NaCl}$ controls, flagella expression and motility behaviour were consistent with that displayed by wild-type EHEC under the same treatments (Figure 9). There was an increase in flagella protein expression and motility when treated with the 30mM SCFA mix, relative to its $\mathrm{NaCl}$ control and the 172mM SCFA mix treatment (Figure 9). Furthermore, the growth rate assay post-SCFA treatments demonstrated consistent growth between both mixes and corresponding $\mathrm{NaCl}$ treatments, therefore eliminating the growth differential contributing to the motility diameter differential (Figure 10). Therefore, since SCFA-induced motility changes were conserved between EHEC and K-12, E. coli $\mathrm{K}-12$ was chosen as the model strain to evaluate the role of selected TCSs.

The K-12 strain was also exposed to individual SCFAs at their respective concentration within the small and large intestinal mixes, as different TCSs may recognize specific SCFAs. E.coli exposed to the small intestinal (SI) acetate concentration produced similar motility halo diameter as the SI SCFA mix treatment (Figure 9B). The SI propionate and butyrate treatments produced significantly smaller motility halo diameter than the acetate treatment (Figure 9B). 
This differential motility behaviour caused by the SI individual SCFAs was also reflected in the immunoblot analysis. The SI acetate treatment produced the most intense flagella protein band compared to that of the other 2 individual SCFAs treatments (Figure 9C). Interestingly, K-12 wild-type flagella protein expression was not as concentrated as what EHEC had demonstrated with its corresponding flagella antibody under the same SCFA treatments. This may be due to the H48 flagellar antibody having cross reactivity to non-flagellar proteins, hence reducing the binding efficacy. In addition, the flagella may not be as highly expressed in the K-12 strain as it is with EHEC.

For E. coli exposed to the large intestinal (LI) concentration of individual SCFAs, the butyrate treatment produced similar motility halo diameters as the LI SCFA mix treatment (Figure 9B). The LI acetate treatment produced slightly larger motility halos than the LI butyrate treatment. The LI propionate treatment produced significantly larger motility halos compared to the LI acetate or butyrate (Figure 9B). Interestingly, the same samples of subcultured E. coli were used to conduct motility and immunoblot assays however the two results were not in accordance, unlike the results from the SI individual or mix treatments. The LI propionate treatment did not produce higher intensity flagella protein band (Figure 9C). Overall, the individual SCFA treatments showed that the SI SCFA mixture and the SI acetate treatments produced similar motility behaviours while the LI SCFA mixture and the LI butyrate treatments produced similar motility behaviours.

Following the motility assay and immunoblot analysis with the wild-type K-12 treated with individual SCFAs and mixes, selected TCS isogenic mutants were subjected to the same treatments. The motility behaviour and flagella protein expression of the selected TCS mutants were obtained and compared to the results of the wild-type. The selected seven TCS mutants 
include the $r c s B$ mutant (of the RcsCB TCS), the $y p d A B$ mutant, the envZ-ompR mutant, the atoSC mutant, the $\operatorname{arcA}$ mutant (of the ArcBA TCS), the $\operatorname{cit} A B$ mutant and the $u v r Y$ mutant (of the BarA-UvrY TCS).

Of the seven mutants, four mutants including the $\operatorname{rcs} B$ mutant, envZ-ompR mutant, atoSC mutant, and $\operatorname{arc} A$ mutant no longer demonstrated the motility differential observed with the 30mM and 172mM SCFA mix treatments of the wild-type K-12 (Figure 11). In addition, nonnormalized bar graph comparing the average halo diameter of the $30 \mathrm{vs.} 172 \mathrm{mM}$ SCFA mix treatments demonstrated general accordance to the previously elucidated positive or negative regulation of flagella for each TCSs (Figure 11B). For example, CitAB has been shown to negatively regulate flagella and the corresponding mutant from this study showed significant increase in motility, regardless of the treatments, agreeing with the negative regulatory pathway by CitAB TCS (Figure 11B). The detailed motility behavior and flagella protein expression of the TCS mutants are discussed in the following sections (and summarized on Table 5). 
A

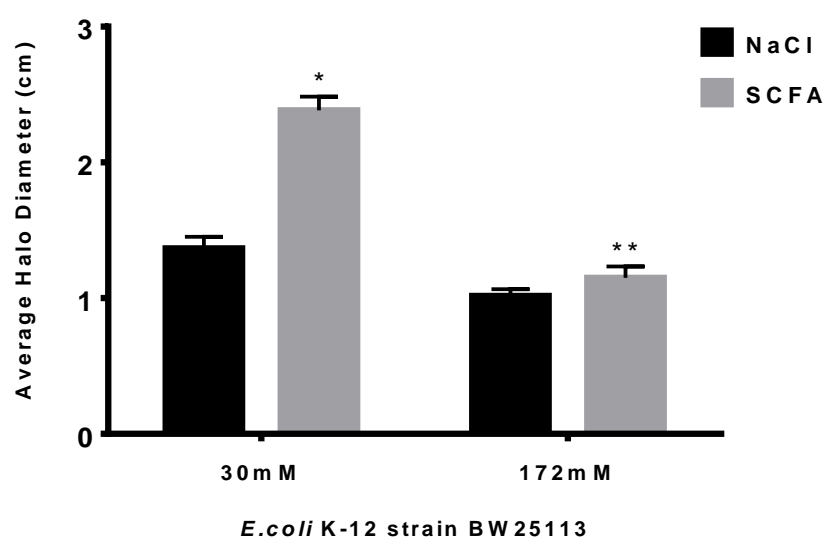

B
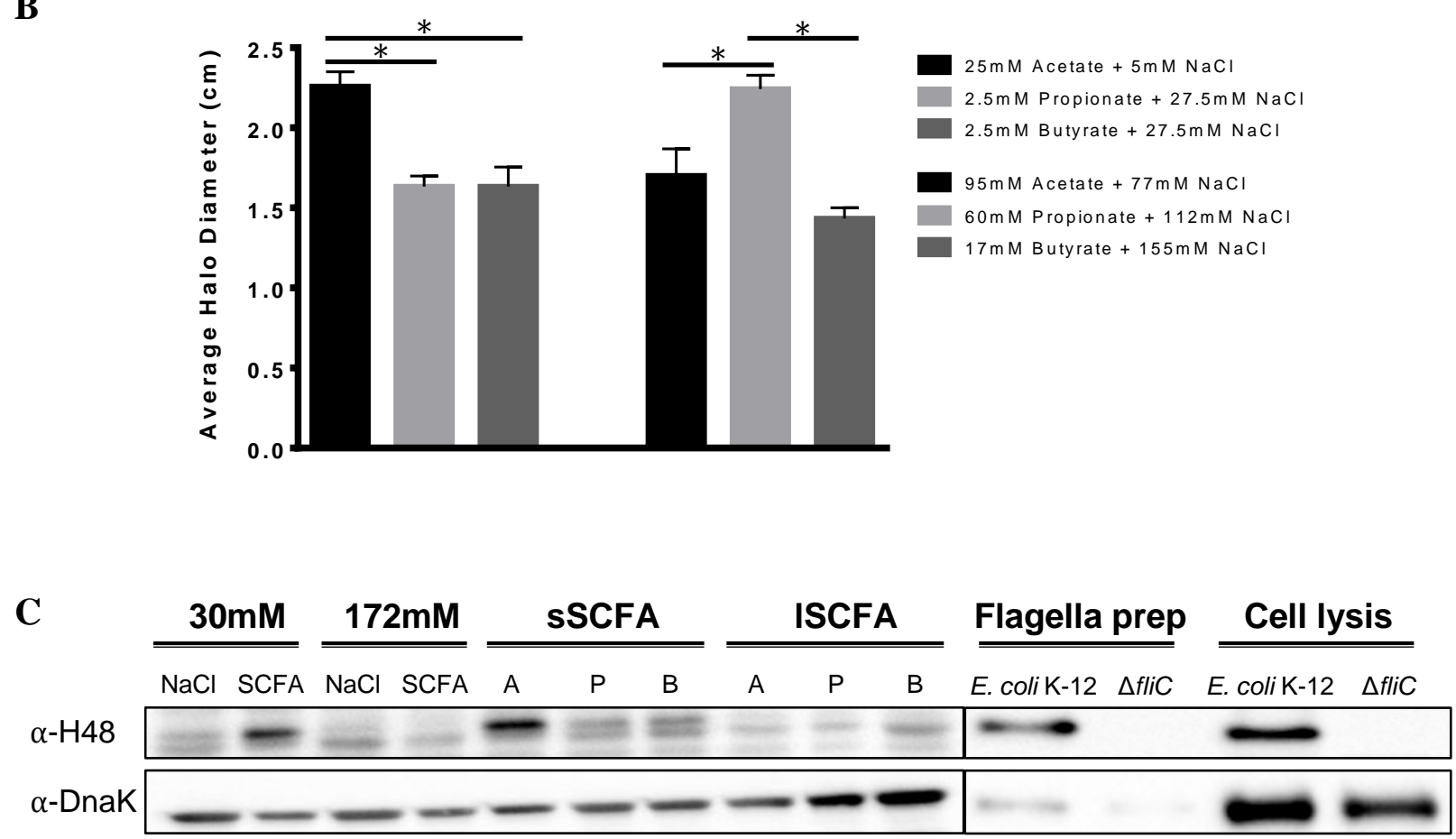

Figure 9. Effect of varying concentrations of SCFAs on the mean \pm SEM of the motility halo diameter and flagella protein expression of E. coli K-12. (A) Effect of small and large intestinal SCFA mixtures on E. coli motility; * significant 2-fold difference from the corresponding sodium chloride control; ** significant difference from the 30mM SCFA mix. (B) Effect of individual SCFAs on E. coli motility; * significant difference. (C) Immunoblot analysis of H48 flagella protein and DnaK (loading control) protein expression of E. coli K-12 treated with mixtures and individual SCFAs. SSCFA=small intestinal individual concentration of A (acetate), $\mathrm{P}$ (propionate) and $\mathrm{B}$ (butyrate). 1SCFA=large intestinal individual concentration of A, P and B. $\triangle f l i C$ mutant without SCFA treatment was used as the negative control. Results obtained from minimum of two independent experiments $(N=2, n=3)$. 


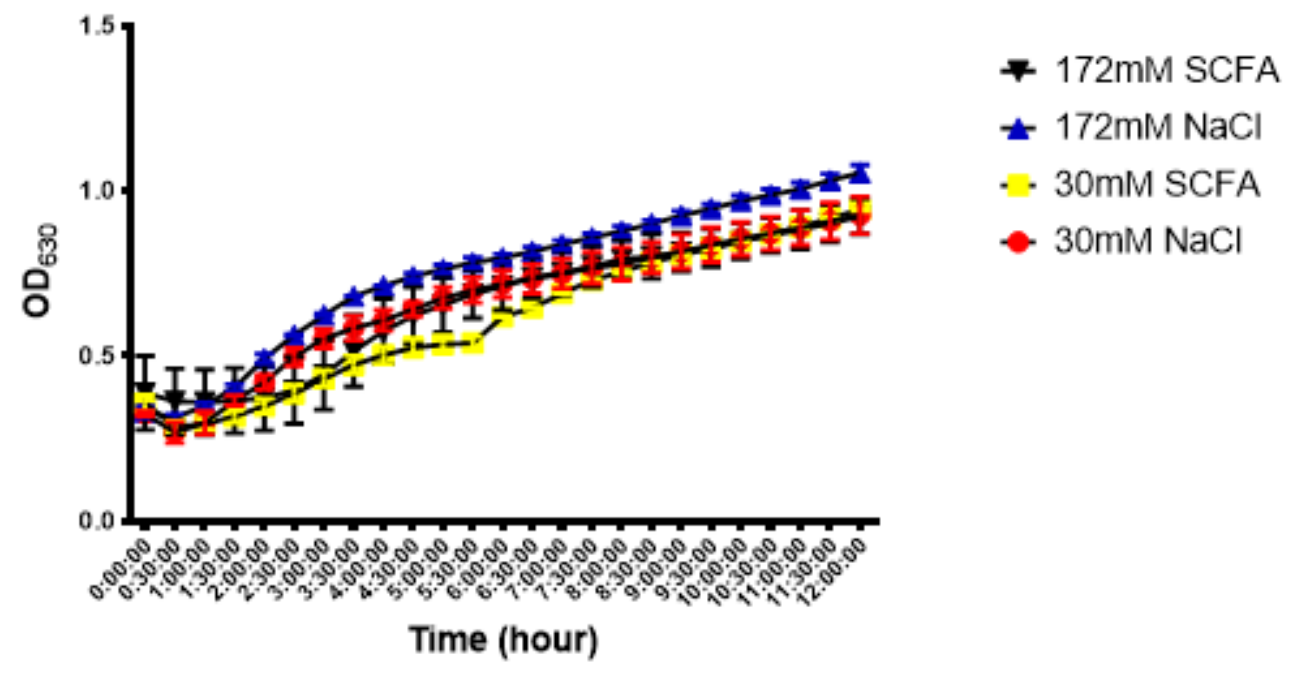

Figure 10. Growth rate of $E$. coli K-12 post-SCFA treatment. E. coli treated with $30 \mathrm{mM}$ and $172 \mathrm{mM}$ SCFA mixtures and their corresponding $\mathrm{NaCl}$ osmolarity controls were inoculated into $300 \mu \mathrm{L}$ of Bacto-Tryptone media and grown for 12 hours. $\mathrm{OD}_{630}$ was measured every 30 minutes $(N=2$; error bar represents SEM). 
A

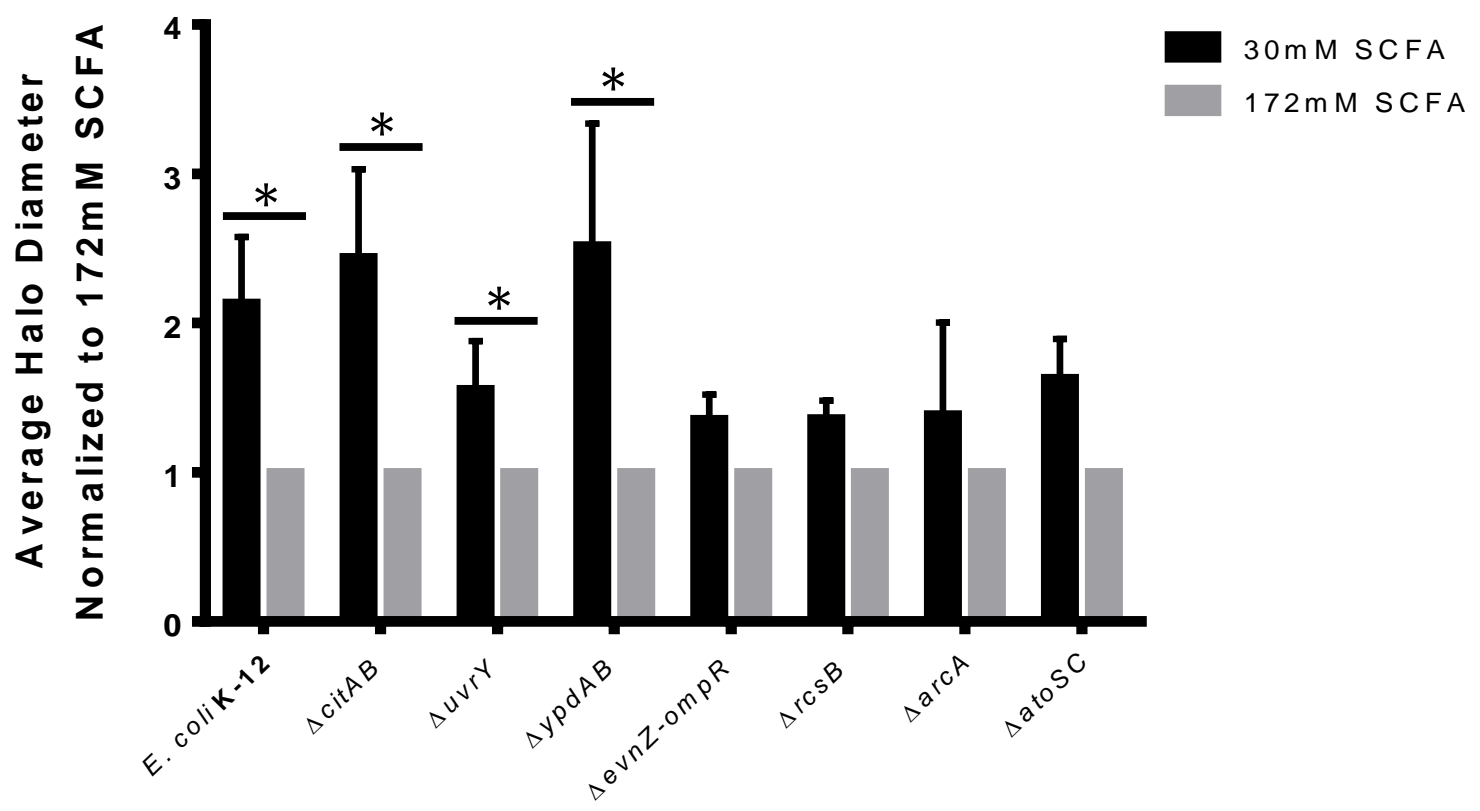

B

TCS mutants

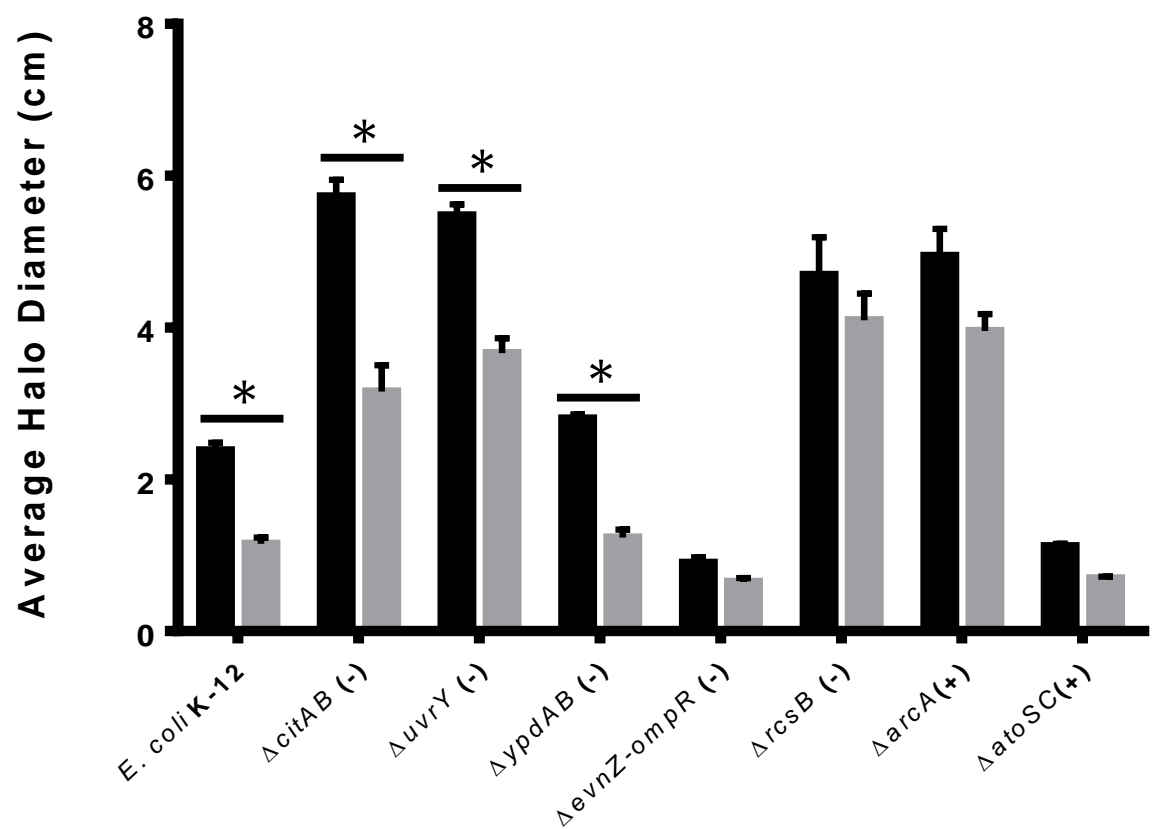

TCS mutants

Figure 11. The overview demonstration of the effect of 30 and 172mM SCFA mix treatments on the motility of $E$. coli K-12 wild-type and TCS mutants. (A) Average halo diameters normalized to the $172 \mathrm{mM}$ SCFA treatment. (B) Non-normalized average halo diameters produced with $30 \mathrm{mM}$ and $172 \mathrm{mM}$ SCFA mix treatments. Positive (+) or negative (-) signs indicate previous findings of regulation of flagella by a TCS. $*=$ significant difference in motility between the two SCFA mix treatments, for that specific TCS mutant. 


\subsection{1 $\Delta r c s B$ of the RcsCB TCS}

\subsubsection{Motility and flagella protein expression with SCFA mix treatments}

The SCFA-modulated differential flagella production and motility behaviour seen with the wild-type was no longer evident for the $\Delta r \operatorname{cs} B$ (Figure 12). Therefore, results suggest that RcsCB TCS may be involved in SCFA sensing.

\subsubsection{2 $\Delta r c s B$ negatively regulates flagella}

This TCS has been shown to negatively regulate flagella (Oshima et al. 2002).The $\Delta r c s B$ mutant demonstrated an increase in flagellin and motility with all treatments, including controls, relative to the wild-type, confirming the negative regulation by RcsB (Figure 12). Significantly higher motility halo diameters were observed with the $\mathrm{NaCl}$ control treatments compared to the SCFA mix treatments (Figure 12). The increased motility halo diameters with the $\mathrm{NaCl}$ control treatments were also in agreement with the growth rate assay results, where we saw slower growth with the SCFA mix treatments relative to the $\mathrm{NaCl}$ control treatments (Figure 13 ). However, the growth appeared not to be the sole reason for the motility differential because the motility halo diameters produced with the SCFA mix treatments and their corresponding $\mathrm{NaCl}$ treatments were significantly higher compared to the wild-type (Figure 12A).

\subsubsection{Motility and flagella protein expression with individual SCFA treatments}

For the SI individual SCFA treatments, it was interesting to see that the acetate treatment resulted in a significantly lower motility compared to butyrate or propionate, which was opposite of that displayed by the wild-type (Figure 12B). For the LI SCFA treatments, the butyrate treatment produced the highest motility halo diameter, in contrast to the wild-type phenotype where the propionate treatment produced the highest motility halo diameter (Figure 12B). 
A

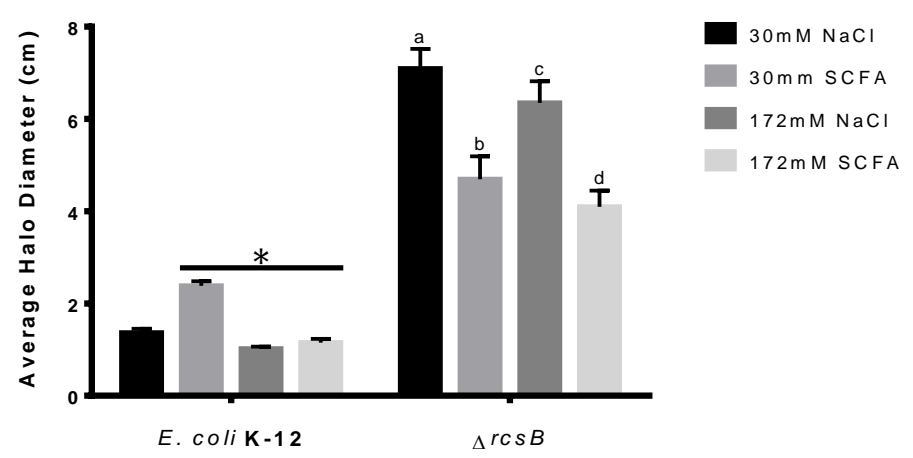

B
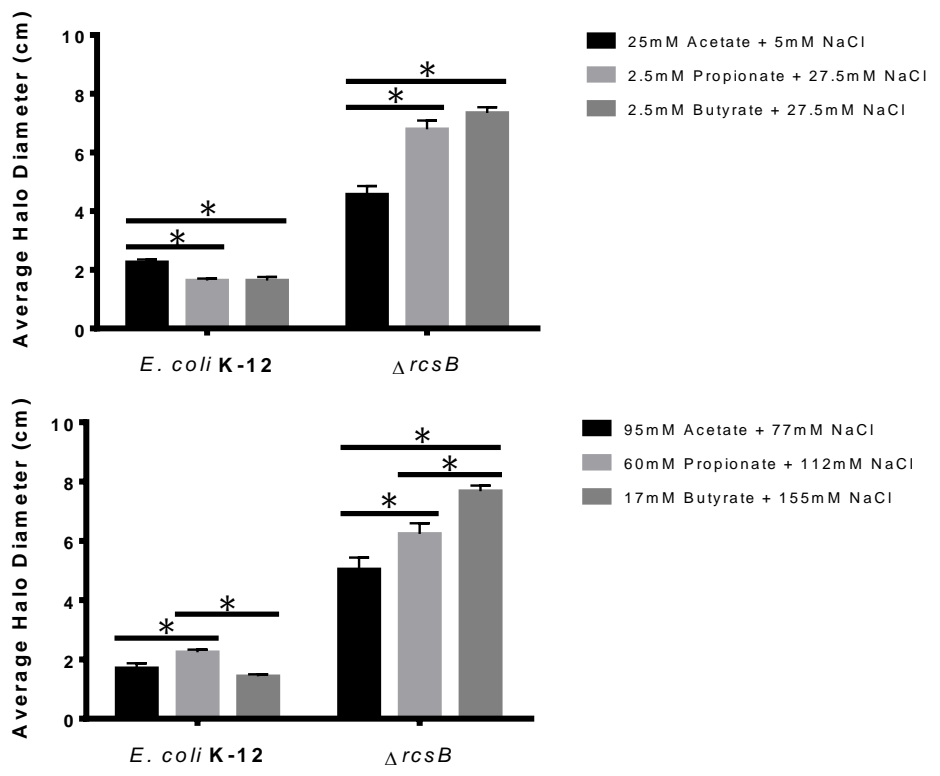

C

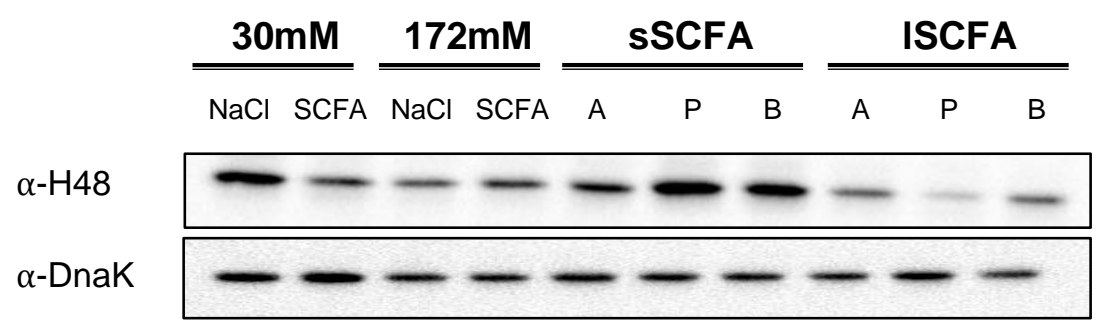

Figure 12. Effect of varying concentrations of SCFAs on the mean \pm SEM of the motility halo diameter and flagellin protein expression of E. coli K-12 and $\Delta \operatorname{rcs} B$. (A) Effect of small and large intestinal SCFA mixtures; each letter indicates the significant difference relative to the motility diameter produced by the same treatment in the wild-type. (B) Effect of individual SCFAs. (C) Immunoblot analysis of H48 flagella protein and DnaK (loading control) protein expression of $\triangle r c s B$ treated with mixtures and individual SCFAs. sSCFA=small intestinal individual concentration of $\mathrm{A}$ (acetate), $\mathrm{P}$ (propionate) and $\mathrm{B}$ (butyrate). 1SCFA=large intestinal individual concentration of $\mathrm{A}, \mathrm{P}$ and $\mathrm{B}$. Results obtained from minimum of two independent experiments $(*=$ significant difference; $N=2, n=3)$. 


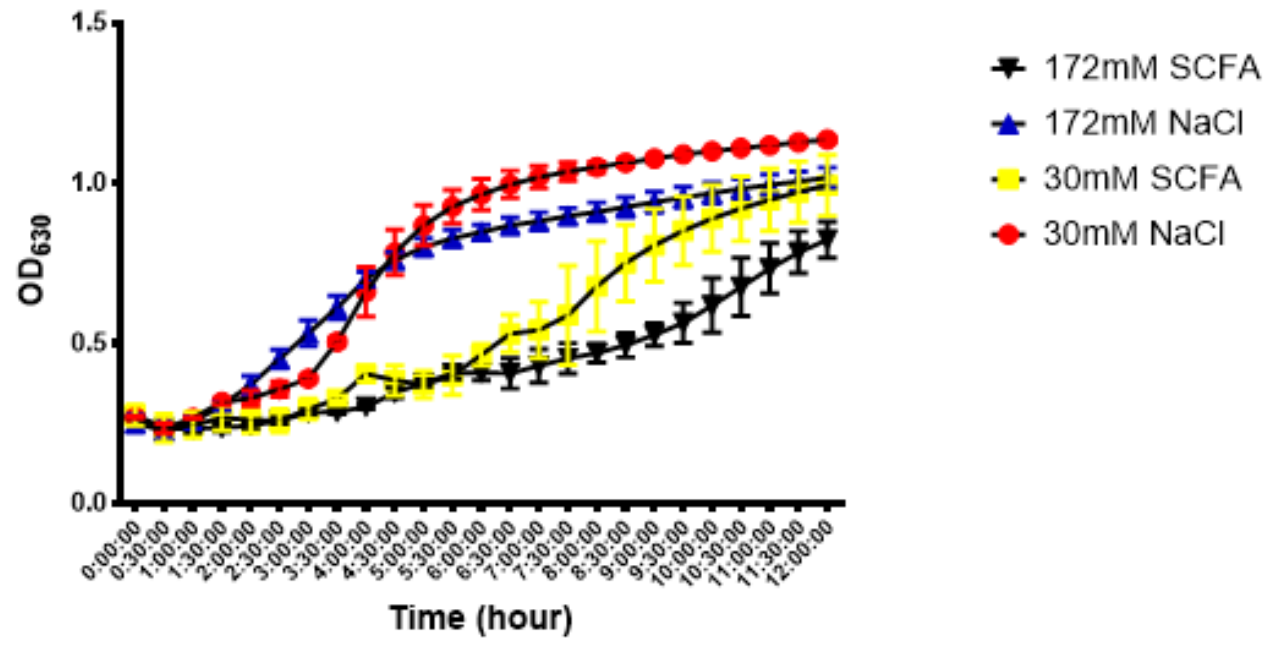

Figure 13. Growth rate of $\Delta r c s B$ post-SCFA treatment. $\Delta r c s B$ treated with $30 \mathrm{mM}$ and $172 \mathrm{mM}$ SCFA mixtures and their corresponding $\mathrm{NaCl}$ osmolarity controls were inoculated into $300 \mu \mathrm{L}$ of Bacto-Tryptone media and grown for 12 hours. $\mathrm{OD}_{630}$ was measured every 30 minutes $(N=2$; error bar represents SEM). 


\subsection{2 $\triangle \operatorname{arcA}$ of the ArcBA TCS}

\subsubsection{Motility and flagella protein expression with SCFA mix treatments}

The SCFA-modulated differential motility behaviour seen with the wild-type was no longer evident for the $\triangle \operatorname{arcA}$ (Figure 14A). Therefore, these results suggest that ArcBA TCS may be involved in SCFA sensing.

\subsubsection{2 $\triangle \operatorname{arcA}$ negatively regulates flagella}

This TCS has been shown to positively regulate flagella (Oshima et al. 2002). However, the $\triangle \operatorname{arc} A$ mutant demonstrated an increase in flagellin and motility with all treatments, including the controls, relative to the wild-type, suggesting negative regulation of flagella by ArcBA (Figure 14). Significantly higher motility diameter was observed with the $\mathrm{NaCl}$ control treatments compared to the SCFA mix treatments (Figure 14A). The increased motility diameter with the $\mathrm{NaCl}$ control treatments were also in agreement with the growth rate assay results, where we saw slower growth with the SCFA mix treatments relative to the $\mathrm{NaCl}$ control treatments (Figure 15). However, the growth appeared not to be the sole reason for the motility differential because the motility halo diameters produced with the SCFA mix treatments and their corresponding $\mathrm{NaCl}$ treatments were significantly higher compared to the wild-type (Figure $14 \mathrm{~A})$.

\subsubsection{Motility and flagella protein expression with individual SCFA treatments}

For the SI individual SCFA treatments, the acetate treatment resulted in a significantly lower motility compared to the butyrate or propionate treatments, which was opposite of that displayed by the wild-type (Figure 14B). For the LI SCFA treatments, the acetate treatment resulted in a significantly lower motility compared to the butyrate and propionate treatments (Figure 14B). 
A

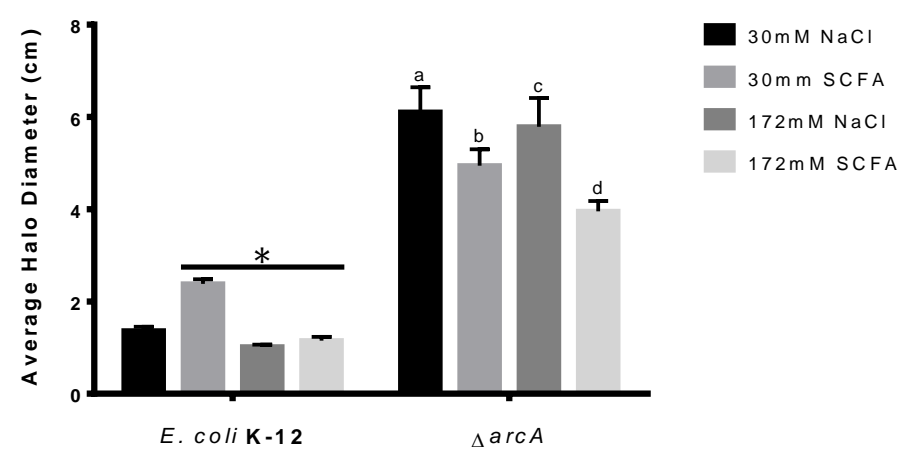

B

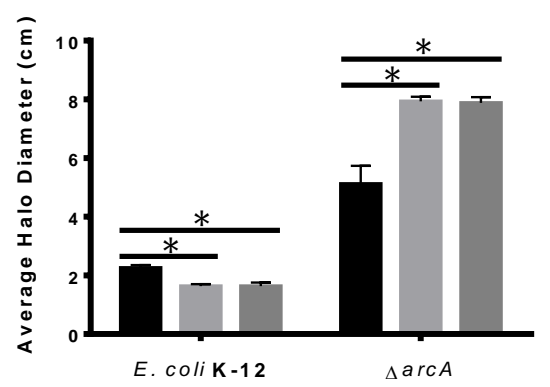

$25 \mathrm{mM} \mathrm{Acetate}+5 \mathrm{~m} \mathrm{M} \mathrm{NaCl}$

$2.5 \mathrm{mM}$ Propionate $+27.5 \mathrm{~m} \mathrm{M} \mathrm{NaCl}$

$2.5 \mathrm{~m} \mathrm{M}$ Butyrate $+27.5 \mathrm{~m} \mathrm{M} \mathrm{NaCl}$

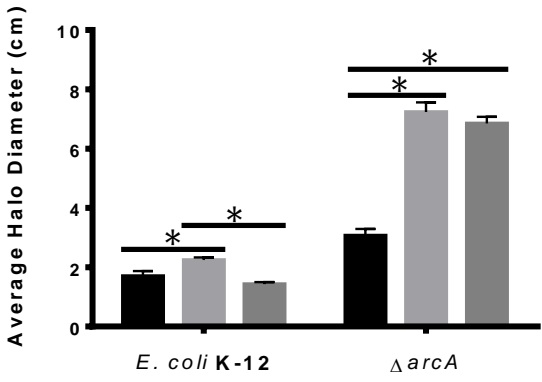

- $95 \mathrm{mM}$ Acetate $+77 \mathrm{~m} \mathrm{M} \mathrm{NaCl}$

$60 \mathrm{mM}$ Propionate $+112 \mathrm{mM} \mathrm{NaCl}$

$17 \mathrm{~m} \mathrm{M}$ Butyrate $+155 \mathrm{~m} \mathrm{M} \mathrm{NaCl}$

C

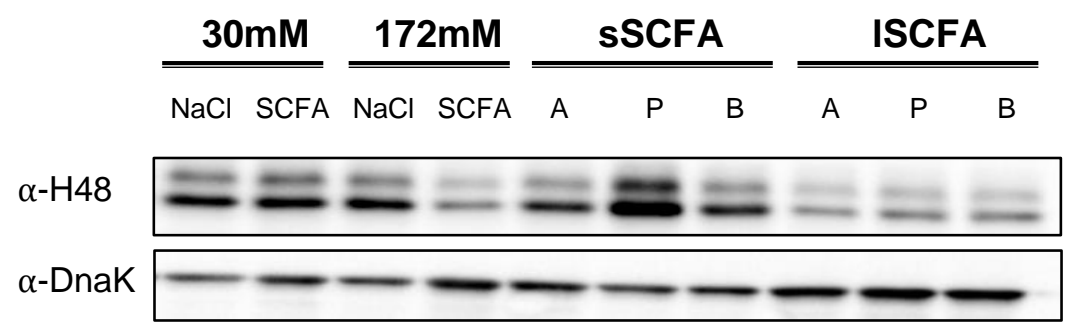

Figure 14. Effect of varying concentrations of SCFAs on the mean \pm SEM of the motility halo diameter and flagellin protein expression of E. coli K-12 and $\triangle \operatorname{arcA}$. (A) Effect of small and large intestinal SCFA mixtures; each letter indicates the significant difference relative to the motility diameter produced by the same treatment in the wild-type. (B) Effect of individual SCFAs. (C) Immunoblot analysis of H48 flagella protein and DnaK (loading control) protein expression of $\triangle a r c A$ treated with mixtures and individual SCFAs. sSCFA=small intestinal individual concentration of $\mathrm{A}$ (acetate), $\mathrm{P}$ (propionate) and $\mathrm{B}$ (butyrate). 1SCFA=large intestinal individual concentration of $\mathrm{A}, \mathrm{P}$ and $\mathrm{B}$. Results obtained from minimum of two independent experiments ( $*$ =significant difference; $N=2, n=3$ ). 


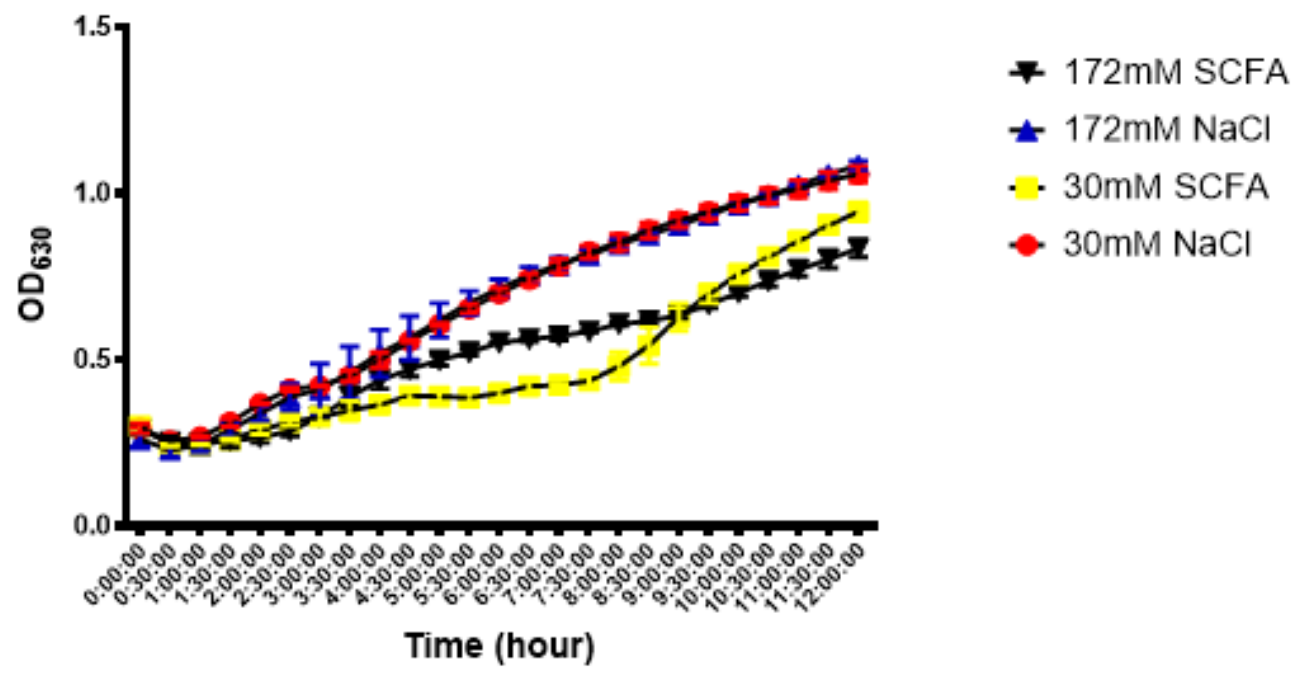

Figure 15. Growth rate of $\triangle \operatorname{arc} A$ post-SCFA treatment. $\triangle \operatorname{arcA}$ treated with $30 \mathrm{mM}$ and $172 \mathrm{mM}$ SCFA mixtures and their corresponding $\mathrm{NaCl}$ osmolarity controls were inoculated into $300 \mu \mathrm{L}$ of Bacto-Tryptone media and grown for 12 hours. $\mathrm{OD}_{630}$ was measured every 30 minutes $(N=2$; error bar represents SEM). 


\section{$\underline{3.4 .3 \triangle a t o S C}$}

\subsubsection{Motility and flagella protein expression with SCFA mix treatments}

The SCFA-modulated differential flagella production and motility behaviour seen with the wild-type was no longer evident for the $\triangle a t o S C$ (Figure 16). Therefore, these results suggest that AtoSC TCS may be involved in SCFA sensing.

\section{$\underline{3.4 .3 .2 \Delta a t o S C \text { regulation of flagella }}$}

This TCS has been shown to positively regulate flagella (Oshima et al. 2002). However, the $\triangle a t o S C$ mutant demonstrated decreased motility with only few treatments, including the 30mM SCFA mix treatment and the SI and LI acetate treatments, relative to the wild-type (Figure 16). Slower growth was observed with $172 \mathrm{mM}$ SCFA mix treatment relative to $30 \mathrm{mM}$ SCFA mix and the $\mathrm{NaCl}$ control treatments (Figure 17), however the motility assay results showed no significant differences in halo sizes between the two mix treatments (Figure 16A). The flagella protein expression was not altered by any individual or mix of SCFAs or $\mathrm{NaCl}$ control treatments (Figure 16C).

\section{$\underline{\text { 3.4.3.3 Motility and flagella protein expression with individual SCFA treatments }}$}

There were no significant differences in the motility halo diameters produced by the $3 \mathrm{SI}$ individual SCFA treatments (Figure 16B). For the LI SCFA treatments, the propionate treatment produced highest motility diameter, consistent with the wild-type phenotype (Figure 16B). 
A

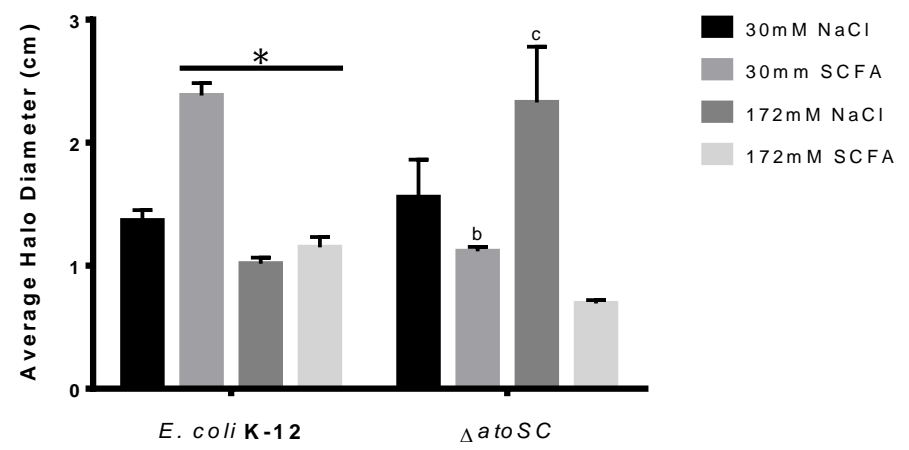

B

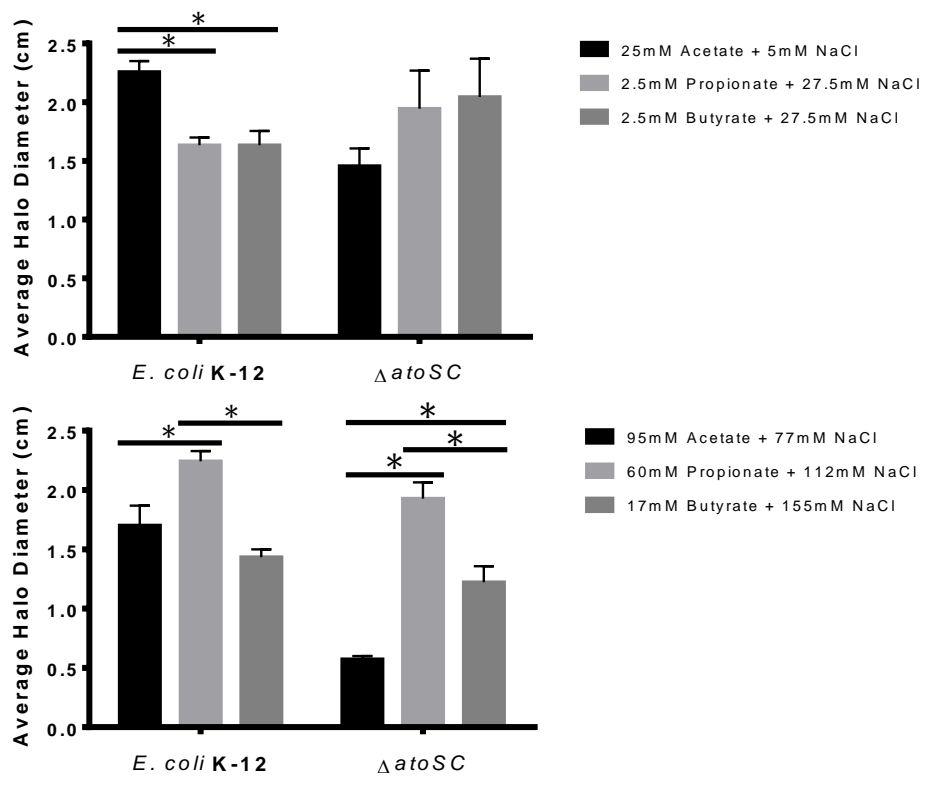

C

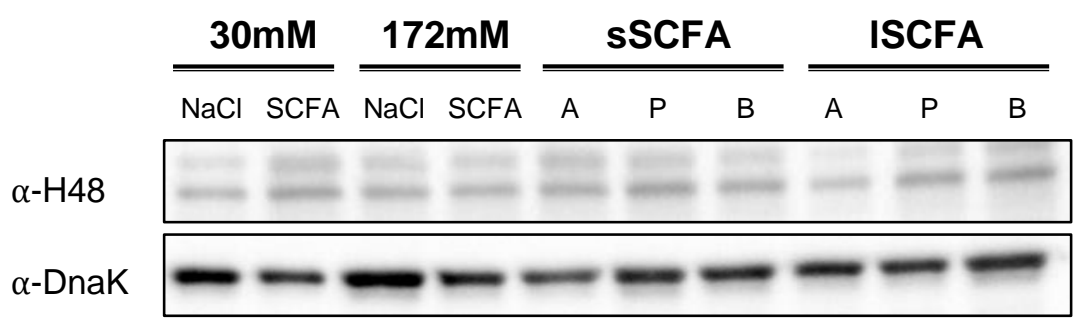

Figure 16. Effect of varying concentrations of SCFAs on the mean \pm SEM of the motility halo diameter and flagellin protein expression of E. coli K-12 and $\triangle a t o S C$. (A) Effect of small and large intestinal SCFA mixtures; each letter indicates the significant difference relative to the motility diameter produced by the same treatment in the wild-type. (B) Effect of individual SCFAs. (C) Immunoblot analysis of H48 flagella protein and DnaK (loading control) protein expression of $\triangle a t o S C$ treated with mixtures and individual SCFAs. sSCFA=small intestinal individual concentration of $\mathrm{A}$ (acetate), $\mathrm{P}$ (propionate) and $\mathrm{B}$ (butyrate). 1SCFA=large intestinal individual concentration of $\mathrm{A}, \mathrm{P}$ and $\mathrm{B}$. Results obtained from minimum of two independent experiments $(*=$ significant difference; $N=2, n=3$ ). 


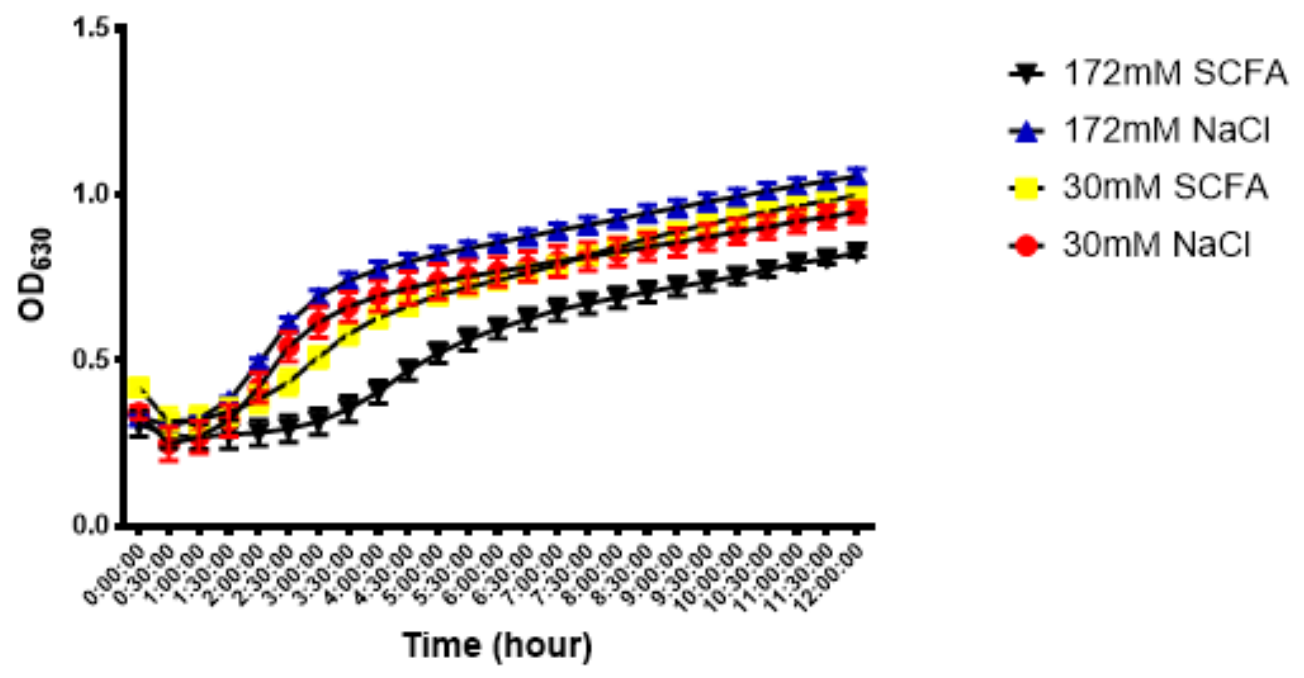

Figure 17. Growth rate of $\triangle a t o S C$ post-SCFA treatment. $\triangle a t o S C$ treated with $30 \mathrm{mM}$ and $172 \mathrm{mM}$ SCFA mixtures and their corresponding $\mathrm{NaCl}$ osmolarity controls were inoculated into $300 \mu \mathrm{L}$ of Bacto-Tryptone media and grown for 12 hours. $\mathrm{OD}_{630}$ was measured every 30 minutes $(N=2$; error bar represents SEM). 


\subsection{4 $\Delta u v r Y$ of the BarA-UvrY TCS}

\subsubsection{Motility and flagella protein expression with SCFA mix treatments}

The SCFA-modulated differential motility behaviour seen with the wild-type was still observed for the $\Delta u v r Y$ (Figure 18A). Therefore, the results suggest that BarA-UvrY TCS may not be involved in SCFA sensing. Previous reports have demonstrated acetate sensing by this TCS and hence it was hypothesized that BarA-UvrY is a potential TCS candidate involved in SCFA induced flagella modulation (Gonzalez Chavez et al. 2010). However, our results did not support the hypothesis.

\subsubsection{2 $\Delta u v r Y$ negatively regulates flagella}

This TCS has been shown to negatively regulate flagella (Oshima et al. 2002).The $\Delta u v r Y$ mutant demonstrated an increase in flagellin and motility with all treatments, including controls, relative to the wild-type, confirming the negative regulation by BarA-UvrY (Figure 18). $\mathrm{NaCl}$ control treatments produced higher motility than the two SCFA mix treatments, which was also reflected in the flagella protein expression and the growth rate (Figure 18\&19).

\subsubsection{Motility and flagella protein expression with individual SCFA treatments}

There were no significant differences in the motility halo diameters produced by the 3 SI individual SCFA treatments (Figure 18B). With the LI individual SCFA treatments, the acetate treatment showed significantly smaller motility diameter than the propionate or butyrate treatments (Figure 18B). 
A

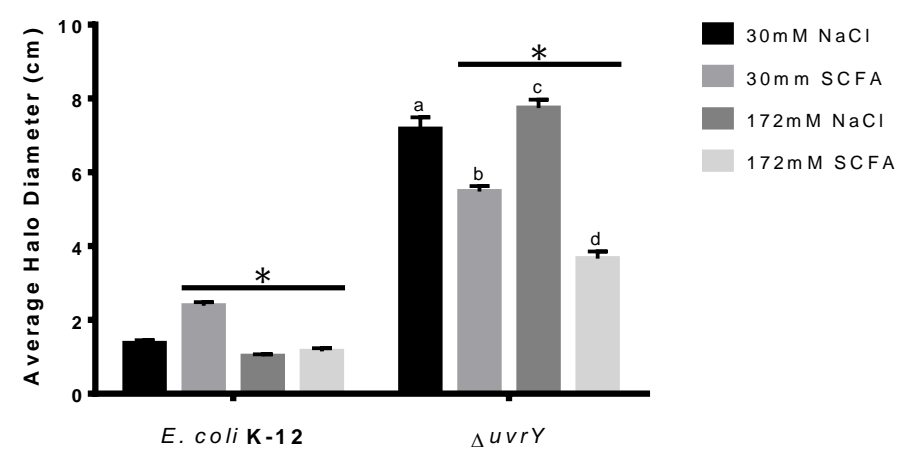

B

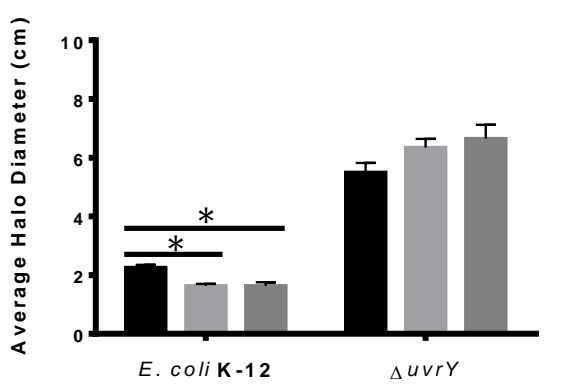

$25 \mathrm{mM}$ Acetate $+5 \mathrm{~m} \mathrm{M} \mathrm{NaCl}$

$2.5 \mathrm{~m} \mathrm{M}$ Propionate $+27.5 \mathrm{~m} \mathrm{M} \mathrm{NaCl}$

$2.5 \mathrm{~m} \mathrm{M} \mathrm{Butyrate}+27.5 \mathrm{~m} \mathrm{M} \mathrm{NaCl}$

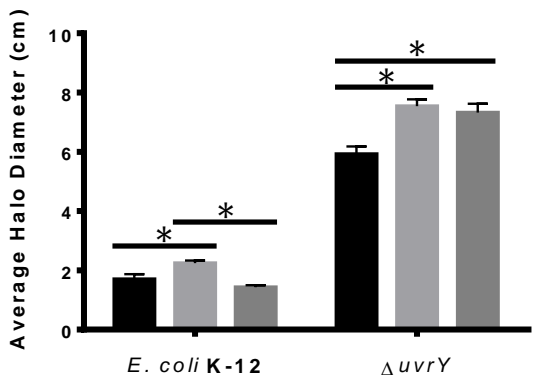

- $95 \mathrm{mM}$ Acetate $+77 \mathrm{~m} \mathrm{M} \mathrm{NaCl}$

$60 \mathrm{mM}$ Propionate $+112 \mathrm{mM} \mathrm{NaCl}$

$17 \mathrm{~m} \mathrm{M}$ Butyrate $+155 \mathrm{~m} \mathrm{M} \mathrm{NaCl}$

C

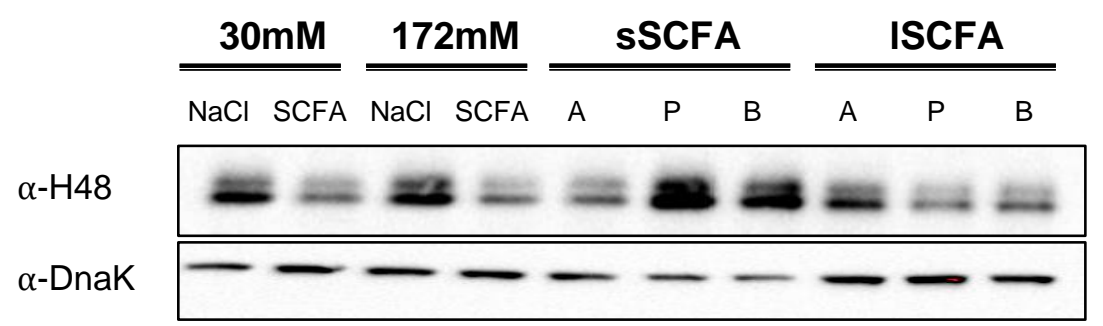

Figure 18. Effect of varying concentrations of SCFAs on the mean \pm SEM of the motility halo diameter and flagellin protein expression of E. coli K-12 and $\Delta u v r Y$. (A) Effect of small and large intestinal SCFA mixtures; each letter indicates the significant difference relative to the motility diameter produced by the same treatment in the wild-type. (B) Effect of individual SCFAs. (C) Immunoblot analysis of H48 flagella protein and DnaK (loading control) protein expression of $\triangle u v r Y$ treated with mixtures and individual SCFAs. sSCFA=small intestinal individual concentration of $\mathrm{A}$ (acetate), $\mathrm{P}$ (propionate) and $\mathrm{B}$ (butyrate). 1SCFA=large intestinal individual concentration of $\mathrm{A}, \mathrm{P}$ and $\mathrm{B}$. Results obtained from minimum of two independent experiments ( $*=$ significant difference; $N=2, n=3$ ). 


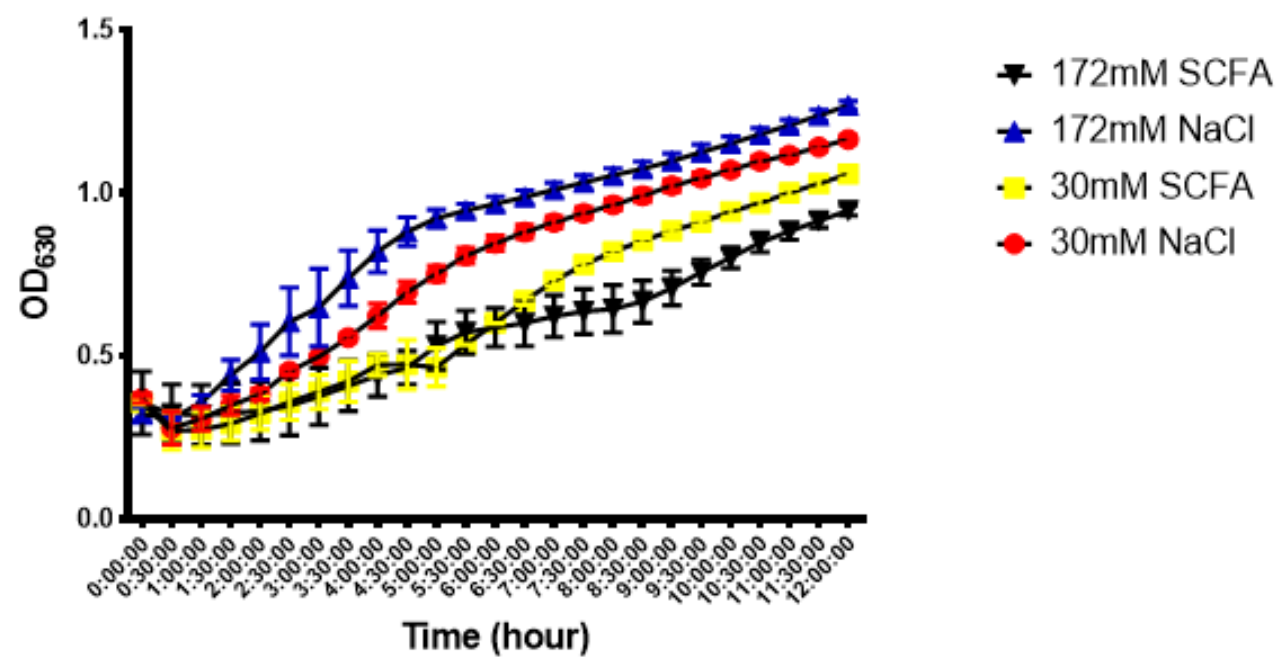

Figure 19. Growth rate of $\triangle u v r Y$ post-SCFA treatment. $\triangle u v r Y$ treated with $30 \mathrm{mM}$ and $172 \mathrm{mM}$ SCFA mixtures and their corresponding $\mathrm{NaCl}$ osmolarity controls were inoculated into $300 \mu \mathrm{L}$ of Bacto-Tryptone media and grown for 12 hours. $\mathrm{OD}_{630}$ was measured every 30 minutes $(N=2$; error bar represents SEM). 


\subsection{5 $\triangle e n v Z-o m p R$}

\subsubsection{Motility and flagella protein expression with SCFA mix treatments}

The SCFA-modulated differential flagella production and motility behaviour seen with the wild-type was no longer evident for the $\triangle e n v Z$-ompR (Figure 20). Therefore, these results suggest that EnvZ-OmpR TCS may be involved in SCFA sensing. However, the growth rate assay of $\Delta e n v Z$-ompR showed substantial growth lag relative to the wild-type and other mutant strains (Figure 21). Therefore, it was suggested that the lost in differential motility behaviour between the two SCFA mix treatments were due to the growth inhibition rather than the differential flagella and motility modulation.

\subsubsection{2 $\Delta e n v Z-o m p R$ regulation of flagella}

This TCS has been shown to negatively regulate flagella (Oshima et al. 2002). However, in this investigation, $\triangle e n v Z$-ompR did not show increased flagella expression nor motility, relative to the wild-type, in most treatments (Figure 20). Since $\triangle e n v Z$-ompR was significantly slower in growth compared to the wild-type and the other mutants, the lack of motility may be because of the interference in growth caused by the mutation (Figure 21).

\subsubsection{Motility and flagella protein expression with individual SCFA treatments}

There were no significant differences in the motility halo diameters produced by the $3 \mathrm{SI}$ individual SCFA treatments (Figure 20B). For the LI individual SCFA treatments, the butyrate treatment resulted in significantly higher motility halo dimeter than the other SCFAs (Figure 20B). Interestingly, the motility diameter and flagella expression produced with the LI butyrate treatment was the highest that was observed across all the mixtures, individuals and control treatments in $\triangle e n v Z$-ompR (Figure 20). 
A

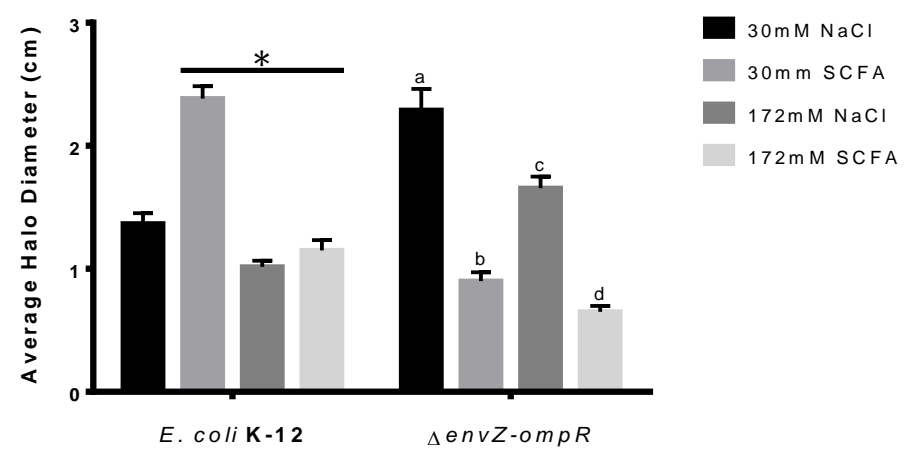

B

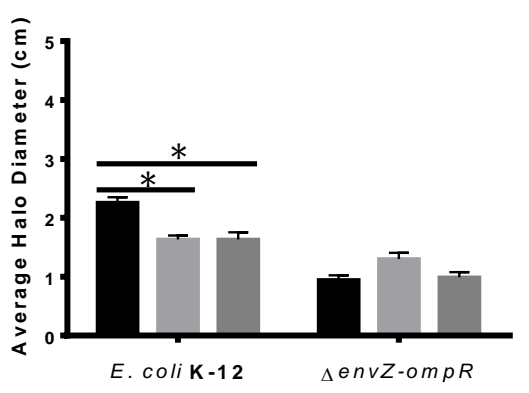

- $25 \mathrm{~m} \mathrm{M}$ Acetate $+5 \mathrm{~m} \mathrm{M} \mathrm{NaCl}$

$2.5 \mathrm{mM}$ Propionate $+27.5 \mathrm{~m} \mathrm{M} \mathrm{NaCl}$

$2.5 \mathrm{mM}$ Butyrate $+27.5 \mathrm{~m} \mathrm{M} \mathrm{NaCl}$

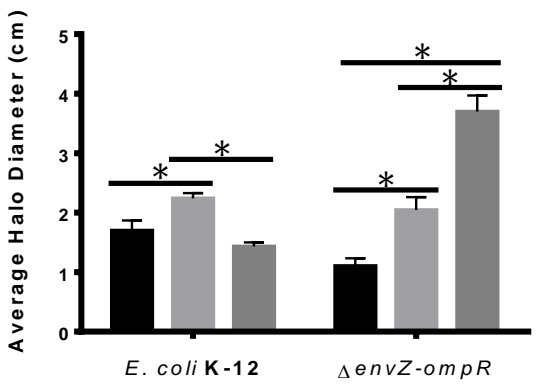

- $95 \mathrm{mM}$ Acetate $+77 \mathrm{~m} \mathrm{M} \mathrm{NaCl}$

$60 \mathrm{mM}$ Propionate $+112 \mathrm{~m} \mathrm{M} \mathrm{NaCl}$

$17 \mathrm{mM}$ Butyrate $+155 \mathrm{~m} \mathrm{M} \mathrm{NaC}$

C

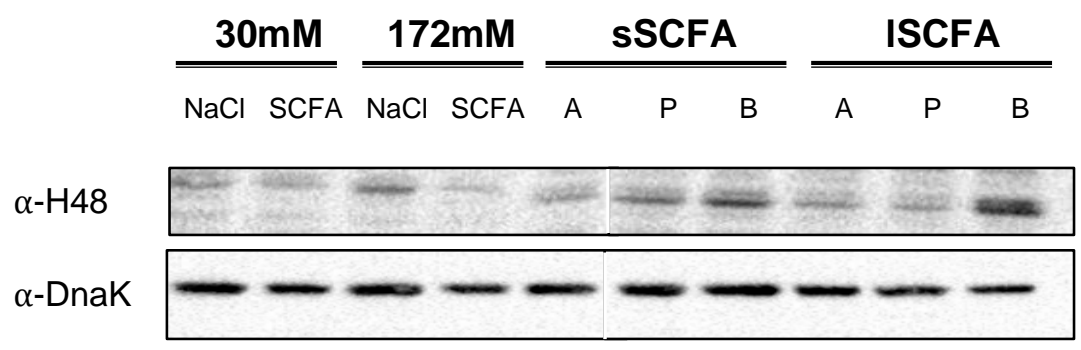

Figure 20. Effect of varying concentrations of SCFAs on the mean \pm SEM of the motility halo diameter and flagellin protein expression of E. coli K-12 and $\Delta e n v Z$-ompR. (A) Effect of small and large intestinal SCFA mixtures; each letter indicates the significant difference relative to the motility diameter produced by the same treatment in the wild-type. (B) Effect of individual SCFAs. (C) Immunoblot analysis of H48 flagella protein and DnaK (loading control) protein expression of $\triangle e n v Z$-ompR treated with mixtures and individual SCFAs. sSCFA=small intestinal individual concentration of $\mathrm{A}$ (acetate), $\mathrm{P}$ (propionate) and $\mathrm{B}$ (butyrate). $1 \mathrm{SCFA}=$ large intestinal individual concentration of $\mathrm{A}, \mathrm{P}$ and $\mathrm{B}$. Results obtained from minimum of two independent experiments ( $*$ =significant difference; $N=2, n=3$ ). 


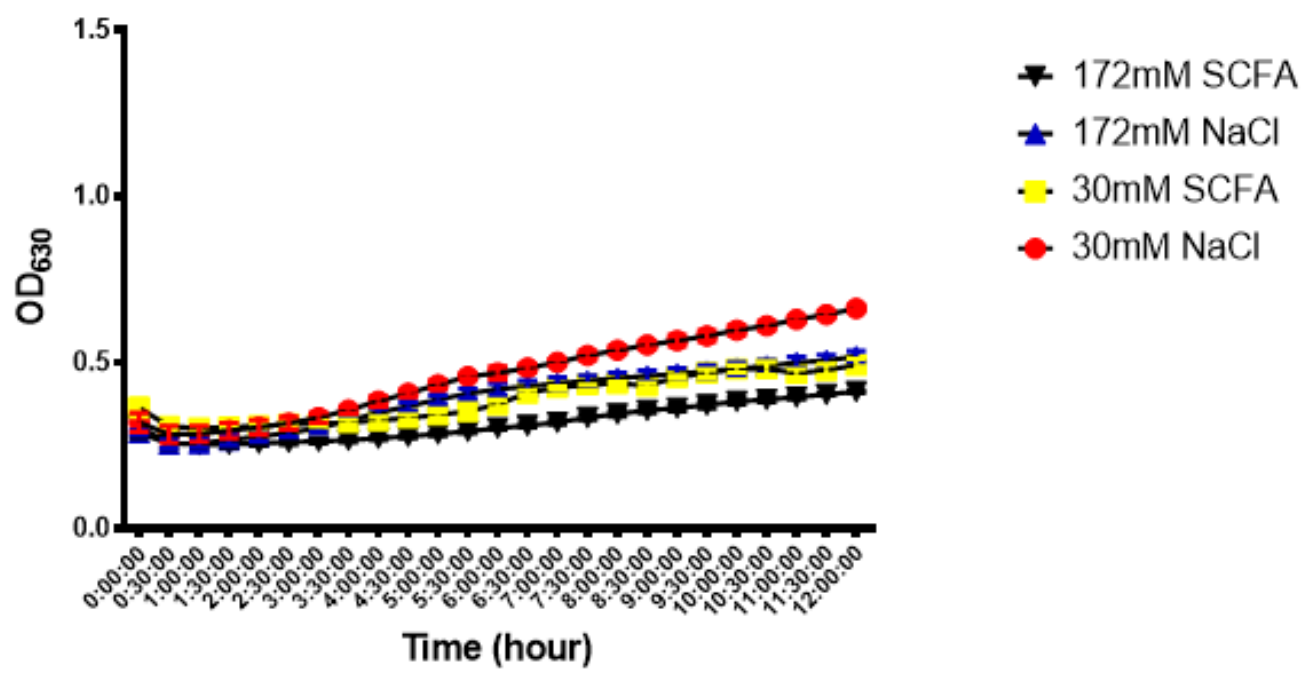

Figure 21. Growth rate of $\triangle e n v Z$-ompR post-SCFA treatment. $\triangle e n v Z$-ompR treated with $30 \mathrm{mM}$ and $172 \mathrm{mM}$ SCFA mixtures and their corresponding $\mathrm{NaCl}$ osmolarity controls were inoculated into $300 \mu \mathrm{L}$ of Bacto-Tryptone media and grown for 12 hours. $\mathrm{OD}_{630}$ was measured every 30 minutes ( $N=2$; error bar represents SEM). 


\section{$\underline{3.4 .6 \triangle \operatorname{cit} A B}$}

\subsubsection{Motility and flagella protein expression with SCFA mix treatments}

The SCFA-modulated differential motility behaviour seen with the wild-type was still evident for the $\triangle$ citAB (Figure 22A). Therefore, these results suggest that CitAB TCS may not be involved in SCFA sensing.

\subsubsection{2 $\triangle$ cit $A B$ negatively regulates flagella}

This TCS has been shown to negatively regulate flagella (Oshima et al. 2002).The $\triangle c i t A B$ mutant demonstrated an increase in motility with all treatments, including the controls, relative to the wild-type, confirming the negative regulation by $\mathrm{CitAB}$ (Figure 22). The $\mathrm{NaCl}$ control treatments and the 30mM SCFA mix treatment produced higher flagella protein and motility diameter than the $172 \mathrm{mM} \mathrm{SCFA}$ mix treatment (Figure 22A). The decreased motility with the $172 \mathrm{mM}$ SCFA mix treatment was also in agreement with the growth rate assay results, where we saw slower growth with the 172mM SCFA mix treatment relative to the other treatments (Figure 23). However, the growth appeared not to be the sole reason for the motility differential because the motility halo diameters produced with the SCFA mix treatments and their corresponding $\mathrm{NaCl}$ treatments were significantly higher compared to the wild-type (Figure 22A).

\subsubsection{Motility and flagella protein expression with individual SCFA treatments}

The motility halo diameters were not significantly different across all the SI and LI individual SCFA treatments, further supporting that this TCS is highly unlikely to be involved in SCFA induced flagella modulation (Figure 22B). However, the protein expression data did not agree with the motility assay results, because the SI propionate treatment produced the most intense flagella protein band relative to the other individual SCFA treatments (Figure 22C). 
A

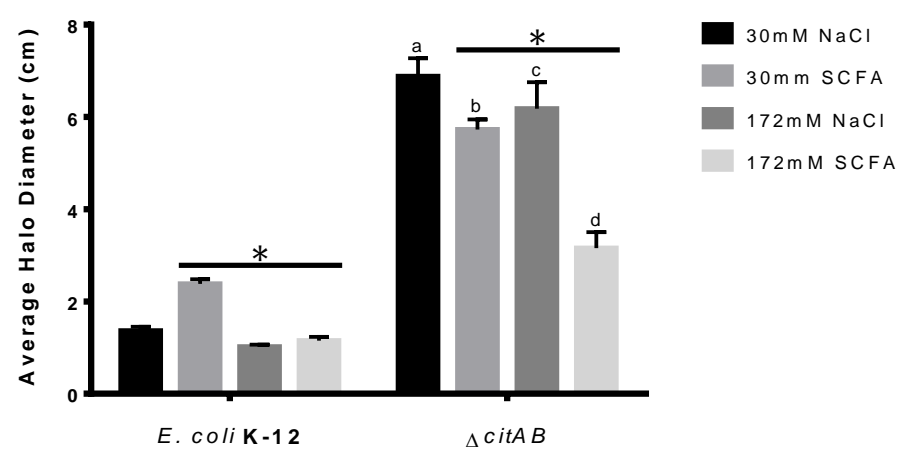

B

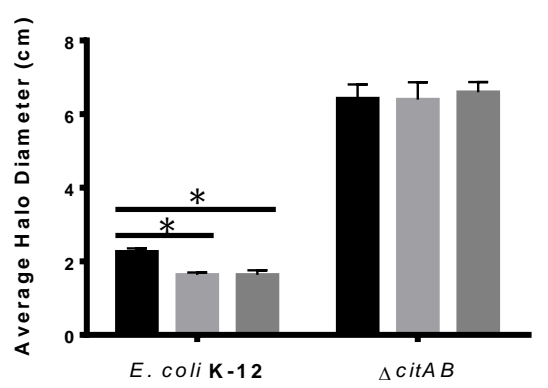

$25 \mathrm{mM}$ Acetate $+5 \mathrm{~m} \mathrm{M} \mathrm{NaCl}$

$2.5 \mathrm{~m} \mathrm{M}$ Propionate $+27.5 \mathrm{~m} \mathrm{M} \mathrm{NaCl}$

$2.5 \mathrm{~m} \mathrm{M}$ Butyrate $+27.5 \mathrm{~m} \mathrm{M} \mathrm{NaCl}$

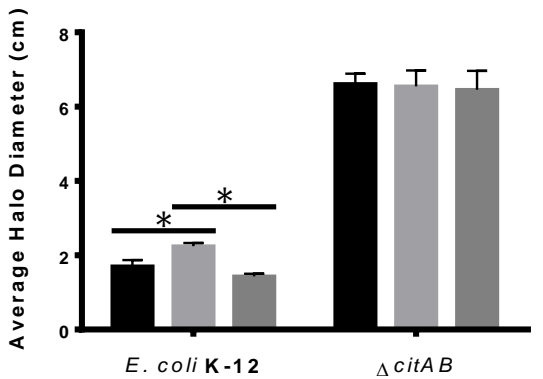

$95 \mathrm{mM}$ Acetate $+77 \mathrm{~m} \mathrm{M} \mathrm{NaCl}$

$60 \mathrm{mM}$ Propionate $+112 \mathrm{~m} \mathrm{M} \mathrm{NaCl}$

$17 \mathrm{mM} \mathrm{Butyrate}+155 \mathrm{~m} \mathrm{M} \mathrm{NaCl}$

$\mathbf{C}$

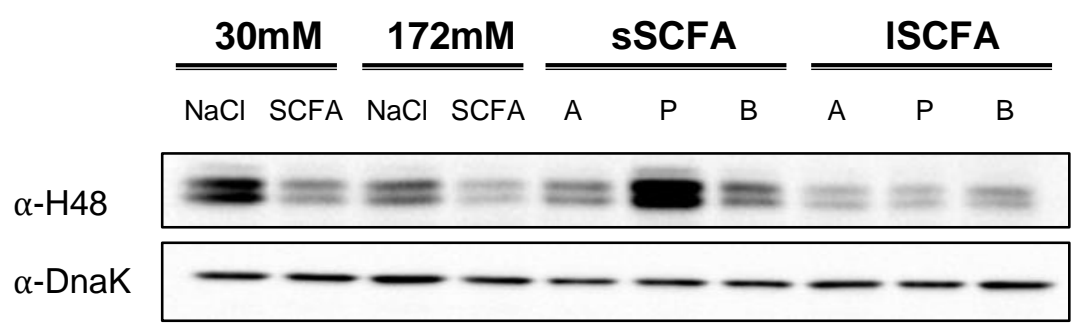

Figure 22. Effect of varying concentrations of SCFAs on the mean \pm SEM of the motility halo diameter and flagellin protein expression of E. coli K-12 and $\triangle$ citAB. (A) Effect of small and large intestinal SCFA mixtures; each letter indicates the significant difference relative to the motility diameter produced by the same treatment in the wild-type. (B) Effect of individual SCFAs. (C) Immunoblot analysis of H48 flagella protein and DnaK (loading control) protein expression of $\triangle$ citAB treated with mixtures and individual SCFAs. sSCFA=small intestinal individual concentration of $\mathrm{A}$ (acetate), $\mathrm{P}$ (propionate) and $\mathrm{B}$ (butyrate). 1SCFA=large intestinal individual concentration of $\mathrm{A}, \mathrm{P}$ and $\mathrm{B}$. Results obtained from minimum of two independent experiments $(*=$ significant difference; $N=2, n=3)$. 


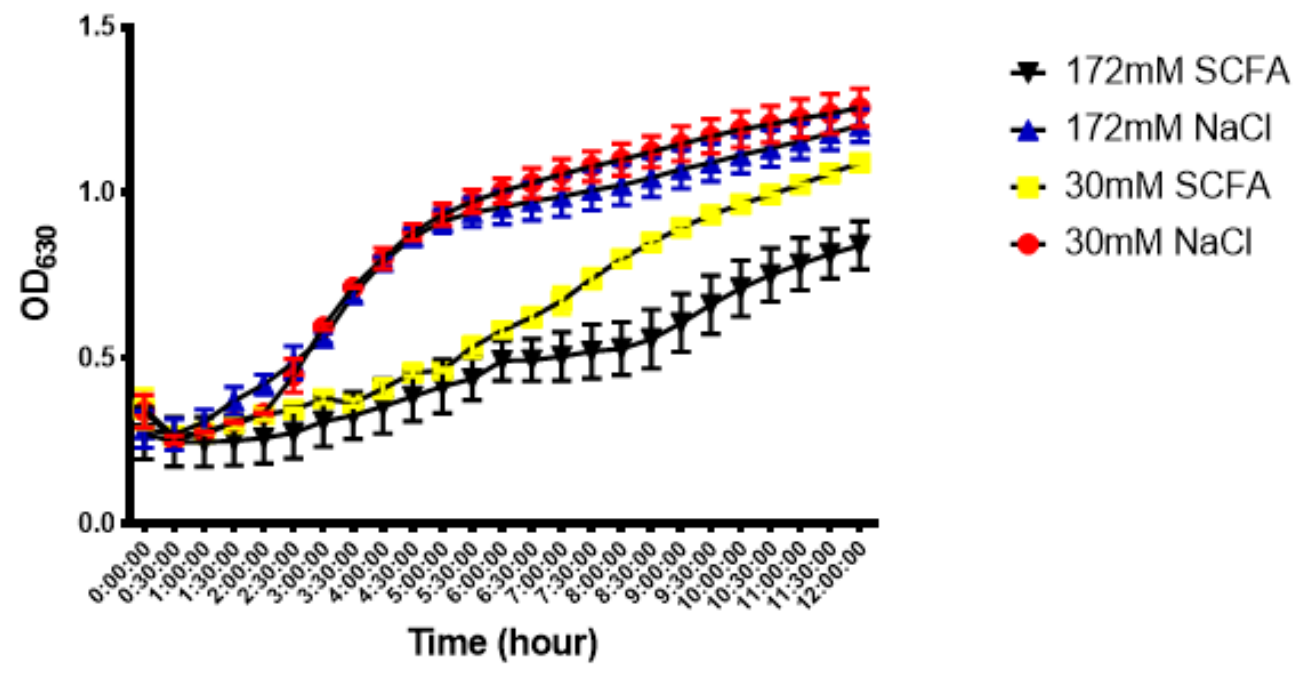

Figure 23. Growth rate of $\triangle c i t A B$ post-SCFA treatment. $\triangle c i t A B$ treated with $30 \mathrm{mM}$ and $172 \mathrm{mM}$ SCFA mixtures and their corresponding $\mathrm{NaCl}$ osmolarity controls were inoculated into $300 \mu \mathrm{L}$ of Bacto-Tryptone media and grown for 12 hours. $\mathrm{OD}_{630}$ was measured every 30 minutes $(N=2$; error bar represents SEM). 


\subsection{7 $\triangle y p d A B$}

\subsubsection{Motility and flagella protein expression with SCFA mix treatments}

The SCFA-modulated differential motility behaviour seen with the wild-type was still evident for the $\triangle y p d A B$ (Figure 24A). Therefore, these results suggest that YpdAB TCS may not be involved in SCFA sensing.

\subsubsection{2 $\triangle y p d A B$ negatively regulates flagella}

This TCS has been shown to negatively regulate flagella (Oshima et al. 2002).The $\triangle y p d A B$ mutant demonstrated an increase in motility with almost all treatments, except for the two SCFA mix treatments, relative to the wild-type, supporting the negative regulation by YpdAB (Figure 24). Interestingly, the flagella protein expression did not amplify under any treatments in $\triangle y p d A B$, relative to the wild-type (Figure 24C).

\subsubsection{Motility and flagella protein expression with individual SCFA treatments}

For the SI individual SCFA treatments, the butyrate treatment resulted in a significantly higher motility compared to the acetate or propionate treatments (Figure 24B). For the LI SCFA treatments, the propionate treatment resulted in a significantly higher motility compared to the acetate or butyrate treatments, consistent with the wild-type phenotype (Figure 24B). 
A

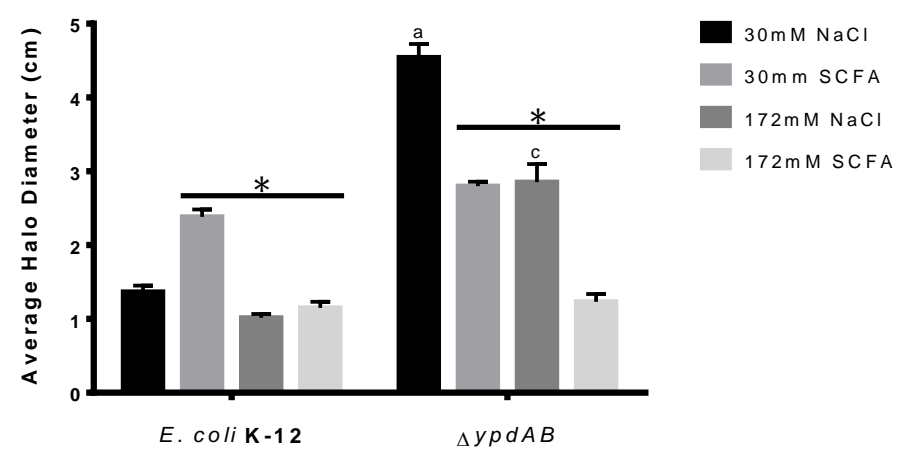

B

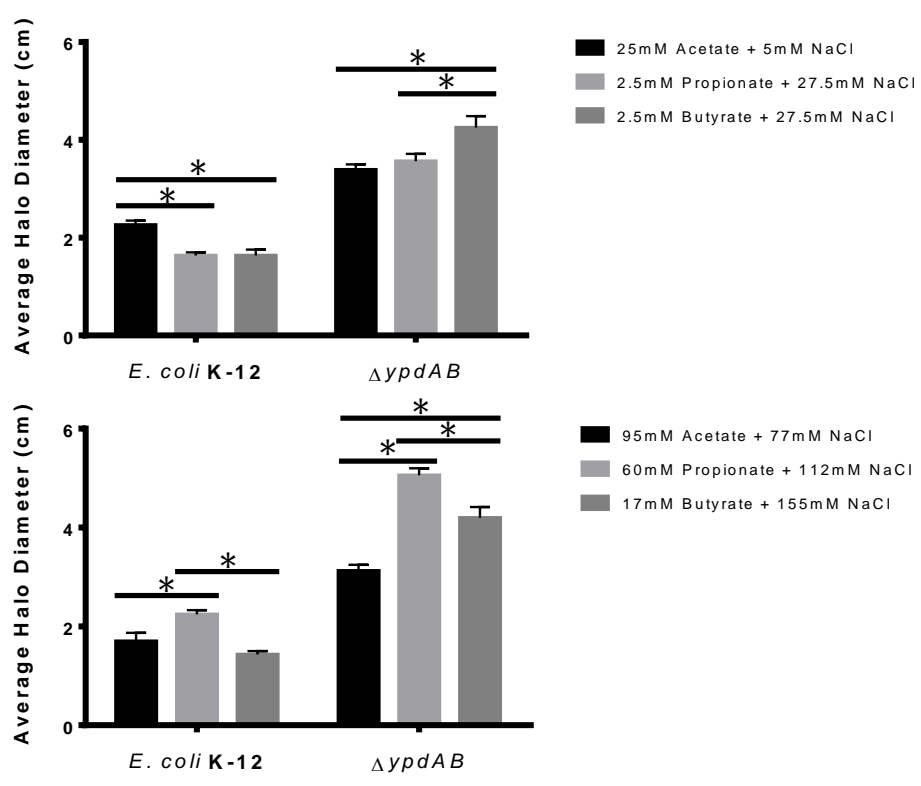

C

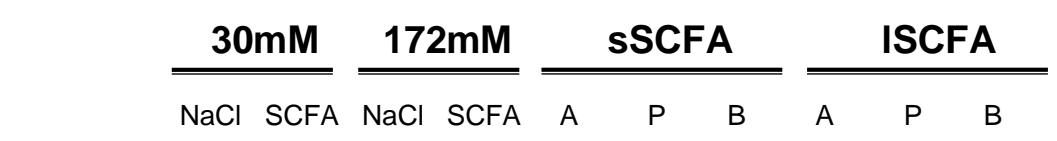

$\alpha-\mathrm{H} 48$

$\alpha$-DnaK

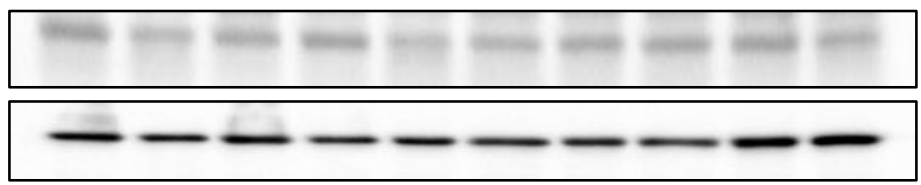

Figure 24. Effect of varying concentrations of SCFAs on the mean \pm SEM of the motility halo diameter and flagellin protein expression of E. coli K-12 and $\triangle y p d A B$. (A) Effect of small and large intestinal SCFA mixtures; each letter indicates the significant difference relative to the motility diameter produced by the same treatment in the wild-type. (B) Effect of individual SCFAs. (C) Immunoblot analysis of H48 flagella protein and DnaK (loading control) protein expression of $\triangle y p d A B$ treated with mixtures and individual SCFAs. sSCFA=small intestinal individual concentration of A (acetate), $\mathrm{P}$ (propionate) and $\mathrm{B}$ (butyrate). 1SCFA=large intestinal individual concentration of $\mathrm{A}, \mathrm{P}$ and $\mathrm{B}$. Results obtained from minimum of two independent experiments $(*=$ significant difference; $N=2, n=3)$. 


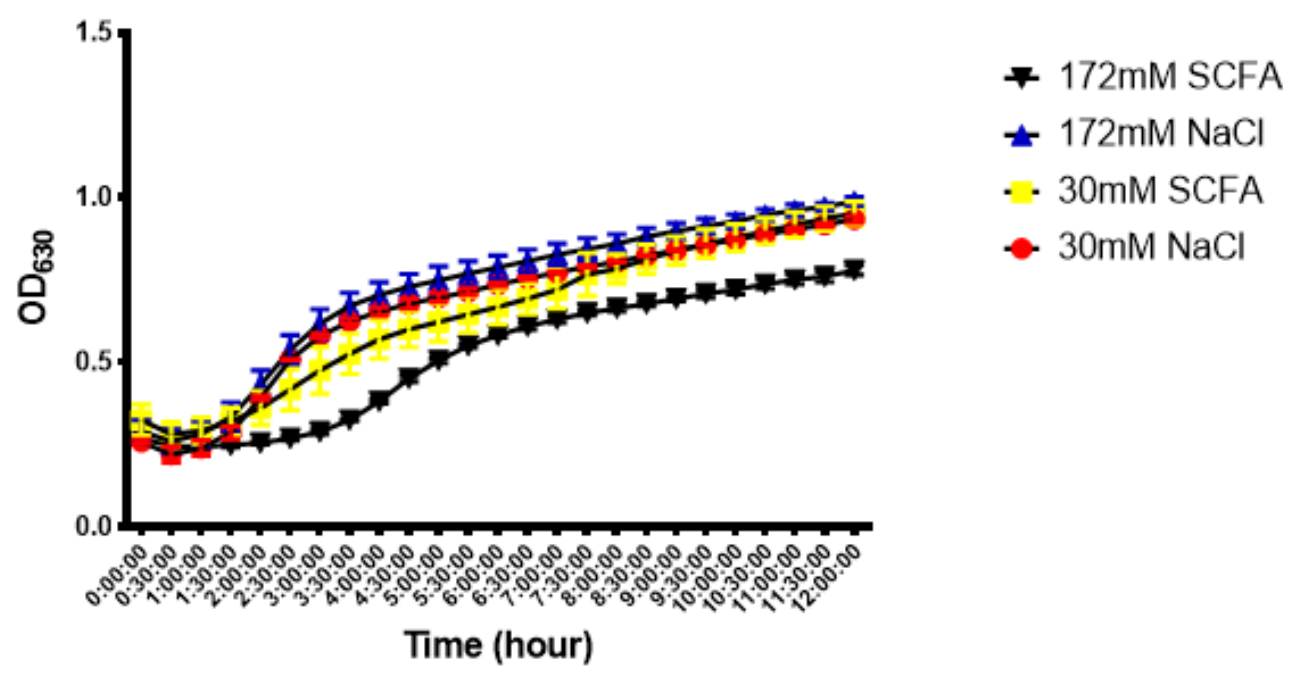

Figure 25. Growth rate of $\triangle y p d A B$ post-SCFA treatment. $\triangle y p d A B$ treated with $30 \mathrm{mM}$ and $172 \mathrm{mM}$ SCFA mixtures and their corresponding $\mathrm{NaCl}$ osmolarity controls were inoculated into $300 \mu \mathrm{L}$ of Bacto-Tryptone media and grown for 12 hours. $\mathrm{OD}_{630}$ was measured every 30 minutes $(N=2$; error bar represents SEM). 
Table 5. Summary of the E. coli K-12 TCS mutant results. Positive or negative annotation in a bracket represents previous findings of positive or negative flagella regulation by a TCS.

\begin{tabular}{|c|c|c|c|c|}
\hline E. coli K-12 & $\begin{array}{c}\text { Significantly different } \\
\text { flagella motility between the } \\
\text { 30mM vs. 172mM SCFA } \\
\text { mix treatments? }\end{array}$ & $\begin{array}{l}+ \text { or - regulation } \\
\text { (from this study) }\end{array}$ & $\begin{array}{c}\text { Significant } \\
\text { SI individual SCFA }\end{array}$ & $\begin{array}{c}\text { Significant } \\
\text { LI individual SCFA }\end{array}$ \\
\hline Wild-type & Yes & & $\begin{array}{l}\text { - Highest motility with the acetate } \\
\text { treatment (similar to that of SI } \\
\text { SCFA mix treatment) }\end{array}$ & $\begin{array}{l}\text { - Highest motility with the } \\
\text { propionate treatment } \\
\text { - The butyrate treatment produced } \\
\text { similar motility halo diameter as } \\
\text { the LI SCFA mix treatment }\end{array}$ \\
\hline$\Delta r c s B(-)$ & No & Negative & $\begin{array}{l}\text { - Lowest motility with the acetate } \\
\text { treatment }\end{array}$ & $\begin{array}{l}\text { - Highest motility with the butyrate } \\
\text { treatment }\end{array}$ \\
\hline$\triangle \operatorname{arc} A(+)$ & No & Negative & $\begin{array}{l}\text { Lowest motility with the acetate } \\
\text { treatment }\end{array}$ & $\begin{array}{l}\text { - Lowest motility with the acetate } \\
\text { treatment }\end{array}$ \\
\hline$\Delta a t o S C(+)$ & No & Inconclusive & $\begin{array}{l}\text { - No significant differences in } \\
\text { motility diameter between the } 3 \\
\text { SCFA treatments }\end{array}$ & $\begin{array}{l}\text { Highest motility with the } \\
\text { propionate treatment }\end{array}$ \\
\hline$\Delta u v r Y(-)$ & Yes & Negative & $\begin{array}{l}\text { - No significant differences in } \\
\text { motility diameter between the } 3 \\
\text { SCFA treatments }\end{array}$ & $\begin{array}{l}\text { - Lowest motility with the acetate } \\
\text { treatment }\end{array}$ \\
\hline$\Delta e n v Z$-ompR (-) & & Inco & clusive due to the inhibited growth & \\
\hline$\triangle c i t A B(-)$ & Yes & Negative & $\begin{array}{l}\text { No significant differences in } \\
\text { motility diameter between the } 3 \\
\text { SCFA treatments }\end{array}$ & $\begin{array}{l}\text { - No significant differences in } \\
\text { motility diameter between the } 3 \\
\text { SCFA treatments }\end{array}$ \\
\hline$\triangle y p d A B(-)$ & Yes & Negative & $\begin{array}{l}\text { - Highest motility with the butyrate } \\
\text { treatment }\end{array}$ & $\begin{array}{l}\text { - Highest motility with the } \\
\text { propionate treatment }\end{array}$ \\
\hline
\end{tabular}




\section{Discussion}

In depth studies of $E$. coli have demonstrated the bacteria's ability to rapidly sense its surrounding (Boor 2006). After sensing its environment, E. coli use the substances found within that environment as cues to precisely modulate appropriate genes to enhance its fitness (Boor 2006). SCFAs are one of the readily found GI tract substances that vary in concentration and composition from small to large intestines. This investigation demonstrates the significance of varying mixtures of SCFAs as an important motility signal for both pathogenic EHEC and nonpathogenic E. coli. In addition, this study also evaluates the role of selected TCSs in SCFAmodulated motility and flagella expression.

In order to gain clues about which gene networks are controlled by the SCFAs mixtures representative of the human small and large intestines, DNA microarray analysis was first conducted with EHEC O157:H7 before and after treatments with SCFA mixtures. Interestingly, the flagellar gene network encompassing the structural, motor and regulatory genes were differentially expressed under the two intestinal-like SCFA mixtures (Table 2). That is, EHEC exposed to the SI SCFA mix demonstrated significant upregulation of the flagellar genes and EHEC exposed to the LI SCFA mix demonstrated signification downregulation of those same flagellar genes (Table 2). The differential expression of EHEC flagellar genes observed with the microarray results was confirmed with the quantitative real-time PCR analysis of selected flagella, motor ands chemotaxis genes (Figure 4). Immunoblot and flow cytometric analyses also confirmed the gene expression results, showing significantly higher expression of EHEC flagellin protein with the SI SCFA mix treatment relative to the LI SCFA mix treatment (Figure 5 and 6). The motility results corroborated the gene and protein expression results where the SI 
SCFA mix treated samples were significantly more motile relative to the LI SCFA mix treated samples (Figure 7).

Flagella are important bacterial structures because they enable kinesis, allowing the pathogen to escape detrimental environments and locate its appropriate colonization and infection site. Our results demonstrate that the lower concentration of SCFA mixture representative of the small intestine cue increased EHEC flagellar expression and function and higher concentration of SCFA mixture typical of the large intestine, the site of colonization, promote diminished flagella expression and function. It has been reported that EHEC prefers to colonize ascending and transverse colon, areas harboring the highest SCFA content (Lewis et al. 2015). Overall, this study suggests that pathogenic EHEC utilize varying concentrations and compositions of SCFAs, key gastrointestinal chemicals, to cue regulation of flagella which is one of many important structures for pathogens to enhance infection capability.

Virulence and flagella gene regulation have previously been correlated with SCFAs (Lawhon et al. 2002; Herold et al. 2009; Tobe et al. 2011; Sun and O'Riordan 2013; Takao et al. 2014). It was reported that when EHEC are treated with $20 \mathrm{mM}$ concentration of the individual SCFAs, flagellar protein expression and motility are both increased through leucine-responsive regulatory protein (Lrp)-dependent and-independent mechanisms (Tobe et al. 2011). In that study, butyrate was found to simultaneously induce LEE expression and enhance adhesion capacity, in addition to inducing flagella (Tobe et al. 2011). Supporting Tobe et al's results, butyrate was shown to induce leucine-responsive regulatory protein (Lrp) which in turn enhances the expression of leuO gene, encoding the transcriptional regulator LeuO, to positively induce Lee genes (Takao et al. 2014). Interestingly, our microarray results did not show modulation of LEE genes with SCFA mix treatments. This may be due to the difference in the culture media 
and condition used by the previous studies and our study. Tobe et al (2011) and Takao et al (2014) cultured EHEC in DMEM (+0.5\% glucose) media with shaking (aerobic culture conditions) as opposed to our study where EHEC were cultured in LB media (+5\% CO2) in static conditions. Culture media and oxygen levels have both been shown to significantly affect EHEC virulence factor expression and may be the reason for the different results in our study compared to Tobe et al study (Schüller and Phillips 2010; Tobe et al. 2011).

Other non-LEE virulence genes have also been demonstrated to be promoted by intestinal SCFAs. Colonic SCFA concentration and composition has shown to trigger expression of iha gene that encodes an adherence-conferring protein Iha, necessary for Shiga-toxigenic E. coli (STEC) pathogenesis (Herold et al. 2009). Intestinal-like mixtures of SCFAs have also been found to alter virulence gene expression of other enteric pathogen such as Salmonella typhimurium. SCFAs can modulate invasion genes found in Salmonella pathogenicity island 1 (SPI-1), which encodes type III secretion apparatus, specifically through BarA/SirA TCS which is homologous to BarA/UvrY TCS of E. coli (Lawhon et al. 2002). Overall, SCFAs have previously been correlated to the regulation of virulence genes and functions for enteric pathogens. However, the effect of varying concentration and composition of SCFAs mixtures on flagella regulation of pathogenic and non-pathogenic $E$. coli is a novel pursuit in the field of SCFA-induced gene signalling. In our study, the focus was on the effect of physiologicallyrelevant mixtures of SCFAs.

The GI tract is a very dynamic organ, and numerous reports have shown various concentrations ranging from $20-40 \mathrm{mM}$ total concentration in the small intestine which increase to a range of $160-200 \mathrm{mM}$ in the ascending and transverse colon and eventually declines as it approaches the rectum (Cummings et al. 1987; Macfarlane et al. 1992; Lawhon et al. 2002; 
Herold et al. 2009). In this investigation, $30 \mathrm{mM}$ and $172 \mathrm{mM}$ total concentrations were selected as the SCFA mixes representative of the human small and large intestines because similar numbers have been used by other pathogenesis studies as the relevant physiological concentrations (Lawhon et al. 2002; Herold et al. 2009). In addition, these selected values are the median number of the concentration ranges mentioned above.

However, it is pertinent to recognize that above SCFA ranges can be altered depending on the individual's diet and microbiota profile. The three factors, diet, microbiota and SCFAs, have a complex and intertwined relationship where high fiber leads to increased SCFAs, lowering the $\mathrm{pH}$ in the intestines, which alters the composition of the microbiota; this ultimately loops back and influence the SCFA production (den Besten et al. 2013). Studies have shown that different bacteria phyla produce different SCFAs, where the Bacteroidetes phylum mainly produces acetate and propionate and the Firmicutes phylum produces butyrate (Macfarlane and Macfarlane 2003). More specifically, it has been recently demonstrated that Eubacterium rectale/Roseburia spp. and Faecalibacterium prausnitzii are the two most abundant groups of butyrate-producers in Gram-positive Firmicutes (Louis and Flint 2009). These phyla are the dominant gastrointestinal inhabitants and a lack of such diversity has shown to be associated with the disease development of GI organ, obesity and increase susceptibility to enteric pathogen infection (Ley et al. 2006; Kerckhoffs et al. 2009; Krogius-Kurikka et al. 2009; De Filippo et al. 2010; Rivera-Chàvez et al. 2016).

Different types of diet can also influence intestinal SCFAs concentration and composition. Diets considered to be "Western" in that they are rich in fat and low in fiber typically reduce bacterial diversity in the GI tract (Sonnenburg et al. 2016). Whereas, rural diets that are rich in fiber have been related to decreased gut inflammation and reduced risk of obesity from rich 
microbiota diversity (De Filippo et al. 2010). The best food group for optimal SCFA production is non-digestible dietary fiber, where different types of dietary fiber lead to different SCFA mixes (Henningsson et al. 2001). Starch, wheat and oat bran fermentation yield higher butyrate content while pectin fermentation yield more acetate (Henningsson et al. 2001).

Overall, our investigation suggests that the concentration gradient of SCFAs in the human intestines, which is the product of the interplay between diet and microbiota composition, significantly influences differential flagella expression of EHEC and E.coli. And because flagellar function is an important factor for colonization and pathogenesis, it would be interesting to further investigate the impact of different SCFAs compositions and ratios associated with different types of diets, on flagella regulation and motility in in vitro studies and infection outcomes in in vivo models.

For E. coli to accurately and efficiently regulate its flagella according to differing SCFAs, precise sensing machinery and corresponding signal transduction systems are required. These systems are crucial for virulence and non-virulence gene expression for adaptation, survival and propagation in their locales. The two-component signalling system is one of the essential sensing mechanism of $E$. coli and other prokaryotes, and this investigation aimed to screen for potential TCSs involved in SCFA-induced flagella regulation. Today, there are 32 TCSs recognized in $E$. coli, of which seven have been shown to be involved in flagella regulation (Oshima et al. 2002; Zhou et al. 2003). The seven TCSs include RcsCB, YpdAB, EnvZ-OmpR, AtoSC, ArcBA, CitAB and BarA-UvrY and their deletion mutants were used to screen for the altered flagella protein expression and motility upon SCFAs treatments. It is important to acknowledge that one TCS is involved in multiple pathways regulating numerous functions therefore mutagenesis 
analysis of a TCS may affect flagella as well as other pathways that may have skewed the results observed in this investigation (Table 1).

Our results show that 4 out of 7 selected TCSs mutants, including $\triangle e n v Z$-ompR, $\Delta r c s B$, $\triangle a t o S C$ and $\triangle a r c A$, lost the SCFA-induced differential motility wild-type phenotype (Figure 11). Because $\Delta e n v Z$-ompR growth rate showed slow growth under the SCFA mixes and the corresponding $\mathrm{NaCl}$ control treatments relative to other mutant strains, the lack of a motility differential in the mutant may have been due to the growth inhibition (Figure 21). For this reason, we excluded EnvZ-OmpR TCS from the candidate list. The remaining three TCSs may be acting as SCFA sensors that modulate flagella expression and function. RcsCB and ArcBA are of particular interest since the transcriptome analysis of 30mM SCFA treated EHEC also showed upregulation of the $\operatorname{rcs} B$ and $s d h$ operon, the latter which is regulated by $\operatorname{arc} A$. Overall, the combined results from the transcriptome analysis and the motility assays using the TCS mutants suggest that RcsCB and ArcBA are the most interesting potential SCFA sensor candidates that play a role in flagella regulation. Signalling systems may involve redundant and/or cross regulating mechanisms and hence our results are only preliminary and further studies area necessary to elucidate the TCSs involved in SCFA-induced flagella regulation.

The seven TCS mutants were also evaluated for their response to individual SCFAs. This evaluation was interesting because it allowed us to assess the relative impact of each SCFA within the mixture and to examine the response of each TCS mutant to the individual SCFAs rather than the combined SCFAs. It is possible that one SCFA could be masking the effect of the other SCFAs within the mixture and that a TCS may be responding to individual SCFAs differently. Through the assessment of individual SCFA treatments, it is possible to identify the SCFA predominantly contributing to the flagella expression and motility behavior in each mutant. 
The expression and functionalities demonstrated with the mix treatments may also represent a synergistic effect of the three SCFAs.

Our data demonstrated only one major trend involving the SI acetate treatment, in which the acetate-driven increased motility was abrogated in all mutants (Table 5). In the wild-type, the SI acetate treatment produced significantly higher motility diameter, compared to either propionate or butyrate (Figure 9). However, in all the seven mutants, the SI acetate treatment led to either no increase or significantly smaller motility diameter relative to the other SCFA treatments (Table 5). This suggests that acetate response of wild-type E. coli is the predominant SCFA response. In the LI individual SCFA treatments, no specific trend was observed.

The results obtained with the individual SCFAs were unexpected and not easily understood in light of current knowledge. In addition, because the motility assay and immunoblot assay results were not always consistent, any conclusions based on these results are preliminary and could be challenged. It is important to note that the immunoblot results were based on flagella proteins probed within the whole cell lysate, rather than from the extracellular flagella preparation. Hence, some flagella detected with the antibody may have been premature flagella that has not yet been exported to the bacteria outer membrane surface that can not participate in the motility function. This could explain the differences in the immunoblot and motility results. This could also be the reason for the double flagellar bands observed in some $E$. coli strains. Consistent with this conclusion, we found that when the wild-type extracellular flagella preparation sample was probed with anti-H48, only one band was observed (Figure 9). $\triangle f l i C$ was used as a negative control for $\mathrm{H} 48$ antibody and no flagella band was observed (Figure 9). However, some mutants demonstrated double flagella protein bands from the immunoblot analysis, in which the second protein band was observed at slightly lower molecular weight than 
the band detected from the flagella preparation samples. This may be premature flagella within the cell. In conclusion, our results suggest differential intestinal SCFA sensing by RcsCB and ArcBC TCSs. Further investigation is required to tease apart and understand the complex TCS sensing mechanisms of GI SCFAs and corresponding flagella regulation.

All in all, this study enhances our understanding of complex sensing and regulating mechanisms by pathogenic and non-pathogenic E. coli. Specifically, it shows that the bacteria can use readily available substances during their passage through the GIT, such as the concentration gradient of SCFAs, to cue flagella modulation which would help them reach the appropriate colonization and infection site. The ability to recognize the SCFAs gradient to precisely regulate flagella would also be beneficial to the commensals as their preferred residence is also the human large intestine. For the pathogens, the knowledge of SCFAs-induced flagella regulation, used to aid in colonization and infection, could potentially lead to the development of preventative strategies through manipulation of those signals. 


\section{Future Studies}

It would make this investigation more comprehensive to treat $E$. coli with various concentrations within the range of total small and large intestinal SCFA concentrations reported with previous publications (Cummings et al. 1987; Macfarlane et al. 1992; Lawhon et al. 2002; Herold et al. 2009). Within each total concentration, the ratio of the individual SCFAs could also be varied. This analysis would enhance the understanding of the role of concentration and composition of SCFAs on flagella expression, which in turn influences the success of colonization. In turn, the information may provide clues about the optimal concentration and composition of SCFAs for infection success that could be used in preventative strategy development for EHEC infections. As well, investigating how altered diet and hence altered SCFAs' effect on flagella modulation and infection capability would be another very interesting investigation related to SCFA concentration and composition. The two major factors, diet and microbiota, both of which influence the GI SCFA mixes, that in turn can affect the pathogen's virulence, are understudied relationships to be investigated in EHEC pathogenesis field.

Our transcriptome analysis demonstrated differential SCFA regulation of other gene networks. Therefore, it would be interesting to examine these other gene networks, including metabolism genes, to further understand the altered physiology of enteric pathogens that are adapting to human GI environment.

Finally, in order to further pursue the TCS elucidation study, the next step would require investigating the effect of differing SCFAs on flagellar gene regulation in the selected TCS mutants. As well, similar TCS mutants should be constructed in EHEC. A more comprehensive study could include mutants of all 32 TCSs in E. coli. In addition, a study involving multiple mutations of TCSs and their complements would help us better understand the mechanism of 
cross-regulation or redundant regulation between TCSs. Finally, it would increase confidence in our current results to run the immunoblot assay with extracellular flagella preparation samples, as flagella preparation samples will only consist of surface membrane flagella contributing to bacterial locomotion. 


\section{References}

Baba T, Ara T, Hasegawa M, Takai Y, Okumura Y, Baba M, Datsenko KA, Tomita M, Wanner BL, Mori H (2006) Construction of Escherichia coli K-12 in-frame, single-gene knockout mutants: the Keio collection. Mol Syst Biol 2:2006.0008. doi: 10.1038/msb4100050

Barembruch C, Hengge R (2007) Cellular levels and activity of the flagellar sigma factor FliA of Escherichia coli are controlled by FlgM-modulated proteolysis. Mol Microbiol 65:76-89. doi: 10.1111/j.1365-2958.2007.05770.x

Beatson SA, Minamino T, Pallen MJ (2006) Variation in bacterial flagellins: from sequence to structure. Trends Microbiol 14:151-155. doi: 10.1016/j.tim.2006.02.008

Besser RE, Griffin PM, Slutsker L (1999) Escherichia coli O157:H7 gastroenteritis and the hemolytic uremic syndrome: an emerging infectious disease. Annu Rev Med 50:355-367. doi: 10.1146/annurev.med.50.1.355

Boor KJ (2006) Bacterial stress responses: What doesn't kill them can make them stronger. PLoS Biol 4:0018-0020. doi: 10.1371/journal.pbio.0040023

Bretl DJ, Demetriadou C, Zahrt TC (2011) Adaptation to environmental stimuli within the host: two-component signal transduction systems of Mycobacterium tuberculosis. Microbiol Mol Biol Rev 75:566-82. doi: 10.1128/MMBR.05004-11

Cai SJ, Inouye M (2002) EnvZ-OmpR interaction and osmoregulation in Escherichia coli. J Biol Chem 277:24155-24161. doi: 10.1074/jbc.M110715200

Carballès F, Bertrand C, Bouché JP, Cam K (1999) Regulation of Escherichia coli cell division genes ftsA and ftsZ by the two-component system RcsC-RcsB. Mol Microbiol 34:442-450. doi: 10.1046/j.1365-2958.1999.01605.x

Chauret C (2011) Survival and control of Escherichia coli O157:H7 in foods, beverages, soil and 
water. Virulence 2:593-601. doi: 10.4161/viru.2.6.18423

Chilcott GS, Hughes KT (2000) Coupling of flagellar gene expression to flagellar assembly in Salmonella enterica serovar typhimurium and Escherichia coli. Microbiol Mol Biol Rev 64:694-708. doi: 10.1128/MMBR.64.4.694-708.2000

Chingcuanco F, Yu Y, Kus JV, Que L, Lackraj T, Lévesque CM, Foster DB (2012)

Identification of a novel adhesin involved in acid-induced adhesion of enterohemorrhagic Escherichia coli O157:H7. Microbiol (United Kingdom) 158:2399-2407. doi:

10.1099/mic.0.056374-0

Cummings JH, Pomare EW, Branch WJ, Naylor CP, Macfarlane GT (1987) Short chain fatty acids in human large intestine, portal, hepatic and venous blood. Gut 28:1221-1227. doi: 10.1136/gut.28.10.1221

Datsenko KA, Wanner BL (2000) One-step inactivation of chromosomal genes in Escherichia coli K-12 using PCR products. Proc Natl Acad Sci U S A 97:6640-5. doi: 10.1073/pnas.120163297

Davalos-Garcia M, Conter A, Toesca I, Gutierrez C, Cam K, Davalos-garcia M, Conter A, Toesca I, Gutierrez C, Cam K (2001) Regulation of osmC gene expression by the twocomponent system RcsB-RcsC in Escherichia coli. 183:5870-5876. doi:

10.1128/JB.183.20.5870

De Filippo C, Cavalieri D, Di Paola M, Ramazzotti M, Poullet JB, Massart S, Collini S, Pieraccini G, Lionetti P (2010) Impact of diet in shaping gut microbiota revealed by a comparative study in children from Europe and rural Africa. Proc Natl Acad Sci 107:14691-14696. doi: 10.1073/pnas.1005963107

den Besten G, van Eunen K, Groen AK, Venema K, Reijngoud DJ, Bakker BM (2013) The role 
of short-chain fatty acids in the interplay between diet, gut microbiota, and host energy metabolism. J Lipid Res 54:2325-2340. doi: 10.1194/jlr.R036012

Dorn CR, Angrick EJ (1991) Serotype O157:H7 Escherichia coli from bovine and meat sources. J Clin Microbiol 29:1225-1231.

Ferens WA, Hovde CJ (2011) Escherichia coli O157:H7: Animal reservoir and sources of human infection. Foodborne Pathog Dis 8:465-487. doi: 10.1089=fpd.2010.0673

Fitzgerald DM, Bonocora RP, Wade JT (2014) Comprehensive mapping of the Escherichia coli flagellar regulatory network. PLoS Genet. doi: 10.1371/journal.pgen.1004649

Fredericks CE, Shibata S, Aizawa SI, Reimann S a., Wolfe AJ (2006) Acetyl phosphate-sensitive regulation of flagellar biogenesis and capsular biosynthesis depends on the Rcs phosphorelay. Mol Microbiol 61:734-747. doi: 10.1111/j.1365-2958.2006.05260.x

Frenzen PD, Drake A, Angulo FJ (2005) Economic cost of illness due to Escherichia coli O157 infections in the United States. J Food Prot 68:2623-2630.

Fried L, Behr S, Jung K (2013) Identification of a target gene and activating stimulus for the YpdA/YpdB histidine kinase/response regulator system in Escherichia coli. J Bacteriol 195:807-815. doi: 10.1128/JB.02051-12

Garmendia J, Garmendia J, Frankel G, Frankel G, Crepin VF, Crepin V (2005) Enteropathogenic and enterohemorrhagic Escherichia coli infections: translocation, translocation, translocation. Infect Immun 73:2573-2585. doi: 10.1128/IAI.73.5.2573

Girón J a, Torres AG, Freer E, Kaper JB (2002) The flagella of enteropathogenic Escherichia coli mediate adherence to epithelial cells. Mol Microbiol 44:361-79.

Gonzalez Chavez R, Alvarez AF, Romeo T, Georgellis D (2010) The physiological stimulus for the BarA sensor kinase. J Bacteriol 192:2009-2012. doi: 10.1128/JB.01685-09 
Guyon SL, Rhen M, Römling U (2015) Rapid preparation of unsheathed bacterial flagella. BioProtocol 5: e1425.

Henningsson A, Bjorck I, Nyman M (2001) Short-chain fatty acid formation at fermentation of indigestible carbohydrates. Scand J Nutr 45:165-168.

Henningsson AM, Margareta E, Nyman GL, Björck IME (2003) Influences of dietary adaptation and source of resistant starch on short-chain fatty acids in the hindgut of rats. Br J Nutr 89:319-28. doi: 10.1079/BJN2003782

Herold S, Paton JC, Srimanote P, Paton AW (2009) Differential effects of short-chain fatty acids and iron on expression of iha in Shiga-toxigenic Escherichia coli. Microbiology 155:355463. doi: 10.1099/mic.0.029454-0

Heroven AK, Böhme K, Dersch P (2012) The Csr/Rsm system of Yersinia and related pathogens: A post-transcriptional strategy for managing virulence. RNA Biol 9:379-391. doi: 10.4161/rna.19333

Hoch JA, Silhavy TJ, Stock AM, Robinson VL, Goudreau PN (1995) Two-component signal transduction. Am Soc Microbiol 2:183-215. doi: 10.1146/annurev.biochem.69.1.183

House B, Kus JV, Prayitno N, Mair R, Que L, Chingcuanco F, Gannon V, Cvitkovitch DG, Barnett Foster D (2009) Acid-stress-induced changes in enterohaemorrhagic Escherichia coli O157 : H7 virulence. Microbiology 155:2907-18. doi: 10.1099/mic.0.025171-0

Hughes AK, Ergonul Z, Stricklett PK, Kohan DE, Ergonal Z (2002) Molecular basis for high renal cell sensitivity to the cytotoxic effects of shigatoxin-1: upregulation of globotriaosylceramide expression. J Am Soc Nephrol 13:2239-45. doi: 10.1097/01.ASN.0000027873.85792.52

Ingmer H, Miller CA, Cohen SN (1998) Destabilized inheritance of pSC101 and other 
Escherichia coli plasmids by DpiA, a novel two-component system regulator. Mol Microbiol 29:49-59. doi: 10.1046/j.1365-2958.1998.00895.x

Iuchi S, Lin EC (1991) Adaptation of Escherichia coli to respiratory conditions: regulation of gene expression. Cell 66:5-7.

Iuchi S, Lin EC (1988) arcA (dye), a global regulatory gene in Escherichia coli mediating repression of enzymes in aerobic pathways. Proc Natl Acad Sci USA 85:1888-1892. doi: 10.1073/pnas. 85.6 .1888

Iyoda S, Koizumi N, Satou H, Lu Y, Saitoh T, Ohnishi M, Watanabe H (2006) The GrlR-GrlA regulatory system coordinately controls the expression of flagellar and LEE-encoded type III protein secretion systems in enterohemorrhagic Escherichia coli. J Bacteriol 188:56825692. doi: 10.1128/JB.00352-06

Kaspar S, Bott M (2002) The sensor kinase CitA (DpiB) of Escherichia coli functions as a highaffinity citrate receptor. Arch Microbiol 177:313-321. doi: 10.1007/s00203-001-0393-z

Kato Y, Sugiura M, Mizuno T, Aiba H (2007) Effect of the $\operatorname{arcA}$ mutation on the expression of flagella genes in Escherichia coli. Biosci Biotechnol Biochem 71:77-83. doi: JST.JSTAGE/bbb/60375 [pii]

Kenny B, DeVinney R, Stein M, Reinscheid DJ, Frey EA, Finlay BB (1997) Enteropathogenic E. coli (EPEC) transfers its receptor for intimate adherence into mammalian cells. Cell 91:511-520. doi: 10.1016/S0092-8674(00)80437-7

Kerckhoffs APM, Samsom M, van der Rest ME, de Vogel J, Knol J, Ben-Amor K, Akkermans LMA (2009) Lower Bifidobacteria counts in both duodenal mucosa-associated and fecal microbiota in irritable bowel syndrome patients. World J Gastroenterol 15:2887-2892. doi: 10.3748/wjg. 15.2887 
Krogius-Kurikka L, Lyra A, Malinen E, Aarnikunnas J, Tuimala J, Paulin L, Mäkivuokko H, Kajander K, Palva A (2009) Microbial community analysis reveals high level phylogenetic alterations in the overall gastrointestinal microbiota of diarrhoea-predominant irritable bowel syndrome sufferers. BMC Gastroenterol 9:95. doi: 10.1186/1471-230X-9-95

Kus J V, Gebremedhin A, Dang V, Tran SL, Serbanescu A, Foster DB (2011) Bile salts induce resistance to polymyxin in enterohemorrhagic Escherichia coli O157:H7. J Bacteriol 193:4509-4515. doi: 10.1128/JB.00200-11

Lackraj T, Kim JI, Tran SL, Foster DB (2016) Differential modulation of flagella expression in enterohemorrhagic Escherichia coli $\mathrm{O} 157: \mathrm{H} 7$ by intestinal short chain fatty acid mixes. Microbiology In press. doi: 10.1099/mic.0.000357

Lawhon SD, Maurer R, Suyemoto M, Altier C (2002) Intestinal short-chain fatty acids alter Salmonella typhimurium invasion gene expression and virulence through BarA / SirA. Mol Microbiol 46:1451-1464.

Lee YS, Han JS, Jeon Y, Hwang DS (2001) The Arc two-component signal transduction system inhibits in vitro Escherichia coli chromosomal initiation. J Biol Chem 276:9917-9923. doi: 10.1074/jbc.M008629200

Lewis SB, Cook V, Tighe R, Schüller S (2015) Enterohemorrhagic Escherichia coli colonization of human colonic epithelium in vitro and ex vivo. Infect Immun 83:942-949. doi:

\subsection{8/IAI.02928-14}

Ley R, Turnbaugh P, Klein S, Gordon J (2006) Microbial ecology: human gut microbes associated with obesity. Nature 444:1022-3. doi: 10.1038/nature4441021a

Li Z, Elliott E, Payne J, Isaacs J, Gunning P, O’Loughlin EV (1999) Shiga toxin-producing Escherichia coli can impair T84 cell structure and function without inducing 
attaching/effacing lesions. Infect Immun 67:5938-5945.

Lior H (1994) Classification of Escherichia coli: Escherichia coli in domestic animals and humans. Gyles CL. Wallingford, UK: CAB International.

Liu H, Radhakrishnan P, Magoun L, Prabu M, Campellone KG, Savage P, He F, Schiffer CA., Leong JM (2002) Point mutants of EHEC intimin that diminish Tir recognition and actin pedestal formation highlight a putative Tir binding pocket. Mol Microbiol 45:1557-1573. doi: $10.1046 / j .1365-2958.2002 .03137 . x$

Louis P, Flint HJ (2009) Diversity, metabolism and microbial ecology of butyrate-producing bacteria from the human large intestine. FEMS Microbiol Lett 294:1-8. doi: 10.1111/j.1574-6968.2009.01514.x

Macfarlane GT, Gibson GR, Cummings JH (1992) Comparison of fermentation reactions in different regions of the human colon. J Appl Bacteriol 72:57-64. doi: 10.1111/j.13652672.1992.tb05187.x

Macfarlane S, Macfarlane GT (2003) Regulation of short-chain fatty acid production. Proc Nutr Soc 62:67-72. doi: 10.1079/PNS2002207

Macnab RM (2003) How bacteria assemble flagella. Annu Rev Microbiol 57:77-100. doi: 10.1146/annurev.micro.57.030502.090832

Majdalani N, Hernandez D, Gottesman S (2002) Regulation and mode of action of the second small RNA activator of RpoS translation, RprA. Mol Microbiol 46:813-826. doi: 10.1046/j.1365-2958.2002.03203.x

McDaniel TK, Jarvis KG, Donnenberg MS, Kaper JB (1995) A genetic locus of enterocyte effacement conserved among diverse enterobacterial pathogens. Proc Natl Acad Sci U S A 92:1664-1668. doi: 10.1073/pnas.92.5.1664 
Mizuno T (1997) Compilation of all genes encoding two-component phosphotransfer signal transducers in the genome of Escherichia coli. DNA Res 4:161-168. doi: 10.1093/dnares/4.2.161

Nataro JP, Kaper JB (1998) Diarrheagenic Escherichia coli. Clin Microbiol Rev 11:142-201. Njoroge JW, Nguyen Y, Curtis MM, Moreira CG, Sperandio V (2012) Virulence meets metabolism: Cra and KdpE gene regulation in enterohemorrhagic Escherichia coli. MBio 3:1-12. doi: 10.1128/mBio.00280-12

Oshima T, Aiba H, Masuda Y, Kanaya S, Sugiura M, Wanner BL, Mori H, Mizuno T (2002) Transcriptome analysis of all two-component regulatory system mutants of Escherichia coli K-12. Mol Microbiol 46:281-291. doi: 10.1046/j.1365-2958.2002.03170.x

Pacheco AR, Curtis MM, Ritchie JM, Munera D, Waldor MK, Moreira CG, Sperandio V (2012) Fucose sensing regulates bacterial intestinal colonization. Nature 492:113-7. doi: 10.1038/nature11623

Pernestig AK, Georgellis D, Romeo T, Suzuki K, Tomenius H, Normark S, Melefors Ö (2003) The Escherichia coli BarA-UvrY two-component system is needed for efficient switching between glycolytic and gluconeogenic carbon sources. J Bacteriol 185:843-853. doi: 10.1128/JB.185.3.843-853.2003

Pernestig AK, Melefors Ö, Georgellis D (2001) Identification of UvrY as the cognate response regulator for the BarA sensor kinase in Escherichia coli. J Biol Chem 276:225-231. doi: 10.1074/jbc.M001550200

Perraud A-L, Weiss V, Gross R (1999) Signalling pathways in two-component phosphorelay systems. Trends Microbiol 7:115-120. doi: 10.1016/S0966-842X(99)01458-4 
PHAC (2000) Waterborne outbreak of gastroenteritis associated with a contaminated municipal water supply, Walkerton, Ontario, May-June. Can Commun Dis Rep 26:170-173.

Rivera-Chàvez F, Zhang LF, Faber F, Lopez CA, Byndloss MX, Olsan EE, Xu G, Velazquez EM, Lebrilla CB, Winter SE, Baumler AJ (2016) Depletion of butyrate-producing Clostridia from the gut microbiota drives an aerobic luminal expansion of Salmonella. Cell Host Microbe 19:443-454. doi: 10.1016/j.chom.2016.03.004

Romeo T (1998) Global regulation by the small RNA-binding protein CsrA and the non-coding RNA molecule CsrB. Mol Microbiol 29:1321-1330. doi: 10.1046/j.13652958.1998.01021.x

Salminen S, Bouley C, Boutron-Ruault MC, Cummings JH, Franck a, Gibson GR, Isolauri E, Moreau MC, Roberfroid M, Rowland I (1998) Functional food science and gastrointestinal physiology and function. Br J Nutr 80 Suppl 1:S147-S171. doi: 10.1079/BJN19980108

Schüller S, Phillips AD (2010) Microaerobic conditions enhance type III secretion and adherence of enterohemorrhagic Escherichia coli to polarized human intestinal epithelial cells. Environ Microbiol 12:2426-2435. doi: 10.1111/j.1462-2920.2010.02216.x

Shi W, Li C, Louise CJ, Adler J (1993) Mechanism of adverse conditions causing lack of flagella in Escherichia coli. J Bacteriol 175:2236-2240.

Shin S, Park C (1995) Modulation of flagellar expression in Escherichia coli by acetyl phosphate and the osmoregulator OmpR. J Bacteriol 177:4696-4702.

Snedeker KG, Shaw DJ, Locking ME, Prescott RJ (2009) Primary and secondary cases in Escherichia coli O157 outbreaks: a statistical analysis. BMC Infect Dis 9:144. doi: $10.1186 / 1471-2334-9-144$

Solomon EB, Yaron S, Matthews KR (2002) Transmission of Escherichia coli O157:H7 from 
contaminated manure and irrigation water to lettuce plant tissue and its subsequent internalization. Appl Environ Microbiol 68:397-400. doi: 10.1128/AEM.68.1.397-400.2002

Sonnenburg ED, Smits SA, Tikhonov M, Higginbottom SK, Wingreen NS, Sonnenburg JL (2016) Diet-induced extinctions in the gut microbiota compound over generations. Nature 529:212-215. doi: 10.1038/nature16504

Stock AM, Robinson VL, Goudreau PN (2000) Two- omponent signal transduction. Annu Rev Biochem 69:183-215. doi: 10.1146/annurev.biochem.69.1.183

Sun Y, O’Riordan MXD (2013) Regulation of bacterial pathogenesis by intestinal short-chain fatty acids. Adv Appl Microbiol 85:93-118. doi: 10.1016/B978-0-12-407672-3.00003-4

Takao M, Yen H, Tobe T (2014) LeuO enhances butyrate-induced virulence expression through a positive regulatory loop in enterohaemorrhagic Escherichia coli. Mol Microbiol 93:13021313. doi: $10.1111 / \mathrm{mmi} .12737$

Takeda SI, Fujisawa Y, Matsubara M, Aiba H, Mizuno T (2001) A novel feature of the multistep phosphorelay in Escherichia coli: A revised model of the $\mathrm{RcsC} \rightarrow$ YojN $\rightarrow$ RcsB signalling pathway implicated in capsular synthesis and swarming behaviour. Mol Microbiol 40:440450. doi: 10.1046/j.1365-2958.2001.02393.x

Tan J, McKenzie C, Potamitis M, Thorburn AN, Mackay CR, Macia L (2014) The role of shortchain fatty acids in health and disease. Adv Immunol 121:91-119. doi: 10.1016/B978-0-12800100-4.00003-9

Theodorou MC, Theodorou EC, Kyriakidis DA (2012) Involvement of AtoSC two-component system in Escherichia coli flagellar regulon. Amino Acids 43:833-844. doi: $10.1007 / \mathrm{s} 00726-011-1140-7$

Tilden J, Young W, McNamara AM, Custer C, Boesel B, Lambert-Fair MA, Majkowski J, Vugia 
D, Werner SB, Hollingsworth J, Morris JG (1996) A new route of transmission for Escherichia coli: infection from dry fermented salami. Am J Public Health 86:1142-5. doi: 10.2105/AJPH.86.8_Pt_1.1142

Tobe T, Nakanishi N, Sugimoto N (2011) Activation of motility by sensing short-chain fatty acids via two steps in a flagellar gene regulatory cascade in enterohemorrhagic Escherichia coli. Infect Immun 79:1016-24. doi: 10.1128/IAI.00927-10

Toth I, Schmidt H, Kardos G, Lancz Z, Creuzburg K, Damjanova I, Paszti J, Beutin L, Nagy B (2009) Virulence genes and molecular typing of different groups of Escherichia coli 0157 strains in cattle. Appl Environ Microbiol 75:6282-6291. doi: 10.1128/AEM.00873-09

Tuttle J, Gomez T, Doyle MP, Wells JG, Zhao T, Tauxe RV, Griffin PM (1999) Lessons from a large outbreak of Escherichia coli $\mathrm{O} 157: \mathrm{H} 7$ infections: insights into the infectious dose and method of widespread contamination of hamburger patties. Epidemiol Infect 122:185-92. doi: $10.1017 / \mathrm{S} 0950268898001976$

Wagner PL, Neely MN, Zhang X, Acheson DWK, Waldor MK, Friedman DI (2001) Role for a phage promoter in Shiga toxin 2 expression from a pathogenic Escherichia coli strain. J Bacteriol 183:2081-2085. doi: 10.1128/JB.183.6.2081-2085.2001

Wei BL, Brun-Zinkernagel AM, Simecka JW, Prüss BM, Babitzke P, Romeo T (2001) Positive regulation of motility and flhDC expression by the RNA-binding protein CsrA of Escherichia coli. Mol Microbiol 40:245-256. doi: 10.1046/j.1365-2958.2001.02380.x

Weiss A, Schmidt H, Stöber H (2011) Mechanisms of enterohemorrhagic Escherichia coli spread along the food-chain and precautionary measures. J für Verbraucherschutz und Leb 6:503-510. doi: 10.1007/s00003-011-0736-x

Wells JG, Davis BR, Wachsmuth IK, Riley LW, Remis RS, Sokolow R, Morris GK (1983) 
Laboratory investigation of hemorrhagic colitis outbreaks associated with a rare Escherichia coli serotype. J Clin Microbiol 18:512-520. doi: 10.1056/NEJM198303243081203

Wolever T, Spadafora P, Eshuis H (1991) Interaction between colonic acetate and propionate in humans. Am J Clin Nutr 53:681-687.

Wong JMW, de Souza R, Kendall CWC, Emam A, Jenkins DJA (2006) Colonic health: fermentation and short chain fatty acids. J Clin Gastroenterol 40:235-43.

Wurgler-Murphy S, Saito H (1997) Two-component signal transducers and MAPK cascades. Trends Biochem Sci 22:172-176. doi: 10.1016/S0968-0004(97)01036-0

Zhou L, Lei XH, Bochner BR, Wanner BL (2003) Phenotype microarray analysis of Escherichia coli K-12 mutants with deletions of all two-component systems. J Bacteriol 185:4956-4972. doi: 10.1128/JB.185.16.4956-4972.2003 